\title{
MEASURING SENSE OF BELONGING AMONG EMPLOYEES WORKING AT A CORPORATE CAMPUS
}

\author{
A Thesis \\ Presented to the Faculty of the Graduate School \\ At Cornell University \\ In Partial Fulfillment of the Requirements for the Degree of \\ Masters of Science
}

By

Ruchika Jaitli

January 2012 
() 2012 Ruchika Jaitli 


\begin{abstract}
This study explores the relationship between the physical factors of a workplace and employees' 'sense of belonging'. To do so, it examined the construct validity of a workplace questionnaire designed by the International Workplace Studies Program (IWSP) at Cornell University, as an instrument to predict employees' 'sense of belonging'. The sample size and research site for this study are 267 employees working at the corporate campus of a global information technology firm; Wipro Technologies, who volunteered to participate in this study. Factor analysis of the survey items identified 5 primary workplace physical factors that underlay the IWSP questionnaire. Correlations among employees' self-reported sense of belonging and the workplace physical factors confirmed that employees' sense of belonging has a statistically significant association with the physical factors of the workplace. A statistically significant model comprising of four workplace physical factors was developed to predict employees' 'sense of belonging'.
\end{abstract}




\section{BIOGRAPHICAL SKETCH}

Ruchika Jaitli was born in New Delhi, India. Prior to commencing the M.S. Program in Design and Environmental Analysis at Cornell University, she received an associates degree in Interior Design and a B.A. in Psychology from Delhi University. After graduating from Cornell in 2003, Ruchika joined Ernst \& Young's Transactions Real Estate Consulting Practice in New York City as an Analyst. While working in New York, she also obtained an advanced graduate certificate in Real Estate Finance and Investment from New York University. In 2007, Ruchika went on to join Essex Property Trust in Palo Alto, CA as an associate with its Structured Finance Group, primarily providing financing for multifamily developments and acquisitions across the Western United States. She currently works with Citi Community Capital which is the Affordable Housing Finance group of Citibank, in New York City. 
To my beautiful child

Raunaq 


\section{ACKNOWLEDGEMENTS}

I owe thanks to many people who helped me through the long and windy path to completing my thesis. However, there are a few individuals whose support has been so immense that it is difficult to reciprocate with words. Yet, with that sense of deep gratitude, I want to thank these individuals; Professor Ying Hua, Professor William Sims, Professor Nancy Wells and Professor Franklin Becker; for their contribution towards the accomplishment of this study. I will forever admire and reminisce them for their noble and dedicated service as educators. Their unreserved guidance helped me build a foundation that opened a world of possibilities for my future and whose association has enriched my life.

I also want to thank the entire faculty of the Department of Design and Environmental Analysis and members of the International Workplace Studies Program, for all that they have taught me. I owe special thanks to the staff of Wipro Technologies, Banagalore, India, for their generous participation in my study. Most of all, I thank Cornell University for allowing me the privilege of attaining an unmatched quality of education. Many will agree that it is not just a name or a label but a legacy that must continue to inspire us through our lives to achieve greater goals for ourselves and our communities.

In the end, I am most grateful to my family for their tireless support in my endeavors. Without them- none of this would be possible or have any worth. 
BIOGRAPHICAL SKETCH

DEDICATIONS

ACKNOWLEDGEMENTS

TABLE OF CONTENTS

LIST OF FIGURES

\section{LIST OF TABLES}

\section{CHAPTER 1: INTRODUCTION}

1.1 Background

1.2 The Survey Instrument

1.3 Research Hypothesis

CHAPTER 2: LITERATURE

2.1 Employees 'Sense of Belonging' or Organizational Identity

2.2 The Contribution of the Physical Workspace towards Employees' Sense of Belonging; the example of a corporate campus

2.3 Employee' Communication is a Key Component of Organizational Identity

2.4 Physical and Organizational Proximity Affect Communication and Collaboration in a Workplace

2.5 Telecommunication Technology has had a significant impact on the Physical Workplace

3.1 The Research Site

3.2 Research Design

3.2.1 Data Collection Technique $\quad 35$

3.2.2 Implementing the Study 36

3.2.3 Sample Size and Selection $\quad 37$

3.4 Data Analysis

3.5 Overview of Survey Sections and Survey Items 38

CHAPTER 4: FINDINGS $\quad 42$

4.1 Descriptive Findings 43

4.1.1 Study Participation by Employee Demographics 43

4.1.2 Employees Sense of Belonging/ Organizational Identity 45

4.1.3 Employee Interaction across Physical and Organizational Distances 47 
4.1.4 Importance of Physical Collocation in the Workplace 51

4.1.5 Wipro's corporate campus'- physical factors 52

4.2 Exploratory Factor Analysis $\quad 55$

4.3 Factor Development $\quad 61$

$\begin{array}{ll}\text { 4.4 Correlations } & 65\end{array}$

4.5 Multiple Regression Assessing Goodness-of-Fit 69

4.6 Model Parameters $\quad 73$

$\begin{array}{ll}4.7 \text { The Regression Equation } & 76\end{array}$

CHAPTER 5: DISCUSSION

5.1 The relevance of a 'corporate campus' 80

5.2 The perceived support from the physical workplace towards employees' 82 productivity

5.3 Employees' level of satisfaction with the physical attributes of their workplace

5.4 The relative importance of employees' immediate versus overall workplace physical environment

5.5 Employees' familiarity with Wipro and the facilities at Wipro's corporate campus

5.6 Face-to-Face Interaction among employees as a result of the physical layout of a workspace

5.7 Implications for design and management of the physical workplace to enhance employees' sense of belonging

CHAPTER 6: LIMITATIONS AND FUTURE REASERCH

6.1 Study Limitations

6.2 Considerations for Future Research

APPENDIX A IWSP Workplace Survey

APPENDIX B SPSS Syntax APPENDIC C Campus Typology by IWSP

APPENDIX D

REFERENCES 


\section{LIST OF FIGURES}

Figure 3.1 Map to display the distance between Wipro Technologies Sarjapur Campus and Electronics City Campus, Bangalore, India*

Figure 3.2 Aerial View and Site Plan of Wipro's Technologies Sarjapur Campus, Bangalore, India

Figure 3.3 Aerial View of Electronics City Business Park and Wipro's Technologies Electronics City Campus, Bangalore, India

Figure 3.4 Site Plan of Wipro Technologies Campus Phase I, at Electronic City Business Park, Bangalore, India

Figure 3.5 Site Plan of Wipro Technologies Campus Phase II and III, at Electronic City Business Park, Bangalore, India

Figure 3.6 Image: Office Building at Wipro's Sarjapur Campus (1)

Figure 3.7 Image: Landscaped Walkways at Wipro's Sarjapur Campus

Figure 3.8 Image: Office Building at Wipro's Sarjapur Campus (2)

Figure 3.9 Image: Office Building at Wipro's Sarjapur Campus (3)

Figure 3.10 Image: Open spaces at Wipro's Electronic City Campus

Figure 3.11 Image: Landscaped exteriors at Wipro's Sarjapur Campus

Figure 3.12 Image: Wipro's Company logo featured on the building exterior at Wipro's Sarjapur Campus (1)

Figure 3.13 Image: Wipro's Company logo featured on the building exterior at Wipro's Sarjapur Campus (2)

Figure 3.14 Image: On-site sports/recreational facilities at Wipro's Sarjapur Campus (1)

Figure 3.15 Image: On-site sports/recreational facilities at Wipro's Sarjapur Campus (2)

Figure 3.16 Image: On-site employee' gymnasium at Wipro's Sarjapur Campus

Figure 3.17 Image: On-site employee' cafeteria at Wipro's Sarjapur Campus 
Figure 3.18 Image: Open spaces at Wipro Electronic City Campus

Figure 3.19 Image: Open courtyard incorporated within an office building at Wipro's Electronics City Campus

Figure 3.20 Image: Water bodies at Wipro's Electronic City Campus

Figure 3.21 Image: Learning Center at Wipro's Electronic City Campus

Figure 3.22 Image: Typical view of open plan layout at Wipro's corporate campus office facilities (1)

Figure 3.23 Image: Typical view of open plan layout at Wipro's Corporate campus office facilities (2)

Figure 4.1 Survey Participation by Gender

Figure 4.2 Survey Participation by Age

Figure 4.3 Survey Participation by Job Level

Figure 4.4 Survey Participation by Term with Wipro

Figure 4.5 Survey Participation by Life Stage

Figure 4.6 Survey Participation by Workspace Type

Figure 4.7 Employees' Self-Reported 'Sense of Belonging' with Wipro

Figure 4.8 Employees' Sense of Belonging by Gender

Figure 4.9 Employees' Sense of Belonging by Job Level

Figure 4.10 Employees' Sense of Belonging by Age

Figure 4.11 Employees' opinion on Appearance of Wipro' Buildings reflecting its Culture and Values

Figure 4.12 Cross-Tab: Employees' Sense of Belonging and Appearance Of Wipro' Buildings reflecting its Culture and Values

Figure 4.13 Meeting Type with One Person across Organizational Distance 
Figure 4.14 Meeting Type with 3+ Persons across Organizational Distance

Figure 4.15 Cross-Tab: Sense of Belonging and Frequency of Interaction across Physical Distances

Figure 4.16 Frequency of Electronic Communication (e-mail, teleconference, intranet, voicemail etc) among Employees, in a typical workday

Figure 4.17 Employees' opinion (agree/disagree) regarding the importance of physical collocation considering the current day computers and telecommunication technology

Figure 4.18 Employees' Self-Reported Sense of Belonging and Opinion regarding the Importance of Collocation with Own-Group

Figure 4.19 Physical Factors Contributing Most to Employees' Satisfaction with Wipros' Corporate

Figure 4.20 Amenities Most Preferred by Employees to have at Wipros' Corporate campus 


\section{LIST OF TABLES}

Table 3.1 Basic Site Data for Wipro's Corporate campus Sites in Bangalore, India

Table 4.1 Basic statistics for 15 statements that are factor analyzed

Table 4.2 Factor Loadings and Communalities, using principle components analysis with promax rotation

Table 4.3 Un-rotated Initial Factor Solution; Total Variance Explained by each Individual Factor with Eigenvalue Greater than 1.0

Table 4.4 Correlation among 'sense of belonging', and control and workspace variables

Table 4.5 Pertinent statistics from the Model(s) Summary and ANOVA for hierarchical multiple regression models

Table 4.6 Summary of Model 7, Beta Coefficients and T-Test scores to assess Model Parameters

Table 4.7 Reduced Regression Model; four significant predictors only 


\section{CHAPTER 1: INTRODUCTION}

\subsection{Background}

Employees' emotional bond to their organization is considered to be an important determinant of dedication and loyalty. Affectively committed employees are seen as having a 'sense of belonging' and identification that; increases their involvement in the organization's activities; their willingness to pursue the organization's goals, and their desire to remain with the organization (Meyer \& Allen, 1991; Mowday, Perter, \& Steers, 1982). Nevertheless, employees' 'sense of belonging' is a construct or an attribute that cannot be directly observed or measured, but has effects that are determined through an indirect measurement.

Past studies have theorized that in the context of the physical workplace, employees organizational identity or their 'sense of belonging' is affected by workplace factors such as; an employees' tenure (Dutton, et. al., 1994) and the consequent familiarity with a company's physical framework; employees' opinion of and the level of satisfaction with the physical attributes of their workplace; the nature and frequency of interaction and collaboration among co-workers (Baik, 2003); and the overall identification of an individual with the culture and values of an organization.

The physical layout of a workspace is relevant because it inherently influences behavioral outcomes such as interaction and collaboration among employees. Spatial layouts of a workspace affect the probability of chance encounters and therefore make people 'available' for interaction which is often ad hoc or unplanned in nature. These 
unplanned meetings lead to informal exchanges and knowledge sharing among coworkers from different parts of an organization and therefore increase the likelihood for collaboration among members from across an organization.

At the same time, more tangible and visual means such as the interior design and architecture of buildings and characterization of the physical workspace with displays of artifacts, company logo's, company's products and articles of relevance to a firm's history, are believed to have a positive affect on employees' 'sense of belonging' or organizational identification.

\subsection{The Survey Instrument}

The International Workplace Studies Program (IWSP) at Cornell University has developed a survey instrument which profiles the interrelation among workplace variables like employee' interaction, collaboration, their opinion and satisfaction with the physical attributes of the workplace and their 'sense of belonging'. This survey has been utilized in several studies to collect data at a variety of corporate campus typologies (See Appendix C for definition of campus typologies by IWSP).

Empirical data from past studies that have utilized the IWSP Workplace Survey, describe the relationship among two or more variables using simple frequencies, cross-tabulations and analysis of variance. However, it is difficult to determine from these data whether workplace variables such as employees' interaction and their opinion regarding the physical or spatial characteristics of their workplace, are in fact predictors of 'sense of belonging' 
and to what extent. Therefore, construct validation is needed in order to interpret the results of an evaluation tool; like the IWSP Workplace Survey, as a measure of a quality or trait, such as 'sense of belonging', that is not readily defined.

\subsection{Research Hypothesis}

The purpose of this master's thesis is to examine if there is a statistically significant association between employees' 'sense of belonging' and the physical factors of a workplace. To do so, this study tests the 'construct validity' of the IWSP Workplace Survey, as an instrument to predict a 'sense of belonging' among employees working in a corporate campus setting. This exercise further seeks to identify and define the primary factors that underlay the IWSP Workplace Survey and to delineate a set of workplace physical factors which, in combination, will likely explain the maximum variance in the data for employees' 'sense of belonging'. Practical knowledge on this subject can help organizations in improving their efficacy and efficiency by incorporating physical and spatial measures in a workplace that will likely enhance employees' 'sense of belonging'.

In order to systematically test for a statistically significant relationship among the physical aspects of the workplace and employees' 'sense of belonging', this research is commenced with a null hypothesis. The null hypothesis assumes that, 'there is no association among the physical (or spatial) characteristics of a workplace and employees' 'sense of belonging'. 


\section{CHAPTER 2: LITERARTURE REVIEW}

\subsection{Employees 'Sense of Belonging' or Organizational Identity:}

The achievement of organizational objectives largely depends on employee behavior. Employee behavior in turn, is influenced by the strength of the organizational identity and employee identification (Jong, Bartels, Douwes, Pruyn. 2006). Organizational identification can affect both the satisfaction and behavior of employees and the effectiveness of the organization (Albert et al., 2000; Ashforth and Mael, 1989; Hall and Schneider, 1972; Lee, 1971. O'Reilly and Chatman, 1986).

As companies grow in size and become more globally dispersed, the issue of identity and commitment to the organization, especially for employees in virtual, remote or geographically distributed teams, has become a crucial concern for organizations. Albert and Whetten (1985), Ashforth and Mawl (1989), and Dutton et. Al (1994), Wisenfeld and Raghuram (1999) argue that 'organizational identity', which can be defined as members' shared beliefs about the organization's central, enduring and distinctive characteristics, may be a critical factor in holding virtual organizations together."

Jong, et. al. (2006) cite three variables may impact organizational identification: (i) the perceived external prestige of the organization (Dutton et al., 1994; Mael and Ashforth, 1992; Smidts, Pruyn and Van Riel, 2001), (ii) value congruence (Box, Odom and Dunn,

1991; Chatman, 1991) and, (ii) length of tenure (Hall and Schneider, 1972; Hall, Schneider and Nygren, 1970; Mael and Ashforth, 1992). 
(i) Perceived External Prestige: Perceived external prestige represents how an employee thinks outsiders view his or her organization (Smidts et al., 2001) and influences employees' identification (Dutton et al., 1994). Employees may feel proud of working in an organization with a good prestige, as it strengthens their feelings of selfworth. The more prestigious the organization the greater the potential boost to selfesteem through identification (Mael and Ashforth, 1992).

Enhancement of organizational identification will occur when employees think that the outsiders positively evaluate the organization (Jong, de M., Gutteling J.M. 2006). The organization's prestige is an antecedent to organizational identity, for as the organization becomes well regarded, the employee "basks in reflected glory" and gladly identifies with its reputation and goals (Bergami \& Bagozzi, 2000; Mael \& Ashforth, 1992).

(ii) Value Congruence: Value congruence is the fit between professed organizational values and the values deemed appropriate by employees. High levels of fit between organizational climate and people's preferences for them have been found to have a positive impact on the individual and the organization. A good fit is associated with high levels of satisfaction and organizational commitment and cohesion (Box et al., 1991; Chatman, 1991), low levels of turnover and intentions to quit (Chatman, 1991; O'Reilly, Chatman and Caldwell, 1991), pro-social behaviors (O'Reilly and Chatman, 1986), and work performance (Downey, Hellriegel and Slocum, 1975). Research shows that greater 
value congruence leads to attitudes and behaviors consistent with stronger identification.

(iii) Length of Tenure: The attractiveness of the organizational identity varies with a member's length of tenure (years in the organization) (Dutton et al., 1994). Jong, et. al. (2006), assume that employees who work in the organization for a longer time will perceive the organizational identity as stronger. In addition, an attractive organizational identity will strengthen organizational identification, and therefore mediates the relationship between tenure and identification (Dutton et al. 1994). March and Simon (1958) proposed that the longer an individual remains in an organization, the more his interactions occur within the organization, the more his needs are satisfied within the organization, and, therefore, the more he identifies with the organization. Jong et. al. (2006) suggest that there is a direct relationship between length of tenure, and organizational identity. Other researcher confirms this direct impact of length of tenure on organizational identification (Hall and Schneider; 1972; Hall et al., 1970; Mael and Ashforth; 1992).

\subsection{The Contribution of the Physical Workspace towards Employees' Sense of Belonging; the example of a Corporate campus:}

A corporate campus, as defined by the International Workplace Studies Program (IWSP) at Cornell University is "a group of multiple buildings located within walking distance of each other." A corporate campus as defined by Haresign (1999) is, 
"buildings that are in close proximity to each other with centralized support, amenities and other internal functions."

The physical form of a corporate campus is widely held in North America, to offer benefits of collocation, enhanced interaction, and increased prospects for collaboration among co-workers from different parts of an organization. According to Haresign (1999), locating employees together in a physical form such as a corporate campus has been found to encourage a greater sense of loyalty and commitment to their companies. Becker et. al (2002) suggest that with respect to employee' interaction and identification; one might assume that employees who interact more frequently with others on different floors and in different buildings, thereby experiencing more of the corporate campus environment, report a stronger 'sense of identity and belonging' to their organization than employees who rarely leave their own floor or building.

Corporate campuses can provide an opportunity for businesses to incorporate design features that enhance employee communication and creativity. For instance, in an effort to mitigate the communication barriers created by physical and organizational distances, companies that rely on a steady supply of new ideas have chosen to incorporate informal meeting spaces and common areas that facilitate communication and creativity. Typically placed between two departments, these interaction nodes can be equipped with dry erase marker boards or outlets for lap top computers to encourage casual knowledge-based work. Common spaces and amenities such as on-site 
cafeterias and fitness facilities also facilitate communication and relationships among employees.

Mark Seiley (2005), National market sector leader for corporate architecture and interior design at Carter \& Burgess, reports that, "In campus settings, many employees conduct meetings during lunch while others end up solving problems during informal discussions at the coffee bar or fitness club. By providing these amenities on site, one increases the opportunity for these idea exchanges to occur." At their best- what buildings and campuses contribute and can inhibit- is to bring together people that nobody could have predicted, on the basis of current knowledge, needed to interact. The type of facility that draws people to them will vary with the function and operation of the organization. In all cases, they only increase the occurrence of chance encounters among occupants of each and all buildings on the campus.

\subsection{Employee' Communication is a Key Component of Organizational Identity:}

The modern workplace is inherently collaborative, and this collaboration relies on effective communication among coworkers (Turner, Pernilla, Biehl, Gene, Back, 2009). Organizations do not only express an organizational identity through their visual expressions; wider aspects of communication and the behavior of employees also have an effect on their identity (Bosch, van den A.L.M., 2005.) If an organization has open organizational communication, it will serve as an effective method to give their 
employees information with which to identify (Bartels, Peters, de Jong, Pruyn, \& van der Molen, 2010).

Research on office interaction in a number of firms, suggests the importance of informal communication (Kraut, Fish, Root, \& Chalfonte, 1990), and reveals that many smaller decisions and much of the coordination during the execution of projects got done in brief and more spontaneous encounters. Unintended meetings were as valuable as scheduled ones for getting tasks accomplished; they occurred four times as frequently as scheduled meetings, yet on a per meeting basis took only one third as much time to accomplish. All types of conversations provide some opportunity to enjoy the company of coworkers, to learn more about them, and build bonds with them. However, scheduled meetings fulfilled these needs inefficiently, occurred less frequently and took more time (Kraut et al., 1990.)

Brown and Duguid (1991), argue that the way people actually work differs fundamentally from the ways organizations describe that work in manuals, training programs, organizational charts, and job descriptions. They argue that, "conventional descriptions of jobs mask not only the way people work, but also significant learning and innovation generated in the informal communities of practice in which they work." "It is through these informal communities that employees learn from their peers how to navigate the corporate bureaucracy, who to contact to get the most accurate technical information, what the undocumented "tricks" are to making a program work, how to best contact different types of clients, how to respond to certain kinds of queries, and so on." 
Various types of communication such as horizontal and vertical communication are imperative to ensure organizational identity. Horizontal communication is described as communication that occurs through conversations with peers and other departments of equal stature in the organization. Vertical communication describes communication through a top-down process as executives and other managers communicate organizational goals and support to their subordinates (Bartels et al., 2010). While both are necessary for identifying with their company, vertical communication is more associated with organizational identity, while horizontal communication encourages identification within their department, branch, or sector of the company.

\subsection{Physical and Organizational Proximity affect Communication and Collaboration in a Workplace:}

A common workplace layout paradigm is that "organizational structure determines physical structure, which in turn determines communication behavior" (Rogers and Agarwal-Rogers, 1976 p.102). In part, physical proximity increases the frequency of communication by putting people who have the prerequisites for conversation in each other's presence (Monge, Rothman, Elsenberg, Miller, and Kirste 1985). As a result, they have chance encounters with others inhabiting or visiting the same location, which provide opportunities for conversation. For example, Kraut, Fish, Root, and Chalfonte (1990) showed that in the university and research labs that they examined; the majority of conversations were opportunistic, planned by neither party before they happened. Architectural features like common rooms and public events like seminars increase the likelihood that inhabiting a common location leads to opportunities for interaction (Allen 1977). 
When people are collocated, it takes relatively little effort for them to start interacting. For this reason, physical collocation has consequences for the frequency of encounters, the likelihood that chance encounters lead to conversations, people's co-membership in a community, and the common ground that they develop due to repeated encounters. Proximity increases frequency of communication. All else being equal, people communicate most with those who are physically close by (Kraut, et. al. 2002).

Research done in office design, communication and productivity explores ways in which workplace design can enhance productivity and quality of work life. Recent studies have focused on changes in design of workspace to support evolving team-based organization structures and the layout and arrangement of space to enhance communication (Peponis, et. al. 1990)

Penn et. al. (1999) studied laboratories, of an energy utility company, and a multi disciplinary advertising and marketing agency. These studies showed that a powerful determinant of who will communicate with whom is the location of a particular person in relation to another. They found in a particular study that patterns of space in building interiors affect patterns of "useful" interaction between groups. Penn et. al. suggest that spatial layout could in fact play a key role in facilitating or inhibiting communication and collaboration. An important finding of their survey was that how "useful" a person was perceived to be in average to everyone who answered the questionnaire, correlated with the average frequency with which people say they saw the respective person. Hence, the perceived "usefulness" of a person is to a measurable extent, derived from 
the frequency of contacts with others and not just from the individual's personal qualities, status, or job description.

\subsection{Advancements in Telecommunication Technology has had a significant impact on the Physical Workplace:}

So far the review of the literature has emphasized the importance of face-to-face communication among co-workers in the workplace, the physical collocation of employees and the role of the physical workspaces as the prerequisites for organizational identity and 'sense of belonging'. Notwithstanding the importance of the face-to-face environment, high technology innovations such as e-mail, teleconferencing and instant messaging abilities have had a significant impact on how people interact, both in the context of formal and informal communication. These technological advancements make remote communication technically more feasible than ever before and as a result put forth an argument that contradicts many of the beliefs that prevailed in the context of a traditional face-to-face physical workspace.

Telecom technology has engineered a new virtual universe which allows people to collaborate across time, space, and physical boundaries. Phrases like 'geographically dispersed teams', 'virtual teams', 'parallel teams', 'networked teams' and 'telecommuters', have become common part of the present day workplace jargon. Teams can now work and collaborate effectively across a multitude of countries and areas. While originally used for simple text exchanges; the advances in technology, such as video channeling and data transfer speeds allows teams to set-up virtual board 
rooms where members can literally interact face-to-face and work on documents and projects together as though they were sitting next to each other. As multinational corporations expand to compete globally, many are benefitting from the use of transnational teams. Working either within the firm's formal structure or as a complement to it, a transnational team can connect the best ideas and innovations from each part of the company and use them in ways that add value throughout the organization. Advancing telecommunication technology has rendered the notion of physical meetings as sporadic or in many cases obsolete (Pietkiewicz, et. al.; 2008).

Different technological tools support different levels of information, expressiveness and context. They provide communicating parties with varying levels of awareness and leave behind differing records of communication acts. Each tool has its own strengths and weaknesses. For instance, email provides a persistent record of its messages, but does not convey non-verbal signals. Face-to-face communication, on the other hand, provides a wealth of information about the communicating parties, gleaned from facial expressions, body language, verbal pauses, and other sources, but generally leaves only an imperfect trace in participants' memories of exactly what was said (Turner, et. al. 2009).

Research on computer-mediated communication indicates that, in contrast to the traditional face-to-face work environment; the distribution of team members over remote networks tends to impair team interaction. Team processes develop more slowly in 
virtual teams. Weaker relational ties are often observed in virtual teams which may be the simple result of these teams needing longer to develop. Crucial aspects of team processes such as team cohesiveness, trust, communication, interpersonal relationship building and feeling a 'sense of belonging', are often overlooked in the bonanza that the technological mediations have presented.

Kraut et al. (1990) analyzed why computers and telecommunications have not created computer mediated work environments for collaboration that are as successful as physically shared environments. They note in reference to the influence of physical proximity on the collaborative relationships between scientific researchers in industry settings, that even in the age of telecommunication and the Internet, collaboration at a distance remains substantially harder to accomplish than collaboration when members of a work group are collocated. For example, in collaboration at a distance, communication is typically less frequent, characterized by longer lags between messages, and more effortful. Physical proximity increases the likelihood of collaboration

Kraut, Egido, and Galegher (1990), collected data for 164 scientists and engineers working at a large telecommunications company to predict the probability of successful collaboration among them. This company had been using Internet-based e-mail since its founding, and at the time of data collection, every member of the research division had an e-mail account and a personal workstation or computer. Majority of the subjects in this study used e-mail heavily. They examined which of the 164 scientists and 
engineers in the sample actually collaborated as a function of the pairs'; (i) organizational proximity (an ordinal measure of how close they were in the organizational chart; same supervisory group, same department, same laboratory, or different laboratory), (ii) research similarity (an index of the semantic similarity of a pair's solo publications), and (ii) physical proximity (an ordinal measure of how close the office of potential collaborators were-same corridor, same floor, same building, different buildings).

Results showed that even in the highly technological communication environment, pairs of researchers were unlikely to complete a technical report together unless their offices were physically near each other. This remained true even if they had previously published on similar topics or worked in the same department in the company. Virtually all joint publications occurred among researchers with similar research interests. Researchers with the most similar interests were more than four times as likely to publish together if their offices were on the same corridor as they were if their offices were on different floors of the same building, and researchers whose offices were in different buildings almost never collaborated regardless of their research interests.

The association of organizational proximity with collaboration was similar. Most successful collaboration occurred among people who were in the same department. However, among researchers in the same department and those in different departments, researchers physically close to each other were more likely to collaborate than those farther apart. The positive statistical interactions between physical proximity and both research similarity and organizational proximity suggests that physical 
proximity stimulates collaboration among people who might otherwise not work together. For example, if two people were in the same department, they were two-thirds more likely to collaborate if their offices were on the same corridor than if the offices were only on the same floor. If they were not in the same department, then being on the same corridor boosted their likelihood of collaborating over eight times.

There is a vast body of research available on the implications of a progressively technological nature of present day workplace interaction. At the same time, it is unclear whether the new mediums of communication can effectively substitute the idiosyncrasies of a face-to-face environment. More specifically, it is difficult to assess how an organization can foster and enhance a 'sense of belonging' among members that primarily work in a virtual environment which is devoid of visual cues that are believed to be requisites for organizational identity. 


\section{CHAPTER 3: METHODOLOGY}

\subsection{The Research Site}

The subject site for this study is an architecturally branded, purpose-built, suburban corporate campus' of a large scale information technology firm called Wipro Technologies, located in Bangalore, India. An 'Architecturally Branded, Purpose-Built, Suburban corporate campus' was selected for this study because this form is considered prototypical of the majority of large-scale corporate campuses.

Wipro Limited was founded in 1945 by M.H.Hasham Premji in Amalner, Maharashtra, India. Wipro Technologies was established in 1980 as subsidiary of Wipro Limited. Wipro Technologies is a global information technology (IT) services company headquartered in Bangalore, India. Based on its 2011 revenues, Wipro was ranked as the third largest IT services company in India. As of March 2011, Wipro employed over 122,385 people worldwide and ranked 31st in the list of IT service providers worldwide. The company operates in three broad segments: IT Services, IT Products, Consumer

Care and Lighting. Wipro Technologies' primary IT services include; outsourced research and development, infrastructure outsourcing, business process outsourcing (BPO) and business consulting services.

During 1970s and 1980s, Wipro Limited shifted its focus from its original business of manufacturing consumer products and ventured into business opportunities in IT and 
computing industry, which at the time were at its nascent stages in India. Wipro Technologies was the first company which marketed the first indigenous homemade PC from India in 1975. Wipro's entry into the IT business was helped by lack of competition from IBM, which was asked to leave India by the government in 1977, following a dispute over investment and intellectual property. With its name and brand established through its parent company, in the early 1980s, Wipro Technologies began selling its IT products through a dealer network and began assembling products made by globally well-known companies such as Canon, Cisco Systems, Epson, Hewlett-Packard and Sun. Over the years Wipro Technologies has transformed itself into one of the largest IT outsourcing services provider of the world. At the time of its IPO in 2000, Wipro Technologies (NYSE: WIT) emerged as the largest publicly listed software exporter in India and the first software services provider to be assessed at SEI Level 5 in the world. Wipro is the world's first Software Services Company to be assessed at SEI Level 5, the highest global ranking for Software Quality certification. Since its entry into the hi-tech arena, Wipro has been focused on helping enterprises leverage technology to achieve business goals, offering services such as IT consulting, Systems integration, Package implementation, Application development and maintenance, IT infrastructure outsourcing, and Total outsourcing.

The corporate headquarters of Wipro are at Doddakannelli, Sarjapur Road, Bangalore, India. The corporate campus is located on the out skirts of the main Bangalore city. Bangalore is a hub of information technology companies in India with several largescale Indian and US based and other multi-national companies including Infosys, 
iGATE, Tata Consultancy Services, Accenture, Google, IBM, Hewlett-Packard, Yahoo, GE, Oracle Corporation, Cisco, Microsoft and Intel have significant operations in Bangalore. For that reason, Bangalore is popularly referred to as the Silicon Valley of India.

Bangalore's IT industry is divided into three main physical clusters - Software Technology Parks of India (STPI); International Tech Park, Bangalore (ITPB); and Electronics City. Wipro's operations in Bangalore are divided over two of its campus sites, The Sarjapur Campus and The Electronic City Campus, both of which were included and studied for this research. Electronics City is one of India's largest master planned electronics industrial park. The industrial park development is spread over 332 acres in Konappana Agrahara and Doddathogur villages, just outside Bangalore, India. It has three phases - Phase I, Phase II and Phase III. Electronics City is known for its world class infrastructure which has housed major IT companies like such as Wipro, Hewlett-Packard, Infosys, HCL Technologies, Patni Computer Systems, CGI, Siemens, Yokogawa Electric etc.

Each of the Wipro's campus buildings reflects a distinct architectural style. Wipro follows global best practices within the organization to promote an open environment and best in class facilities. 
Table 3.1 below provides basic data for Wipro's campus buildings at its Sajarpur and Electronic city sites and the headcount at each location.

Table 3.1 Basic Site Data for Wipro's Corporate campus Site in Bangalore, India

\begin{tabular}{|l|l|l|}
\hline Building Details & SARJAPUR & ELECTRONIC CITY (EC 1, 2 \& 3) \\
\hline $\begin{array}{l}\text { Number of Building } \\
\text { on Campus }\end{array}$ & $\begin{array}{l}\text { 4 Office Blocks, } \\
\text { Learning Center, } \\
\text { Cafeteria \& Guest } \\
\text { Block }\end{array}$ & $\begin{array}{l}\text { EC1 - 4 Office Buildings \& 1 Learning centre } \\
\text { EC2 -3 Office Buildings, Data center \& 1 Learning } \\
\text { centre } \\
\text { EC 3- 1 Office Building, Cafeteria, Recreation } \\
\text { Center }\end{array}$ \\
\hline $\begin{array}{l}\text { Total Sq. Ft. (Excl. } \\
\text { Basement) }\end{array}$ & $\begin{array}{l}\text { EC1- 274,000 Sq. ft } \\
\text { EC2 - 410,000 Sq. ft } \\
\text { EC 3- 350,055 Sq. ft. }\end{array}$ \\
\hline $\begin{array}{l}\text { Year Built/Occupied } \\
\text { Total Employees (as of }\end{array}$ & $\begin{array}{l}\text { March 2000 } \\
\text { June 2003) }\end{array}$ & $\begin{array}{l}\text { EC1 - December 1998 } \\
\text { EC2- August 2000 } \\
\text { EC 3- 2004-2005 }\end{array}$ \\
\hline $\begin{array}{l}\text { Major Departments and/or } \\
\text { Divisions }\end{array}$ & $\begin{array}{l}\text { Wechnologies, Health } \\
\text { Science, Learning } \\
\text { Center, Guest } \\
\text { Accommodations }\end{array}$ & $\begin{array}{l}\text { IT Development and Related Services } \\
\text { General Administrative }\end{array}$ \\
\hline
\end{tabular}


Fig 3.1 Map: Distance between Wipro Technologies Sarjapur Campus and Electronics City Campus, Bangalore, India*

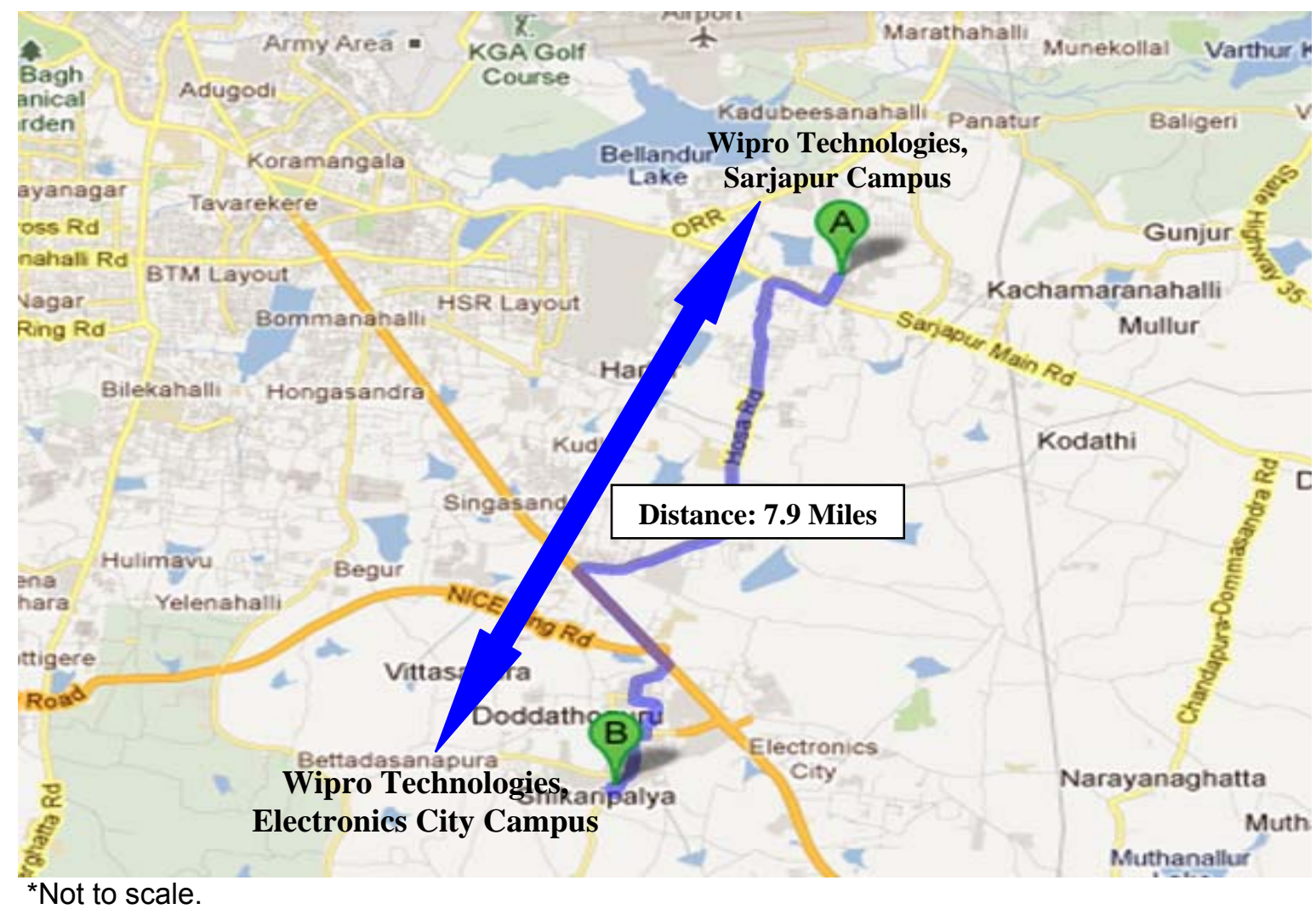

A:

Wipro Limited Headquarter- Sarjapur Main Campus

Doddakannelli

Sarjapur Road

Bangalore - 560035

Karnataka-India

B:

Wipro Limited- Software Development Center- Electronics City Campus

Electronics City 1 No. 72

Keonics Electronic City

Hosur Road

Bangalore - 561229

Karnataka - India 
Fig 3.2 Aerial View and Site Plan of Wipro's Technologies Sarjapur Campus, Bangalore, India

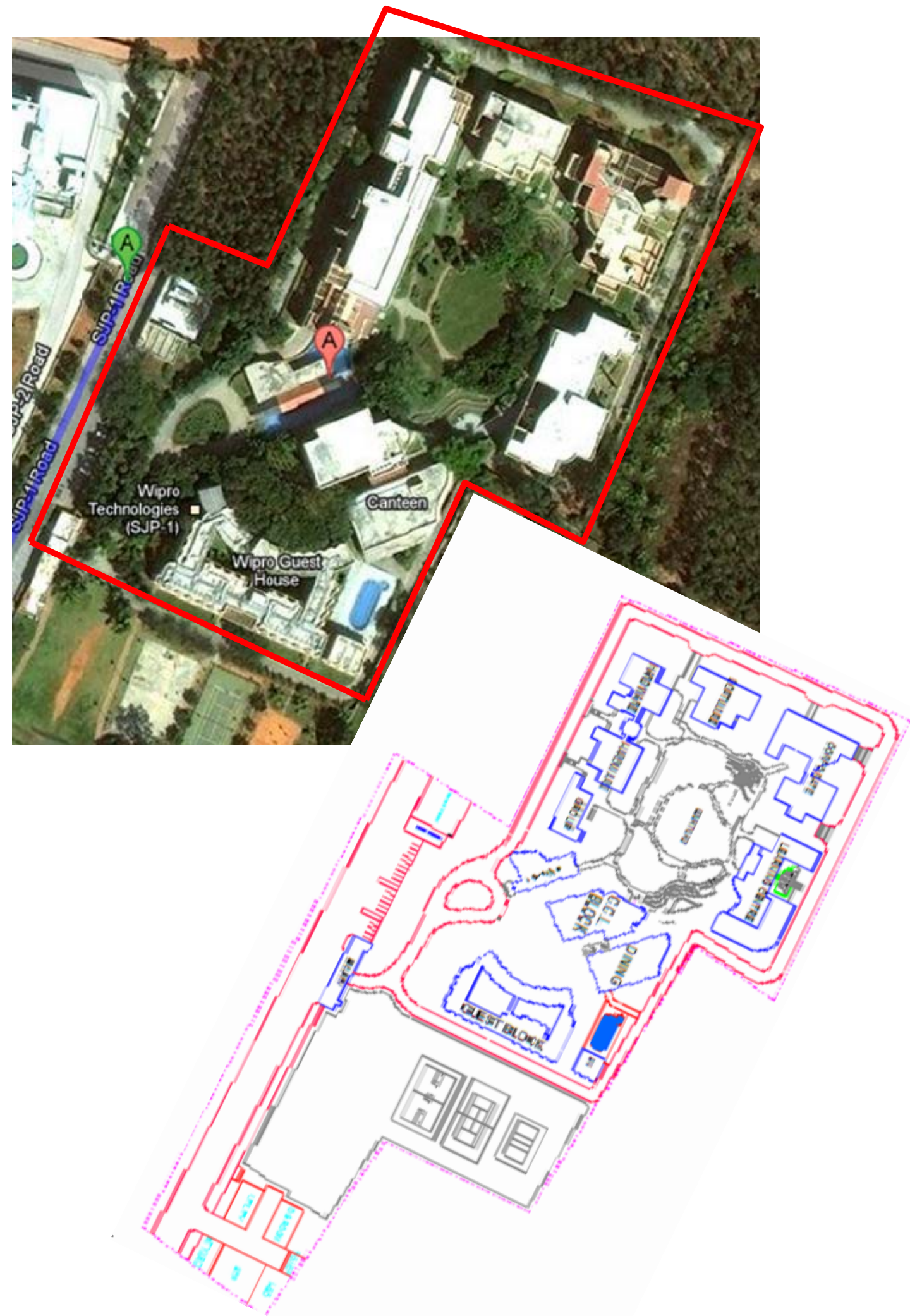


Fig 3.3 Aerial View of Electronics City Business Park and Wipro's Technologies Electronics City Campus, Bangalore, India
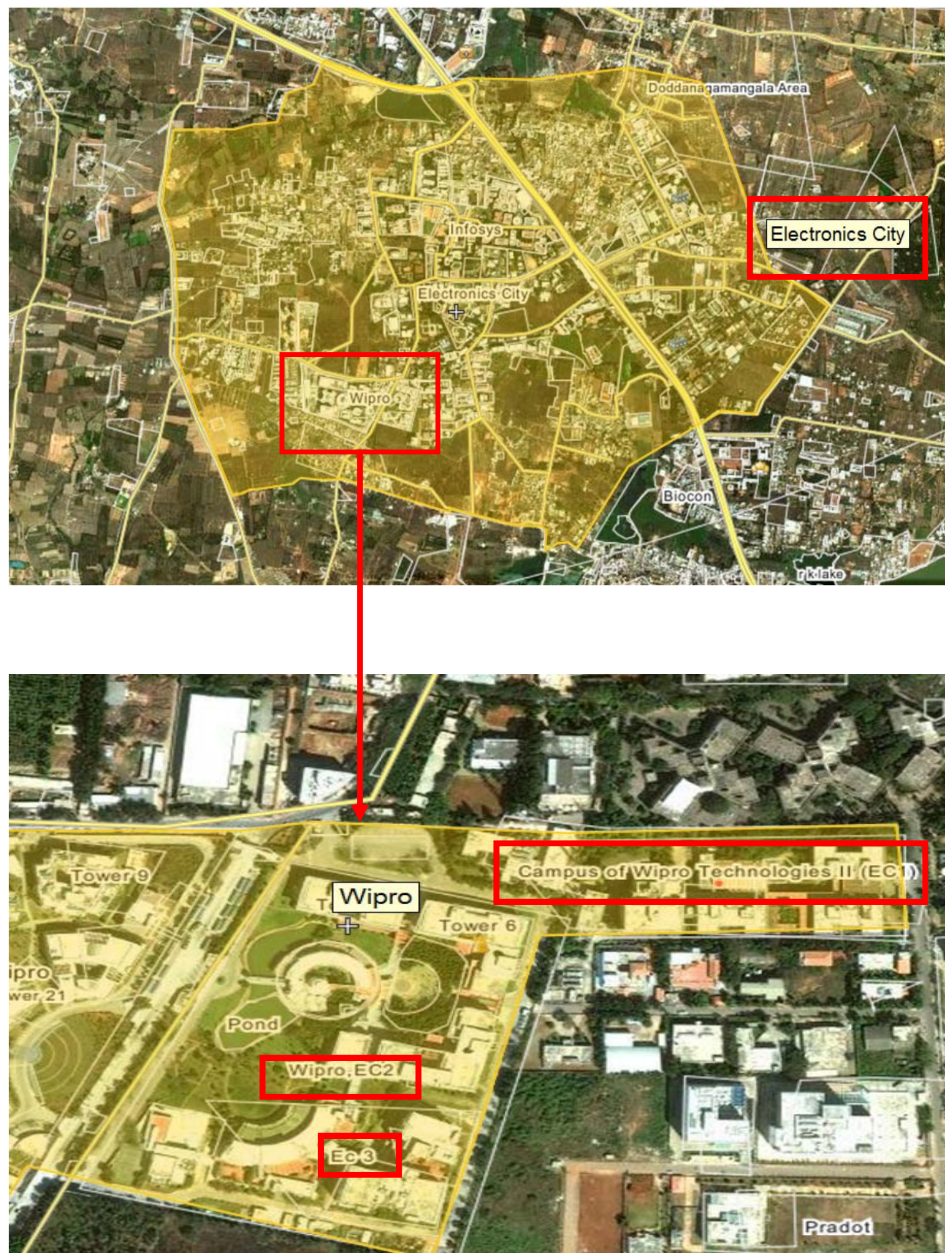
Fig 3.4 Site Plan of Wipro Technologies Campus Phase I, at Electronic City Business Park, Bangalore, India
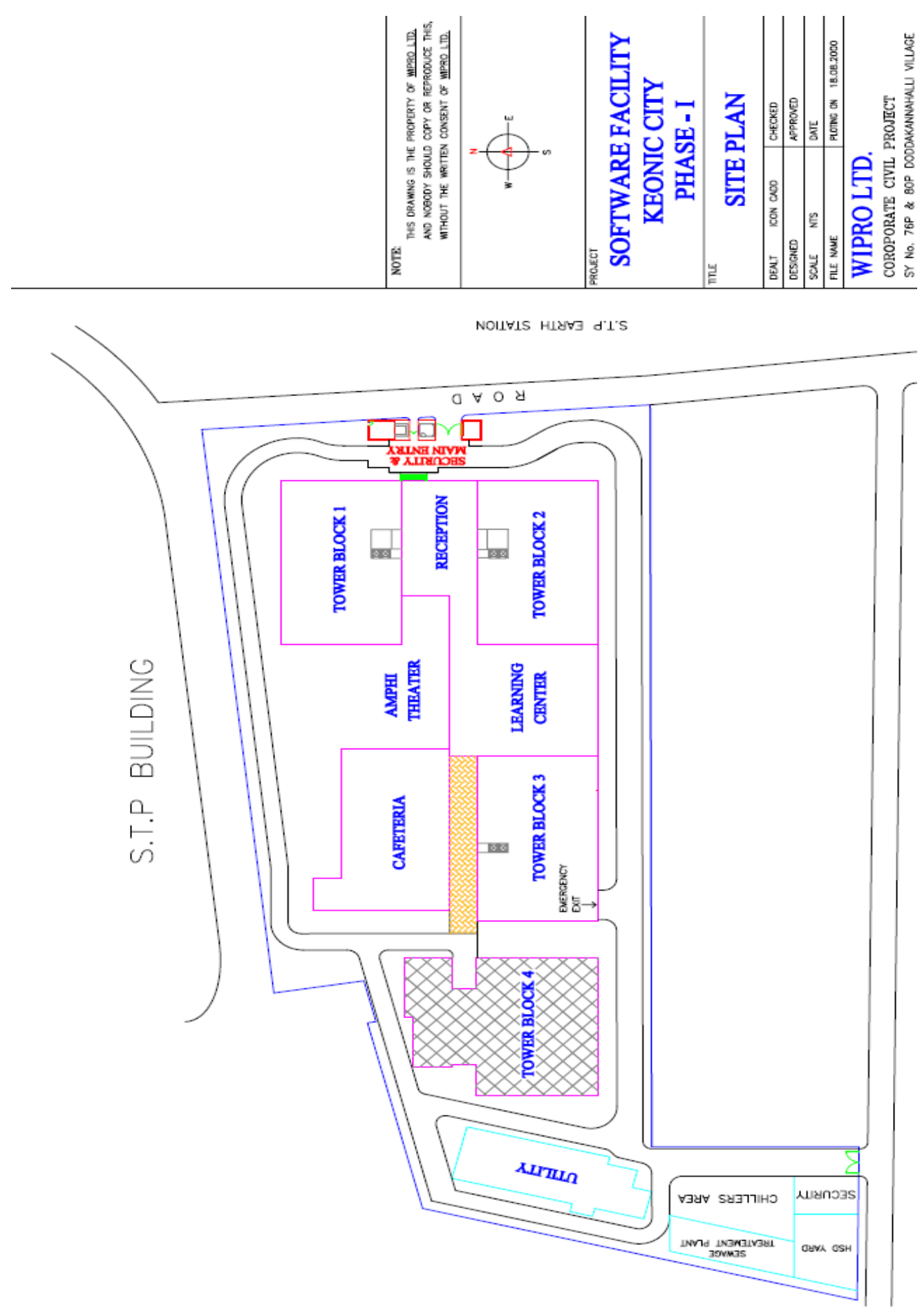
Fig 3.5 Site Plan of Wipro Technologies Campus Phase II and III, at Electronic City Business Park, Bangalore, India

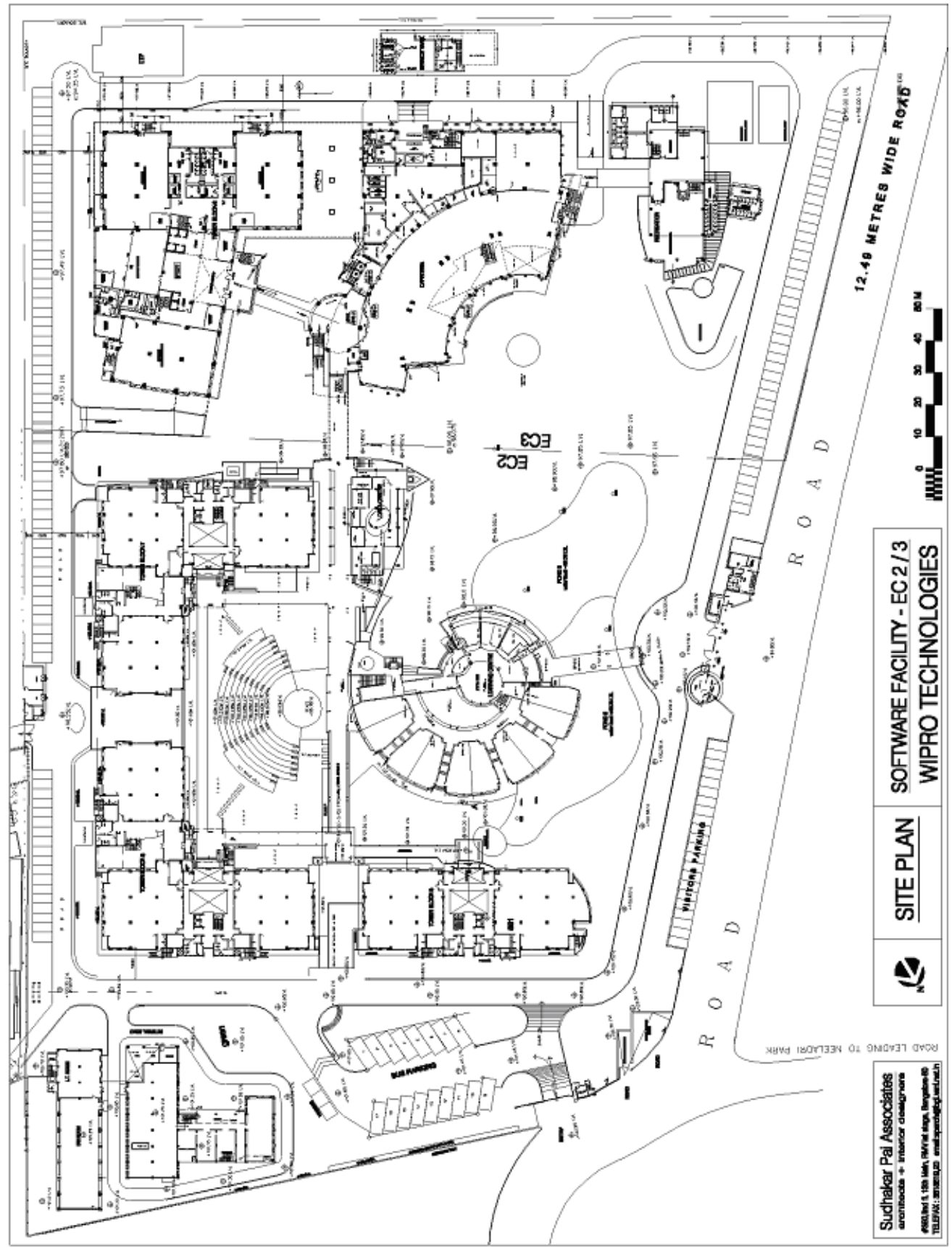




\section{Images of the Wipro's Corporate campus Facilities}

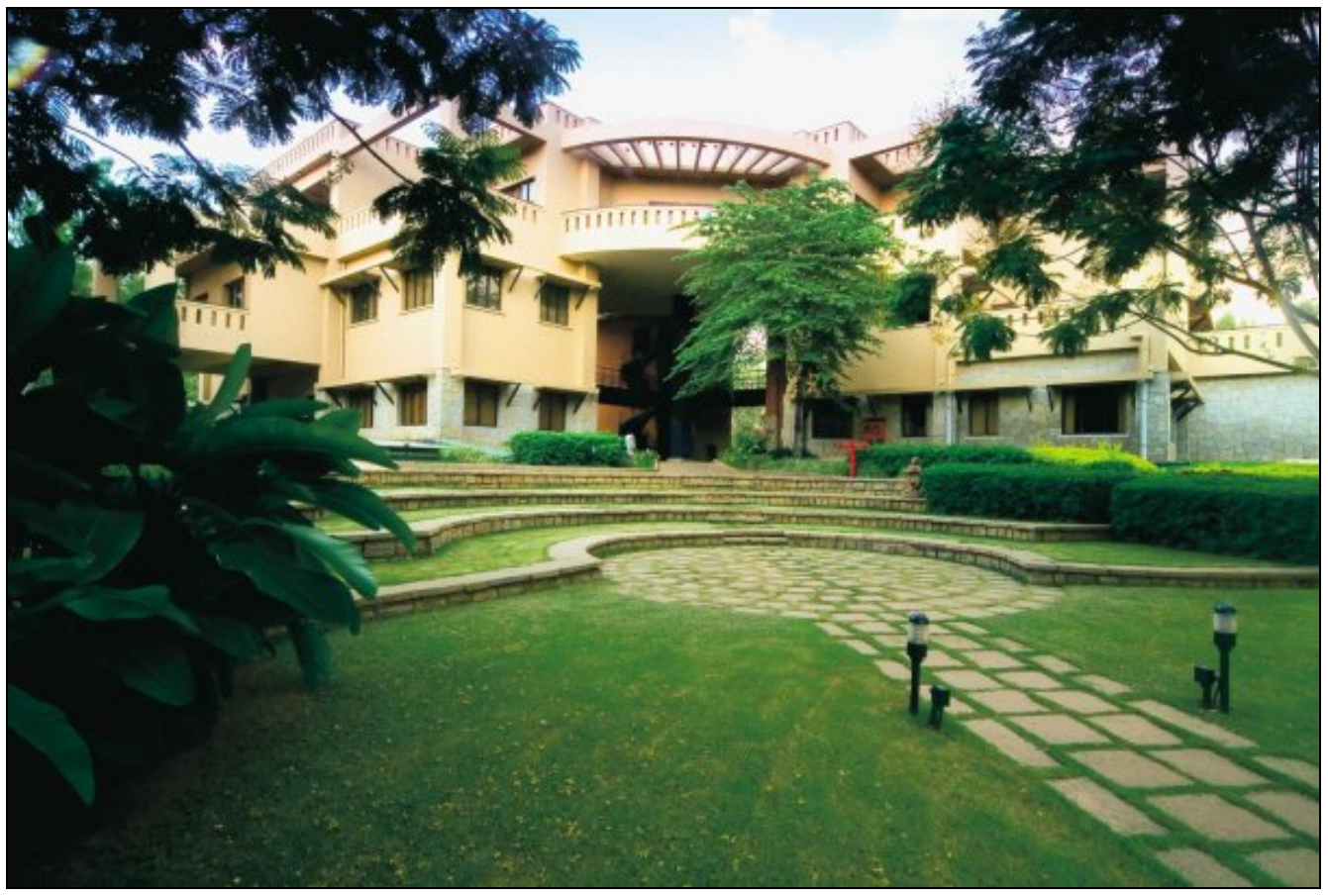

Figure 3.6- Office Building at Wipro's Sarjapur Campus

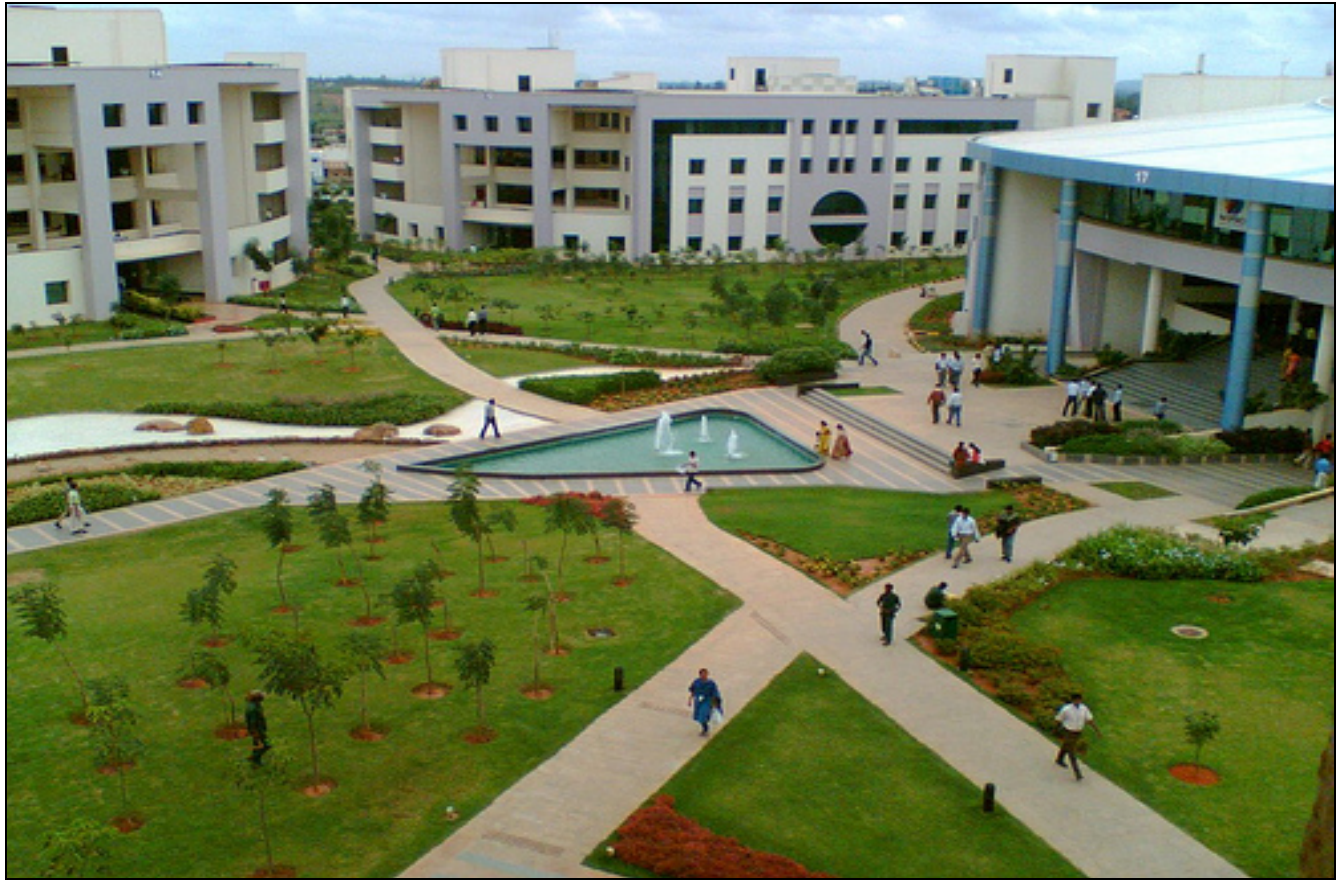

Figure 3.7-Landscaped Walkways at Wipro's Sarjapur Campus 


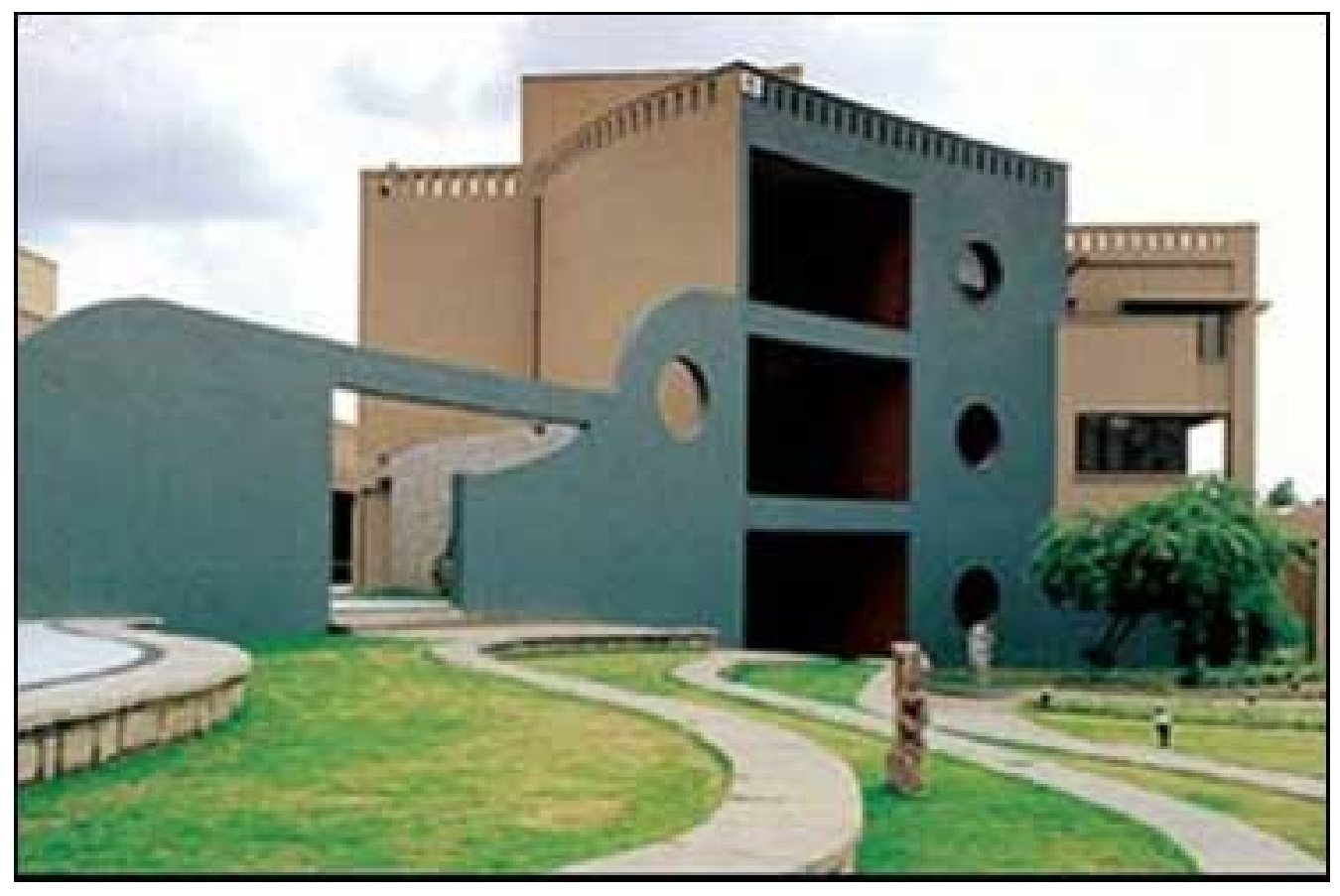

Figure 3.8-Wipro's Office building are demarcated with their distinct architectural style at Wipro's Sarjapur Campus

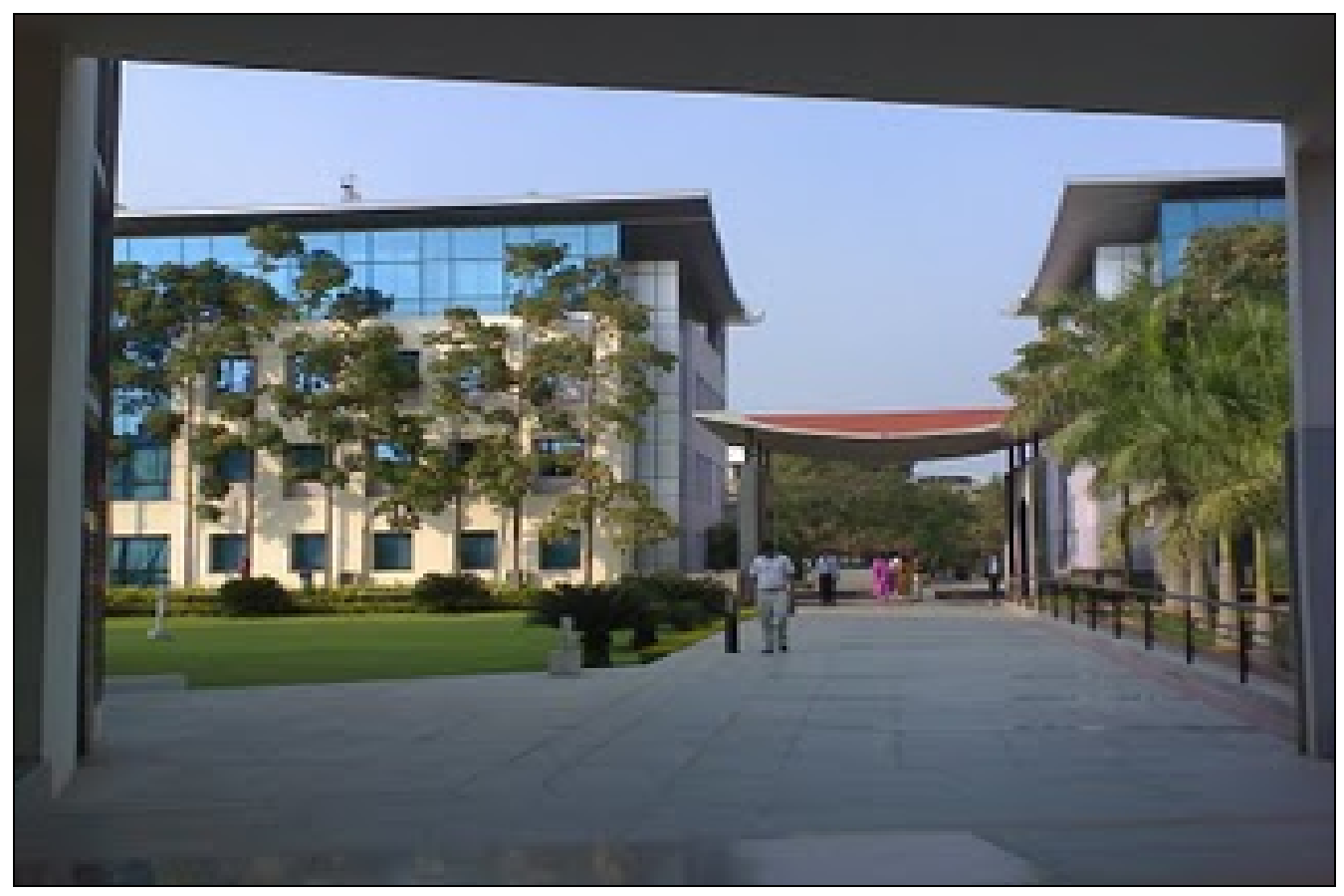

Figure 3.9-The Architectural style of the office buildings at Wipro's Sarjapur Campus, represent a mix of modern styles with tasteful aesthetics 


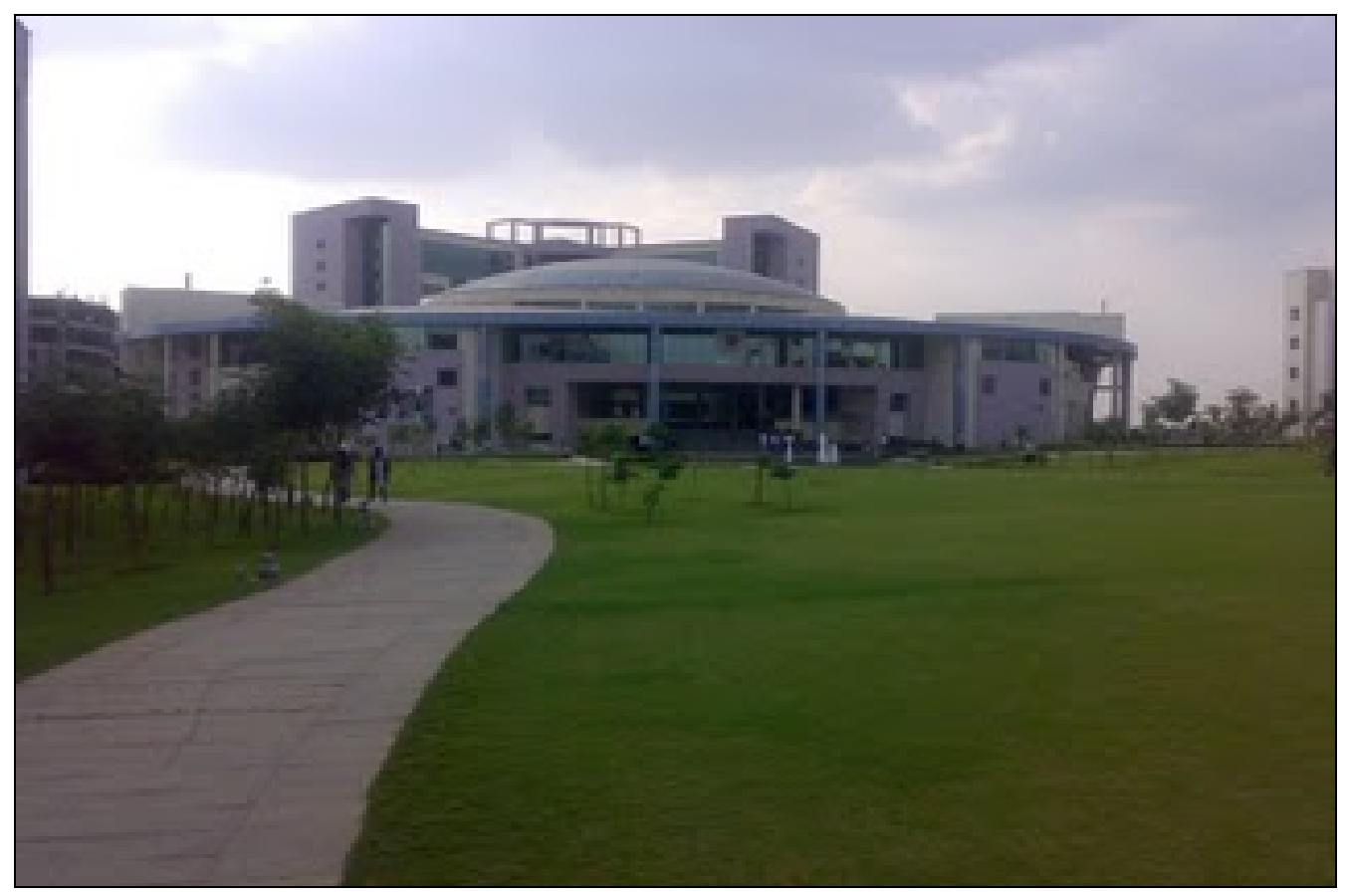

Figure 3.10-Ample and Well maintained landscaping is a common attribute of Wipro's Corporate campus

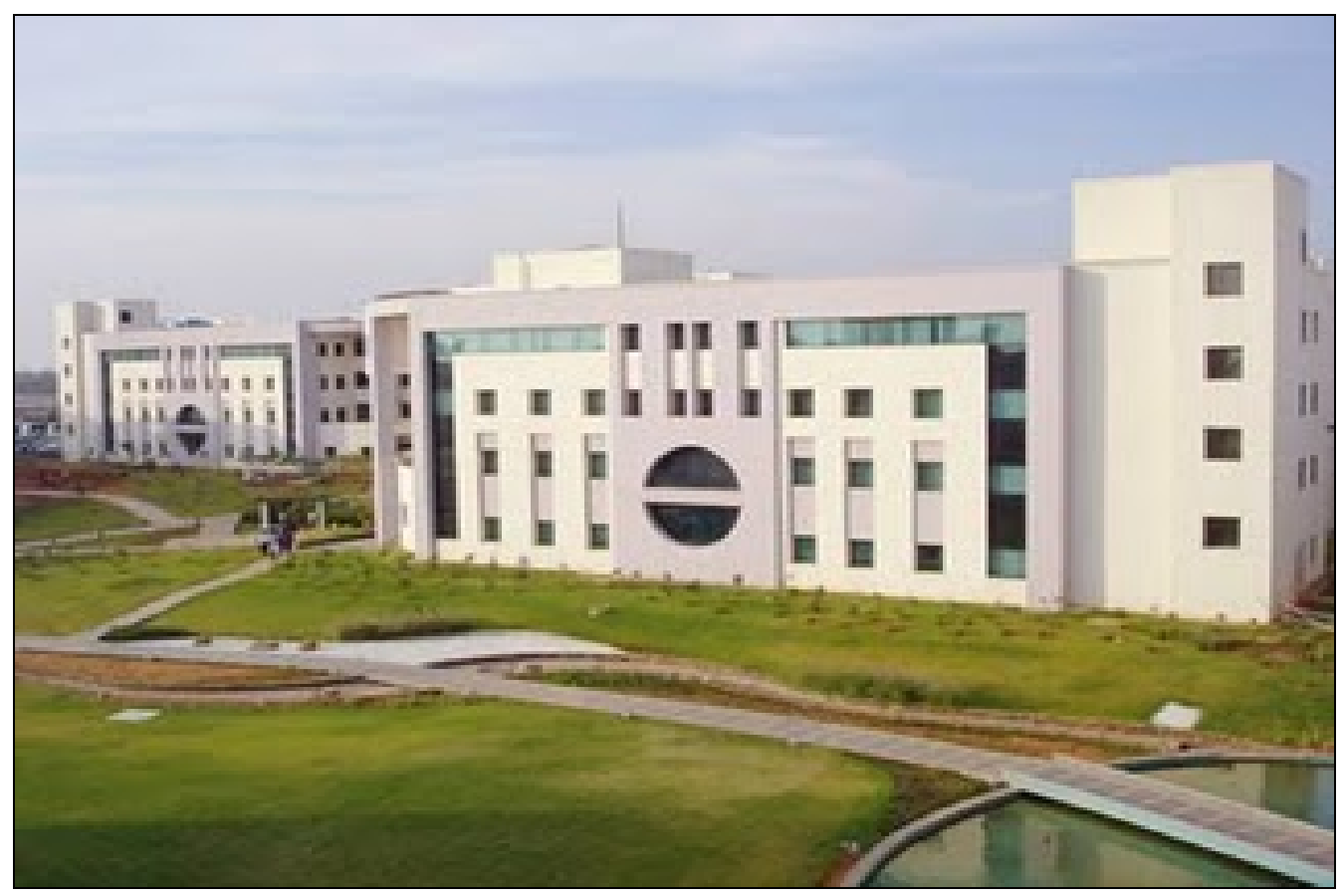

Figure 3.11-The layout of Wipro's buildings at its Sarjapur Campus, represent a sense of openness and grandeur 


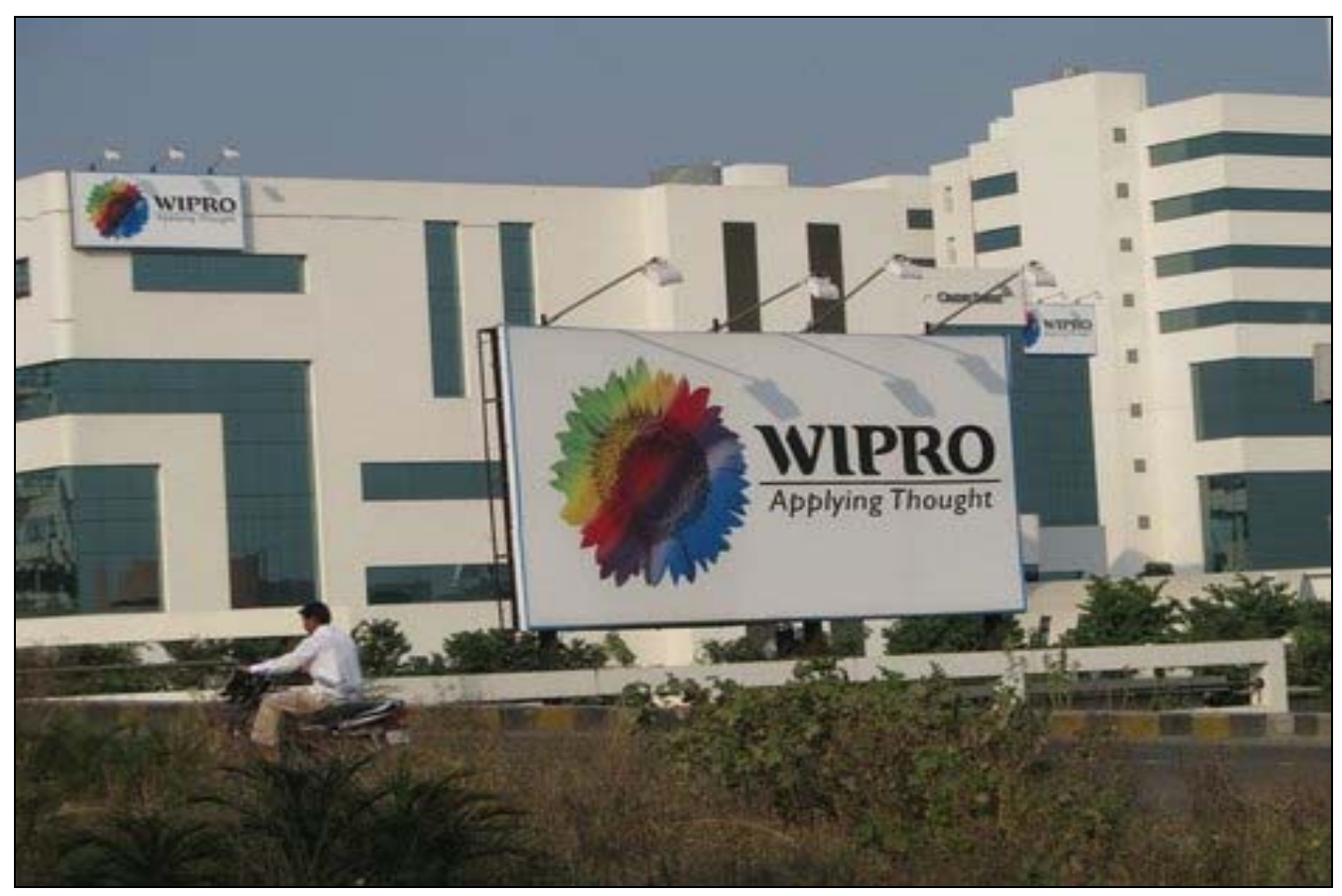

Figure 3.12-Company Logo featured on the exterior of Wipro's campus buildings at Wipro's Sarjapur Campus, promote a strong brand identity for passer-by's who do not work at Wipro

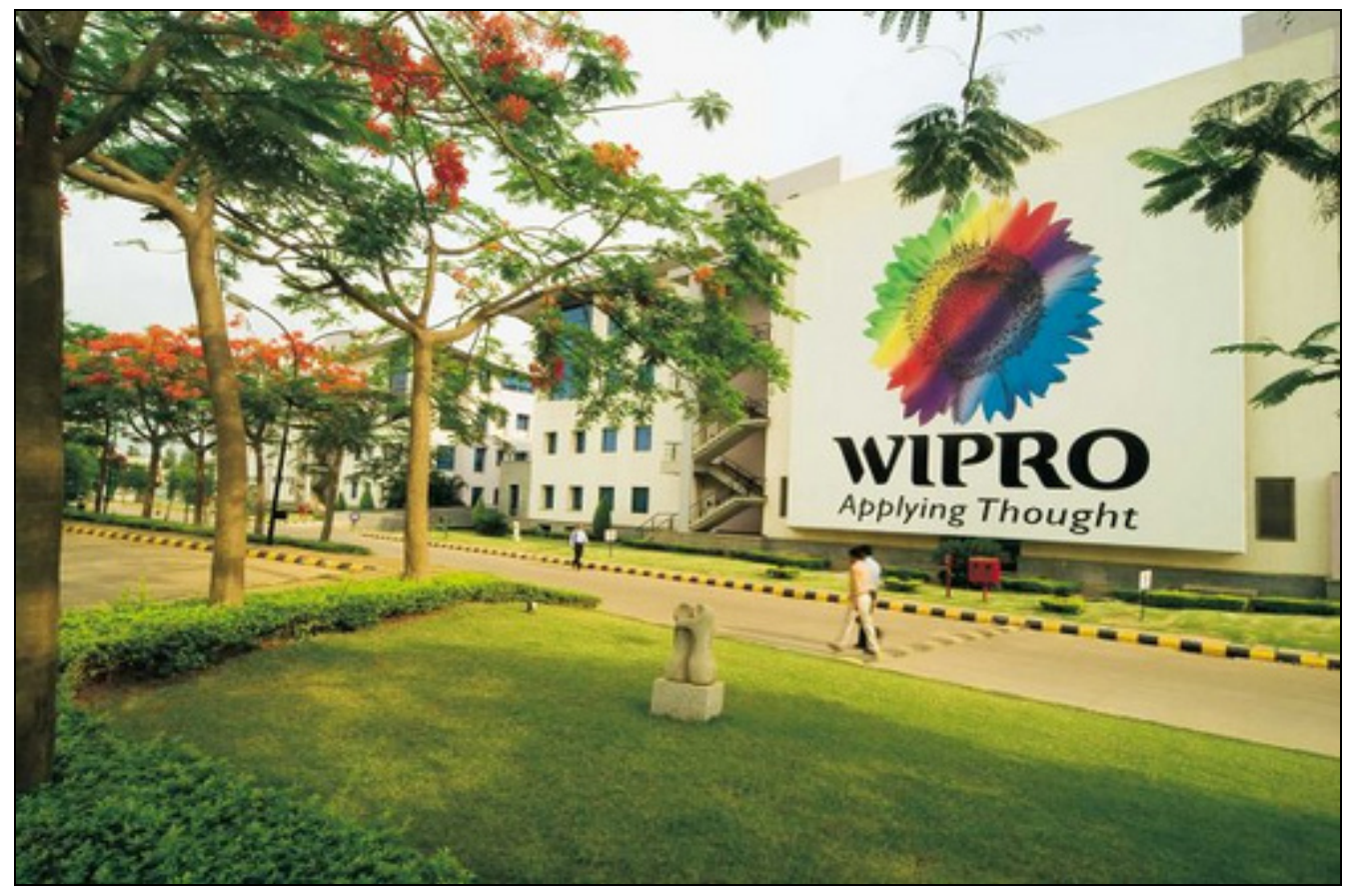

Figure 3.13 Company Logo featured on the exterior of Wipro's campus buildings at Wipro's Sarjapur Campus promote a strong brand identity for its employees' who at Wipro's Campus 


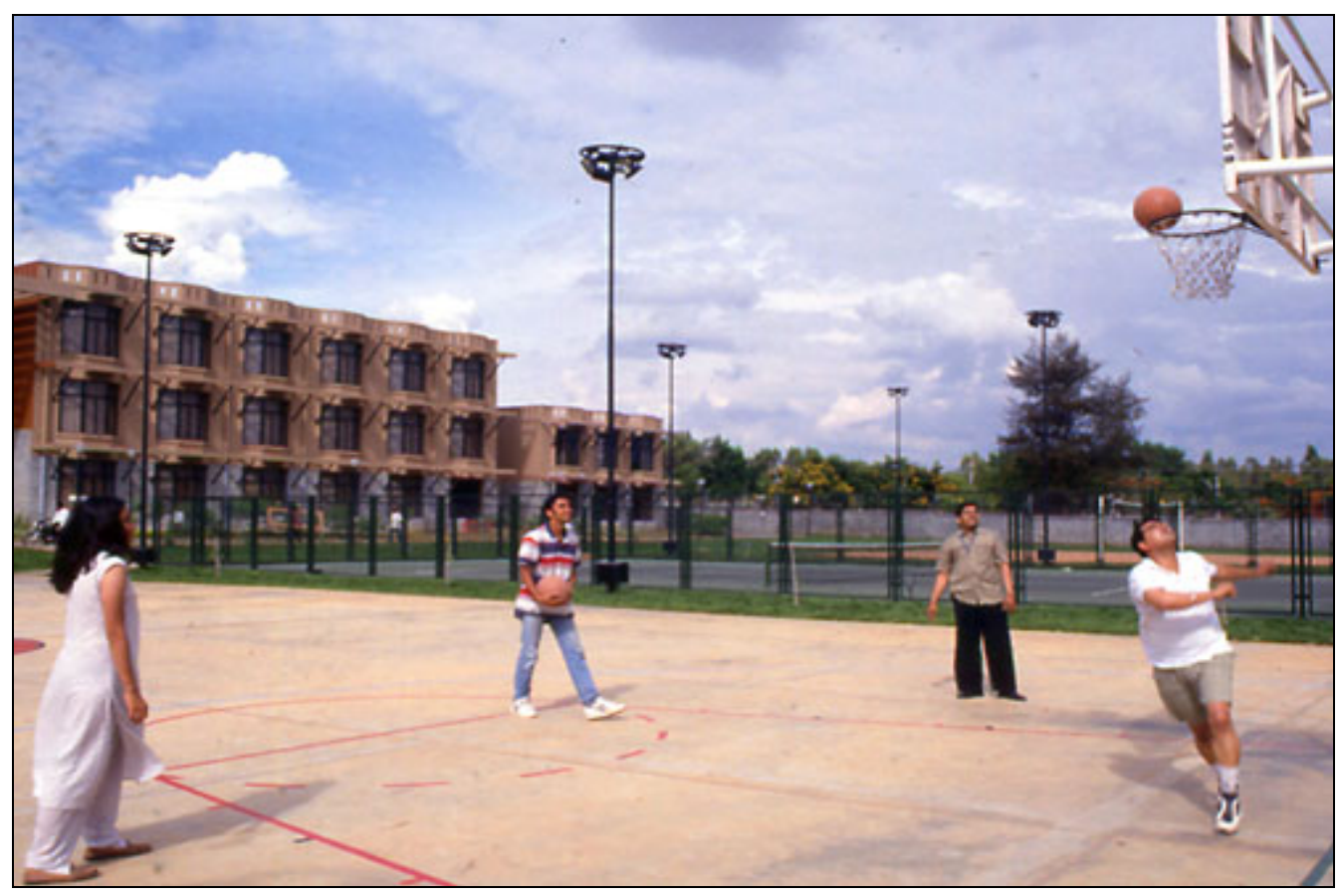

Figure 3.14- Open Sports/ Recreational Amenities at Wipro's Sarjapur Campus where employees can catch a refreshing break during or after working hours

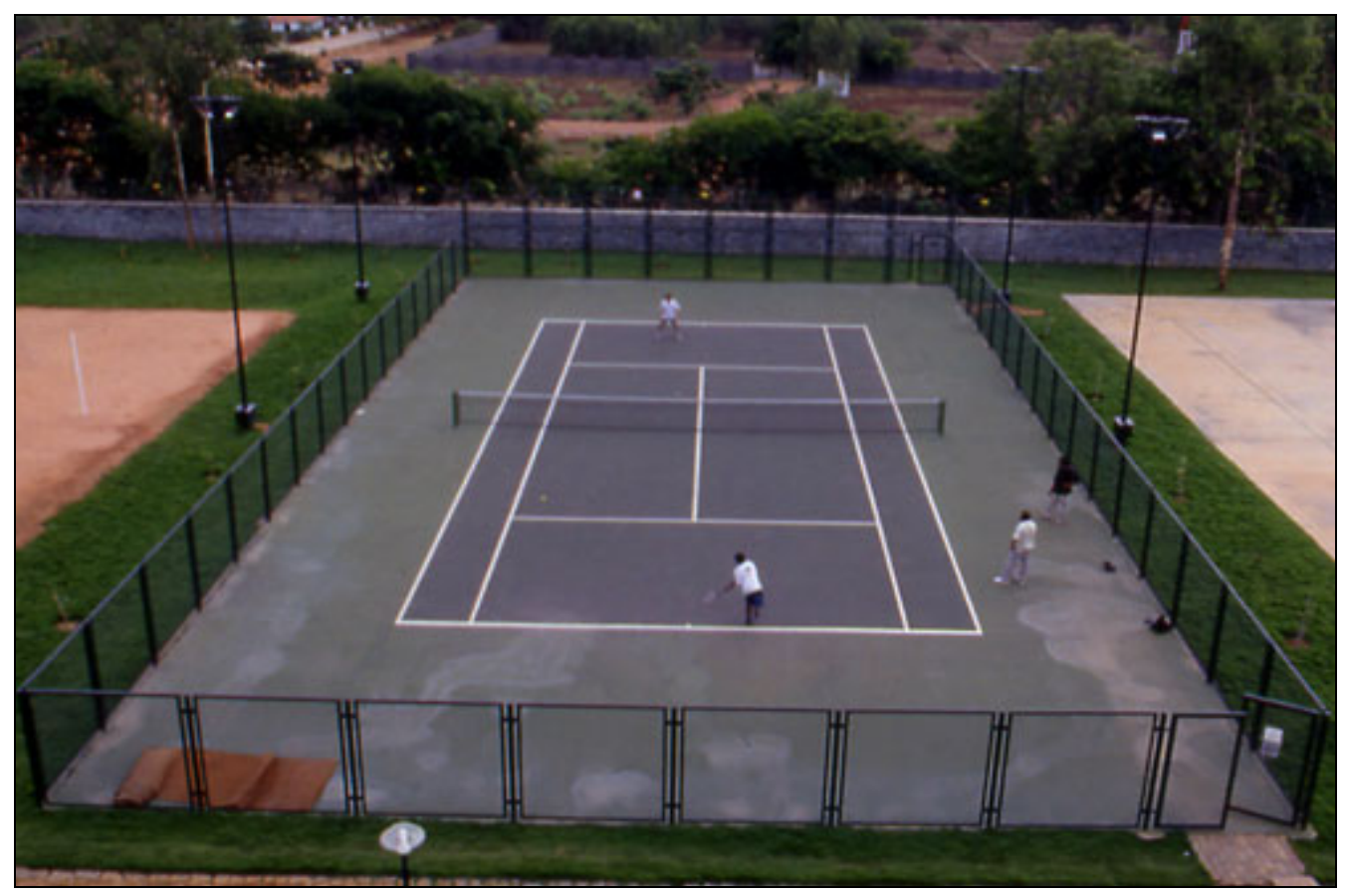

Figure 3.15- Provision of On-Site Sports/ Recreational Amenities at Wipro's Sarjapur Campus also support and encourage an active lifestyle for Wipro's employees 


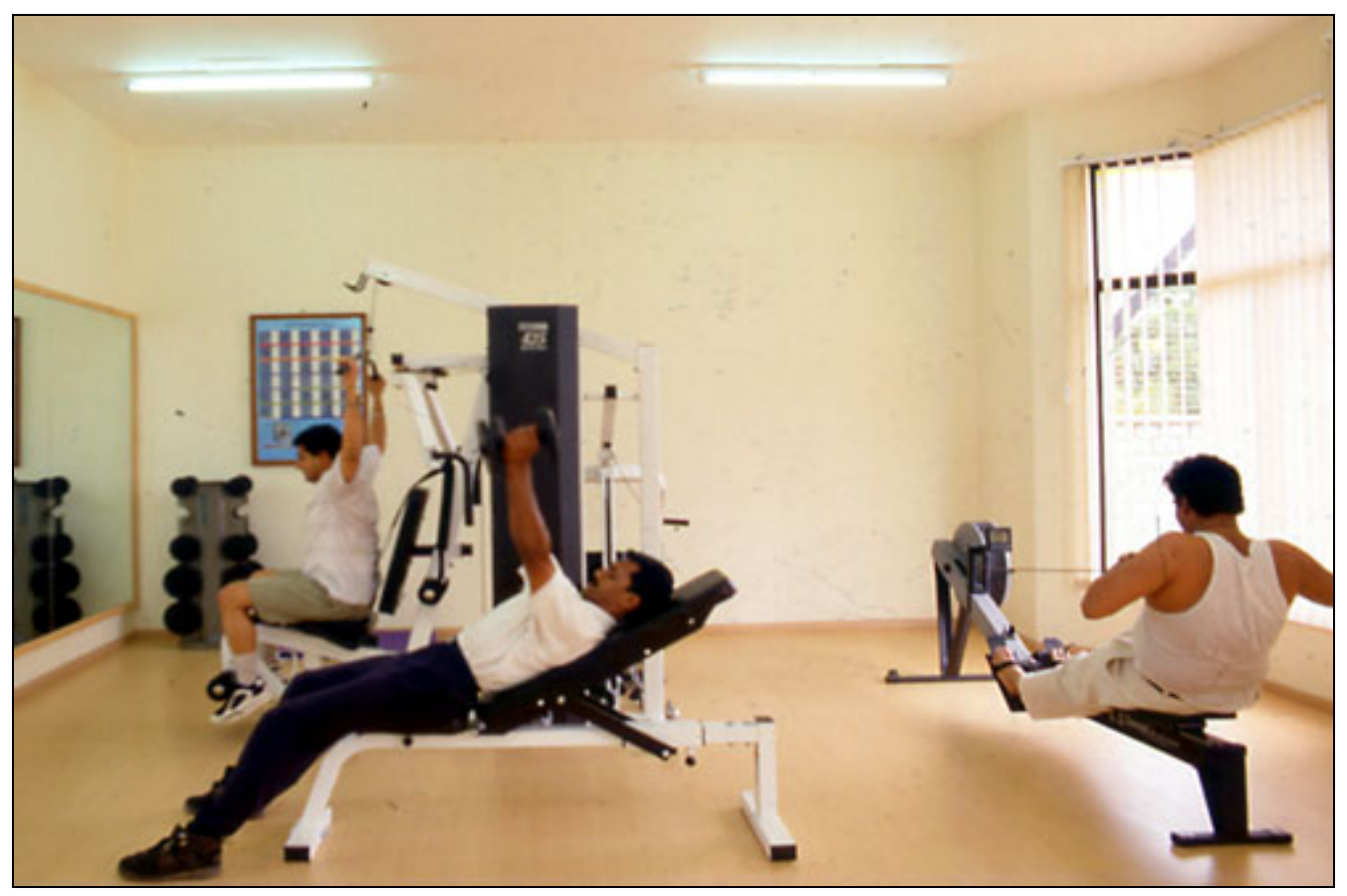

Figure 3.16-On-Site Gymnasium at Wipro's Sarjapur Campus promotes a healthy lifestyle for its employees

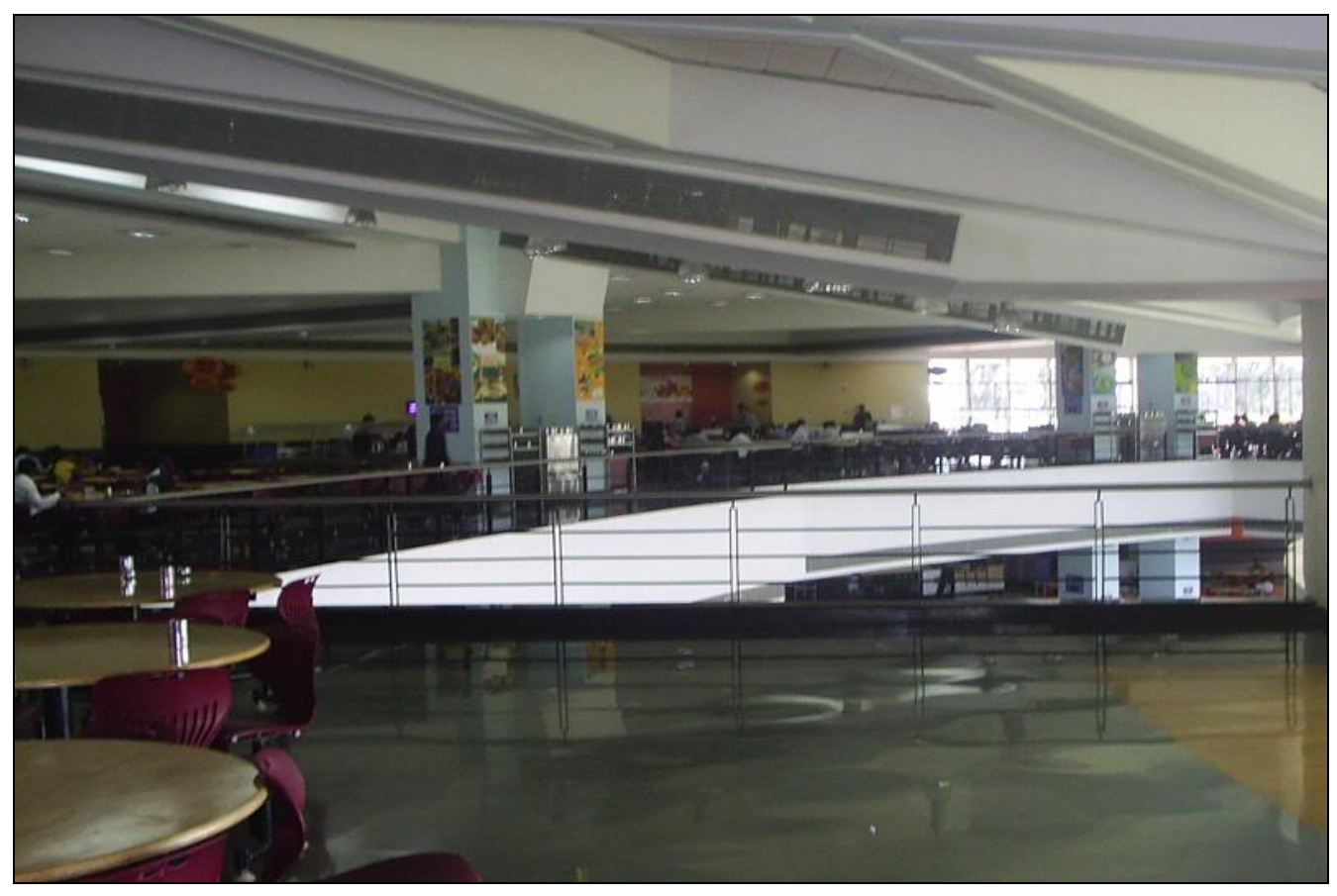

Figure 3.17-Employee' Cafeteria at Wipro's Electronics City Campus 


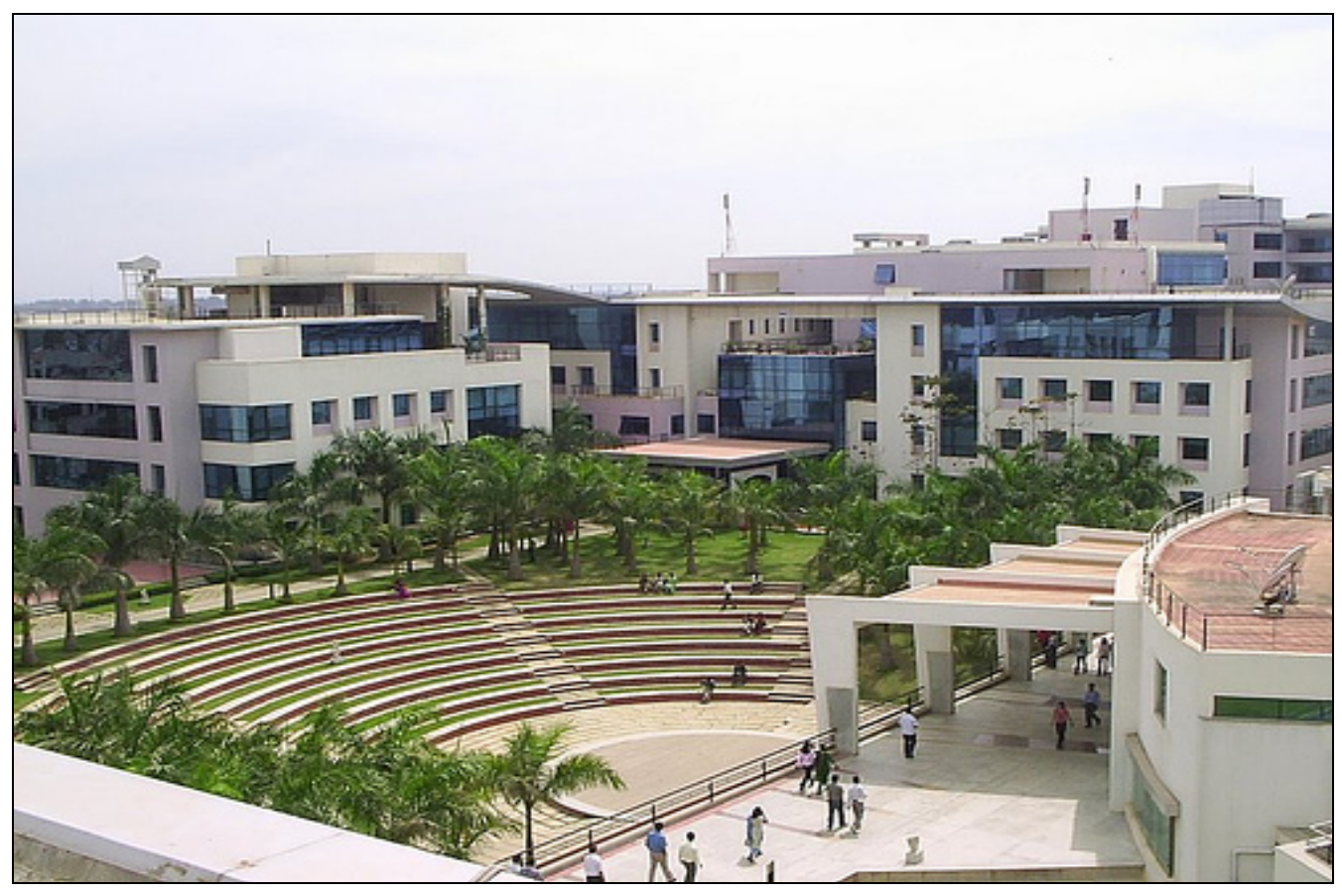

Figure 3.18 Open environment at Wipro Electronic City Campus promotes formal as well as informal culture to reinforce the employees.

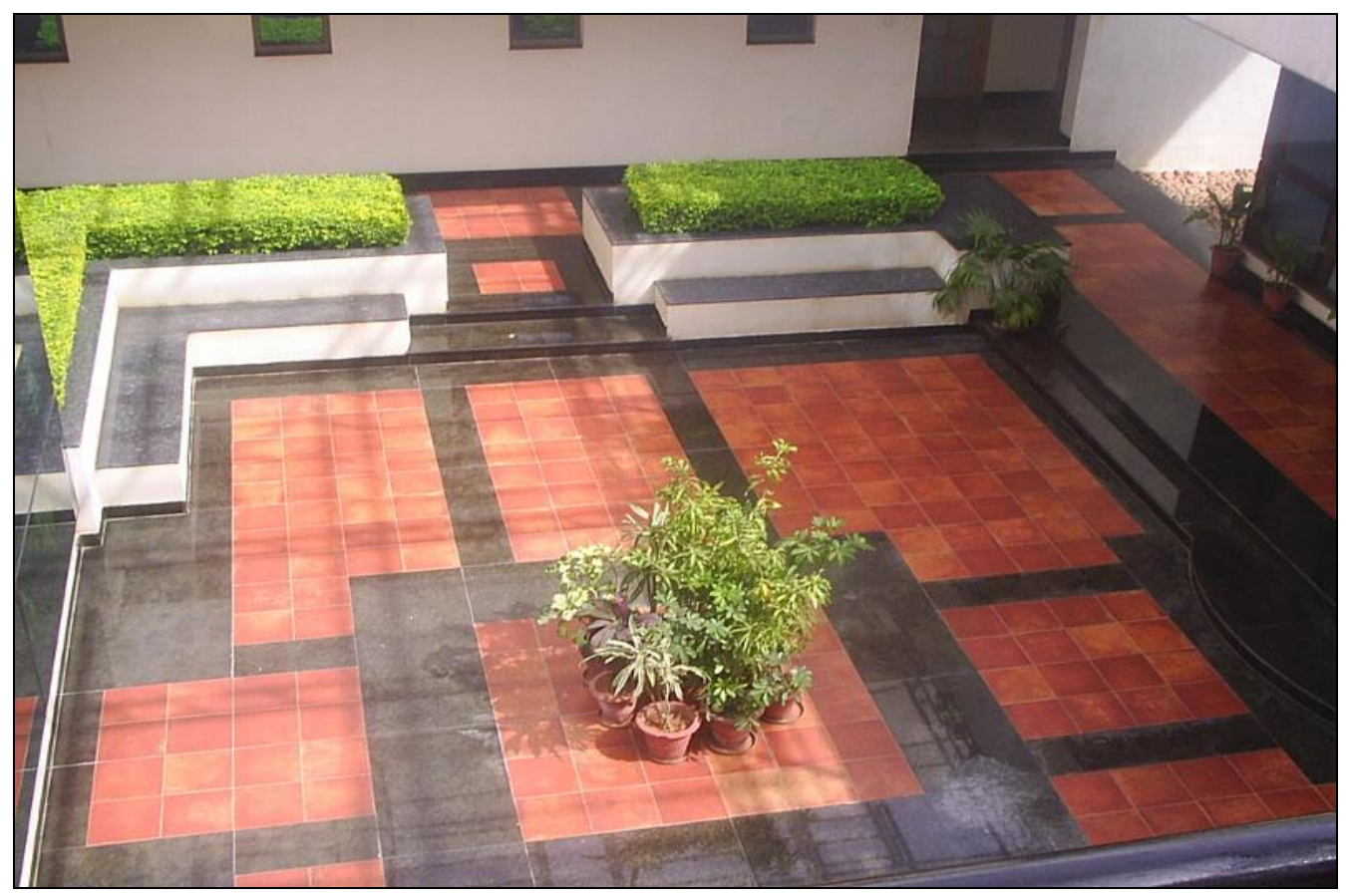

Figure 3.19- Open Courtyard incorporated within an Office Building at Wipro's Electronics City Campus 


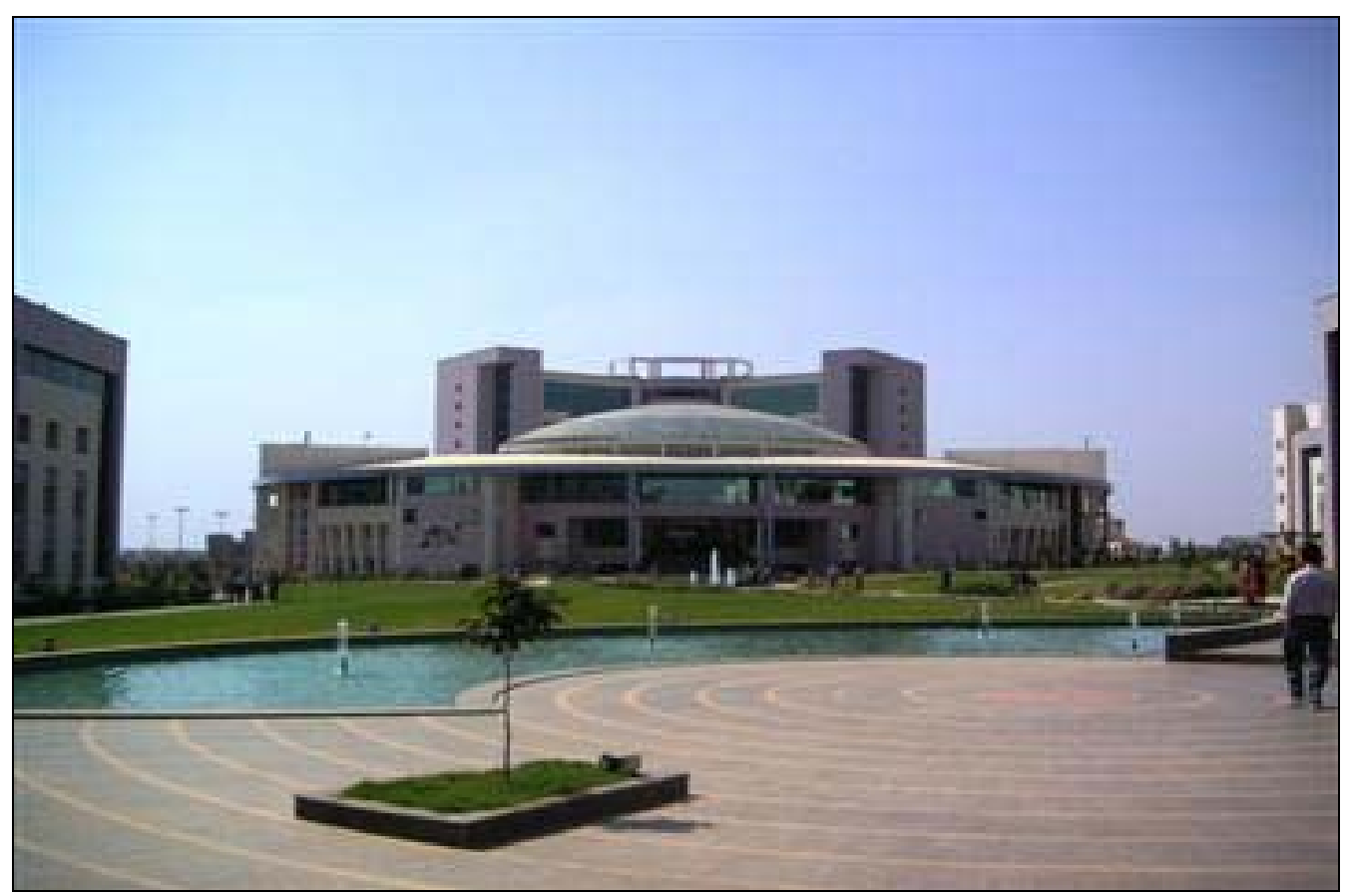

Figure 3.20-Architecturally-Branded Campus, features water bodies, at Wipro's Electronics City Campus

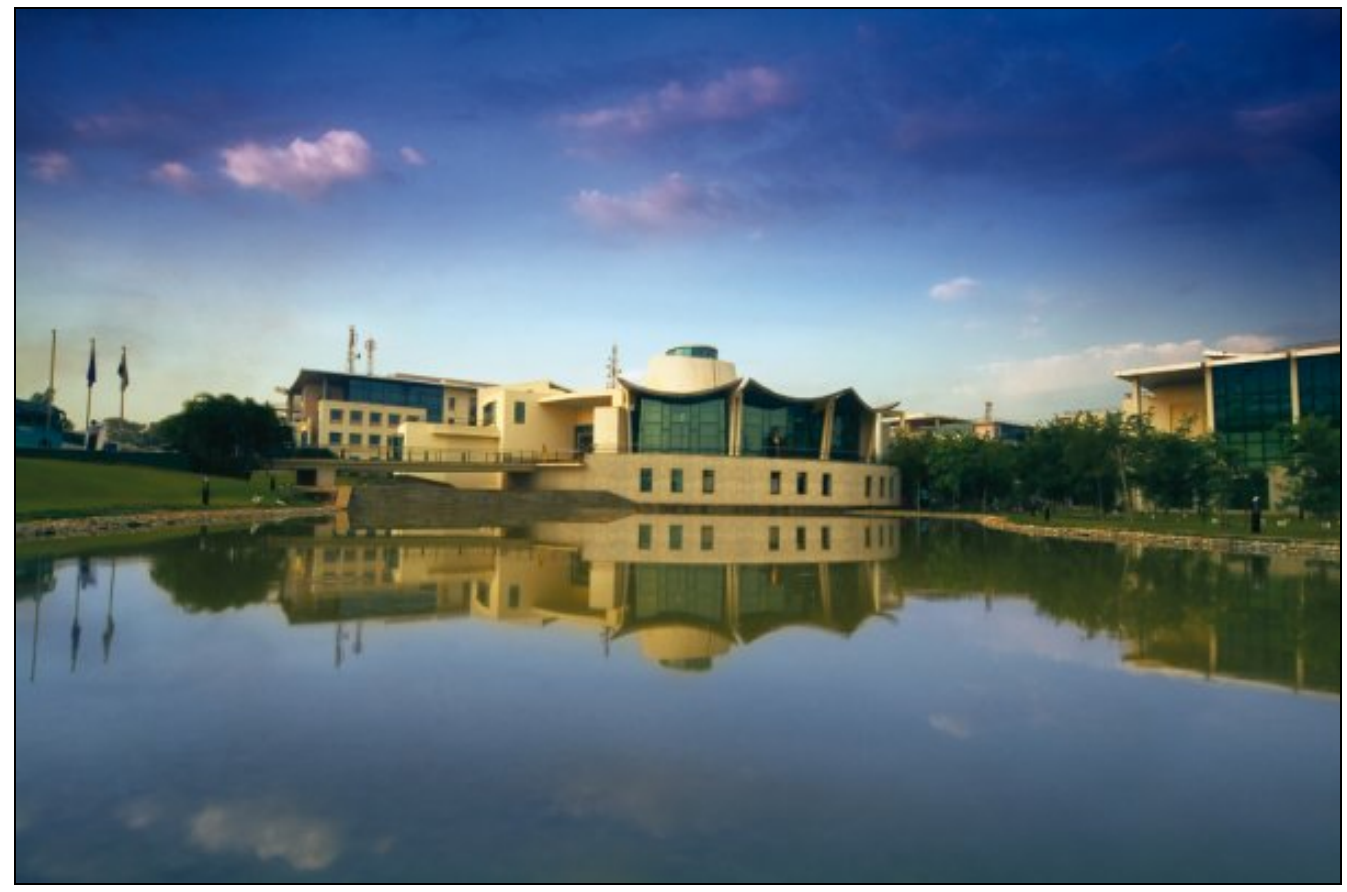

Figure 3.21-State-of-the art Learning Center Facility at Wipro's Electronics City Campus 


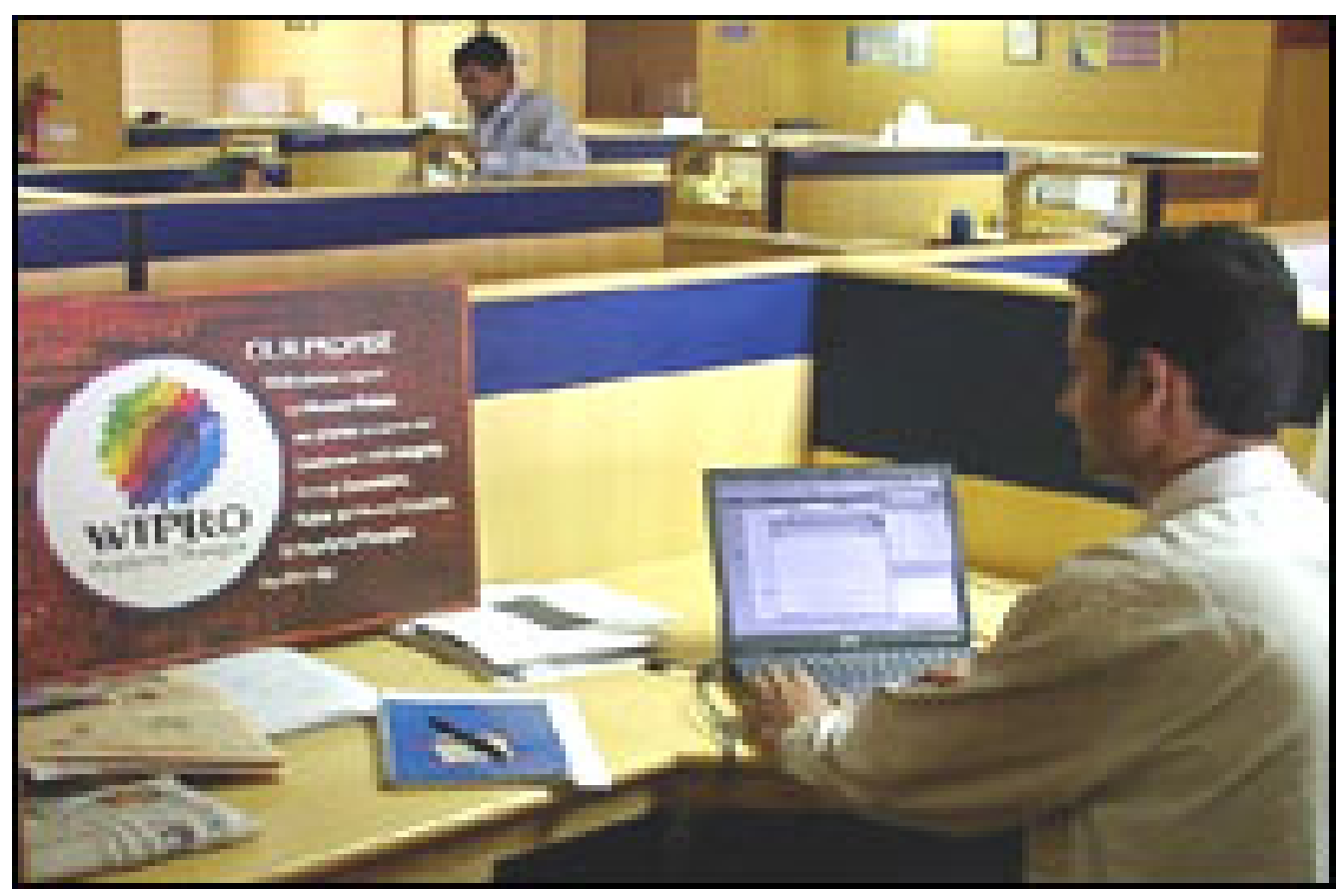

Figure 3.22-Typical View of Open Plan Layouts at Wipro's Corporate campus Facilities

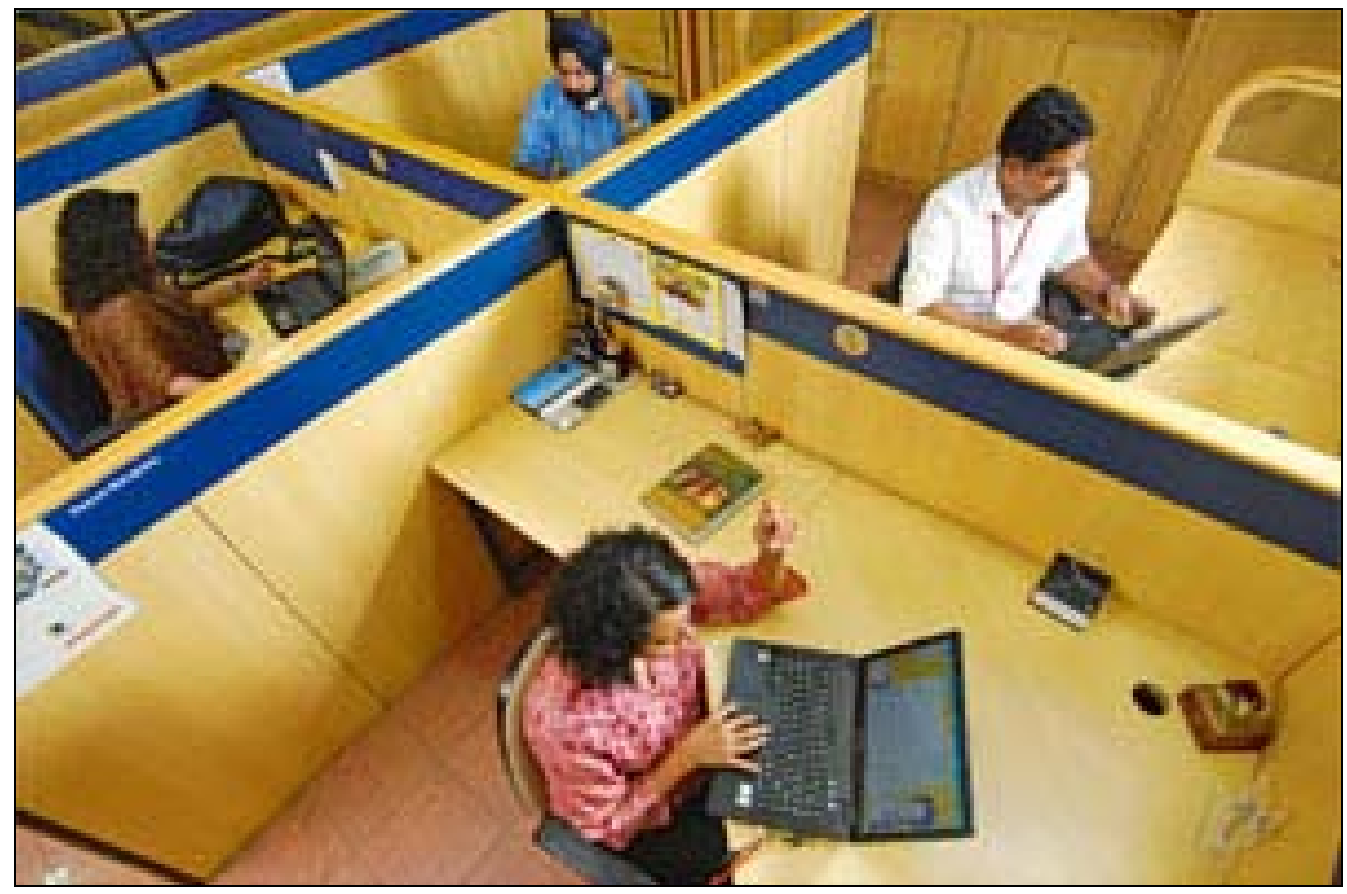

Figure 3.23-Typical View of Open Plan Layouts at Wipro's Corporate campus Facilities 


\subsection{Research Design}

\subsubsection{Data Collection Technique}

A web-based version of the IWSP Workplace Survey questionnaire was used in this study to collect data at the research site. The web-based version of the survey questionnaire was reviewed by Cornell University's Computer Assisted Survey Team (CAST), which had consulted with the IWSP team on the survey.

Prior to use in this study, the IWSP Workplace Survey was customized per Wipro's organizational and physical characteristics such as job levels and per the physical characteristics of the site such as building names. Customization of the survey items included the appropriate labeling of job levels specific to Wipro and the building names at Wipro's corporate campus. The survey was compartmentalized by five broad sections; (i) employee communication and interaction as a result of the physical layout of the workplace, (ii) employees' perception of the physical attributes of their workplace (iii) employees' level of satisfaction with the corporate campus and current facilities, (iv) workplace physical factors contributing towards employee' attraction and retention, and (v) preferred amenities. Likewise, the questions on the survey were designed to conceptually address communication and interaction among employees working on the corporate campus, employees' perception of the physical attributes of their workplace, workplace physical factors contributing towards employee' attraction and retention, physical factors contributing most towards employees' level of satisfaction with Wipro's corporate campus and current facilities, and amenities most preferred by employees, to have on their corporate campus. Personal and organizational background information 
about respondents such as gender, age, job level, work location etc, were requested from each participant.

The questionnaire consisted of multiple check-ended questions and statements scored on a five-point likert scale where $1=$ 'Strongly Agree' and $5=$ 'Strongly Disagree'. Employees simply checked one bar of the menu to answer a question. The survey also included closed-ended questions coded as 'yes', 'neutral' or 'no', that employees could click a button to answer. The last part of the survey provided an open-ended section, for employees to comment about their corporate campus as desired.

\subsubsection{Implementing the Study}

The web-based survey was hosted on Cornell University's server and uploaded onto the web so that Wipro employees could simply access it on their workstation. Once the survey was live, an e-mail was sent to the entire population of Wipro's employees at its Sajarpur and Electronic sites, by Facilities Management personnel at Wipro. The e-mail message informed Wipro's employees regarding its participation in the study and requested them to contribute through completing the on-line survey (see Appendix $D$ for a copy of the original e-mail correspondence).

To participate, an employee simply had to click on the URL link provided in the e-mail message which linked the participant to the Cornell University Research Center (CAST) server where the survey was hosted. Employees who visited this site read an announcement and directions about how to complete the survey provided at the 
beginning of the questionnaire. The survey was designed to take approximately fifteen minutes to complete. Upon completion, the participants clicked on a 'Submit' button which allowed their responses to the Cornell server by clicking on the 'Submit' button. The programming of the survey provides total anonymity of the responses. The webbased survey was available on the internet for 10 days, from July 01, 2003 through July 10, 2003.

\subsubsection{Sample Size and Selection}

The survey was made available to the entire employee population across all job levels and business units at Wipro's Sarjapur and Electronic City campuses (approximately 5,190 employees). Respondents were self-selected from those who visited a web page that contained a link to the web-survey. Participation was voluntary and anonymous. There was no incentive offered for participation in this study. A total of 267 employees (5.0\% of total sample population) attempted the web-survey. Of the 267 attempted surveys, a total of 239 usable surveys were completed with no missing items, that were spread across all job levels and functions at the research site.

\subsection{Data Analysis}

Responses were sent directly to CAST at Cornell University. Each survey was coded by CAST into different variables and transferred into the SPSS database for further statistical analysis. A total of 142 variables were generated from the survey. Descriptive analysis of the data using simple frequencies and cross tabulations were conducted on selected variables and by employee demographics of gender, age, manager/individual 
contributor, job level, length of time working for Wipro, and life stage. In order to confirm the construct validity of the Wipro Workplace Survey questionnaire, statistical tests including exploratory factor analysis, correlations and multiple regressions assessing the ANOVA and T-Tests were performed. All statistical analyses in this study were conducted using Version 17.0 of the Statistical Package for the Social Sciences (SPSS) desktop software program.

\subsection{Overview of Survey Sections and Survey Items}

The variables on the IWSP Workplace Survey questionnaire were designed to capture employees' opinions regarding five broad topics to place them in context of the physical aspects of the workplace, as follows; (i) employee communication and interaction as a result of the physical layout of the workplace, (ii) employees' perception of the physical attributes of their workplace (iii) employees' level of satisfaction with the corporate campus and current facilities, (iv) workplace physical factors contributing towards employee' attraction and retention, and (v) preferred amenities. Each broad topic was conceptually addressed with statements and questions to record employee responses as follows;

\section{(i) Employee' Communication and Interaction:}

The survey included items that addressed the frequency, pattern and nature of interaction among employees working on Wipro's corporate campus.

To record the frequency of meetings across physical distances employees were asked to report the frequency of meetings as:

- Meet on own floor

- Meet on different floor within own building 
- Meet in different buildings

To record the frequency of meetings across organizational distances employees were asked to report the frequency of meetings as:

Meet within own group

Meet within own line of business

Meet with other business units

Meet with different business units/ divisions

To analyze the pattern of meetings, employees were asked to report the frequency of meetings as 'Majority Scheduled' versus 'Majority Unscheduled' and by the timelines for how far in advance were most scheduled meetings planned. Employees were also requested to report the time spent travelling to and from meetings held at other buildings on Wipro's corporate campus and the average length of time spent in meetings in a typical week.

The nature of employee interaction was recorded by asking questions on the frequency of interaction while travelling to a meeting with another employee(s) (versus travelling alone) and regarding the nature of their interaction with co-workers while travelling together to meetings as business or non-business related.

\section{(ii) Employees' self-reported 'Sense of Belonging' and their perception of the physical attributes of the workplace:}

This section included several questions to assess how employees perceived the physical aspects of the workplace. It also included statements that directly asked employees' to report the extent to which they felt a 'sense of belonging' with Wipro. Some of the statements included in this section were:

- I feel a strong sense of belonging and identity with Wipro

- I feel that the exterior and interior appearance of the Wipro buildings on the campus reflect Wipro's culture and values

- The interior and exterior of the buildings at WIPRO's campus reflect the company's culture and values.

- The layout of the interior of the building enhances productivity

- The interior appearance of the building enhances productivity

- The overall layout of buildings on WIPRO's campus enhance productivity

- The layout of the interior of the building is more valuable than the layout of buildings on the campus overall

- The design of the personal workspace is of more value than the design of the entire campus

- The importance of working on a corporate campus

- There are adequate places in the building that get together informally with other employees 
- The movement pattern around the building is well designed to encourage informal interactions

(iii) Employee's level of satisfaction with the Wipro's corporate campus and current facilities

The questions about satisfaction were designed to determine if employees were satisfied with certain physical and other related aspects of Wipro's corporate campus. Some of the statement/ideas addressed in this section were:

- Level of satisfaction with own workspace/office

- Level of satisfaction with Wipro's corporate campus

- The quality and extent of Wipro's mobile computing, technology (intranet/internet) and telecommunications (phone/video conferencing)

- Significance of physical collocation, considering the quality of Wipro's telecommunication infrastructure

- Average time spent commuting to and from home to Wipro's Corporate campus

- Desirability to telecommute/work remotely from home

\section{(iv) Factors contributing to Employee' Attraction and Retention}

The questions on attraction and retention were included to determine the employees' motivation behind taking a job with WIPRO and in continuing to work there, including the physical factors of Wipro's corporate campus. Variables were categorized into the two categories as follows:

A) Campus Physical Characteristics

- Having a corporate campus

- Look and feel of interior of the building

- Look and feel of the exterior of the building

- Own personal office or workstation

- Campus amenities

- Security design and services

- Location of the campus- in the Sajarpur area

- Location of the campus- in the part of the Bangalore city

B) Other Factors

- Opportunities for face-to-face meeting with own group as well as outside of own group and business unit

- Pride in working for a major corporation

- Corporate culture and values

- People with whom you work 


\section{(v) Preferred Amenities:}

To determine preferred amenities, subjects were asked to select the most important amenities that can be provided on the corporate campus, including those that were already existing on Wipro's campus. The suggested amenities were:

- Dining Center

- Conference Centers

- Learning Center

- Fitness Centers

- Baby Crèche

- Temple

- Health/Medical Services

- ATM Banking

- Car Service

- Convenience Store

- Bank

- Dry Cleaner/Shoe Repair

- Film Developing

- Florist

- Gift Shop

- Hair Salon

- Chemist

- Post Office

- Dormitory

\section{Personal Background Information:}

Each respondent was requested to provide personal demographic/background information as follows: Age, Gender, and Life Stage.

\section{Organizational Background Information:}

Each respondent was requested to provide organizational background information as follows: Job level, Tenure with Wipro, Physical Location of Wipro's Campus, Number of times re-located on Wipro's Campus and Number of Buildings worked at Wipro's Campus. 


\section{CHAPTER 4: FINDINGS}

The results of this study confirmed the construct validity of the IWSP Workplace Survey (customized to collect data at Wipro Technologies' Corporate campus) as an instrument to predict a 'sense of belonging' among employees working on a corporate campus. Exploratory factor analysis was conducted in this study; (i) to identify and describe the number of latent factors underlying the IWSP Workplace Survey questionnaire, (ii) to reduce the survey items to a smaller number of underlying factors and (iii) to compute composite scores for the derived factors. The composite scores of the underlying factors were saved for further statistical analysis. Correlation of variables confirmed a statistically significant association between workplace physical factors and employees' self reported 'sense of belonging'.

A statistically significant model to predict employees' 'sense of belonging', comprising of four workplace physical factors was derived using hierarchical multiple regression. The model combines those physical factors of the workplace that will likely be strong predictors of 'sense of belonging' among employees' working on a corporate campus. Descriptive analysis of the data using simple frequencies and cross-tabulations were computed for selected variables to gain a better understanding of the respondent characteristics and the dynamics among key variables in this study. The results from the analyses of the data are presented below. 


\subsection{Descriptive Findings}

\subsubsection{Study Participation by Employee Demographics:}

Figures 4.1 to 4.6 present a summary of the biographical and organizational characteristics of the respondents who participated in this study. A greater number of male than female respondents participated in this study (fig. 4.1). Majority of the participants were from the age groups of 26 to 35 years, followed by participants who were 25 years or less in age (fig 4.2).

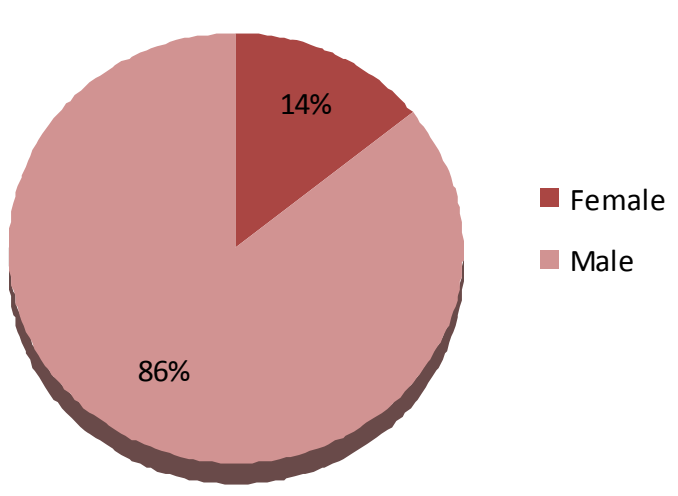

Fig 4.1 Participation by Gender

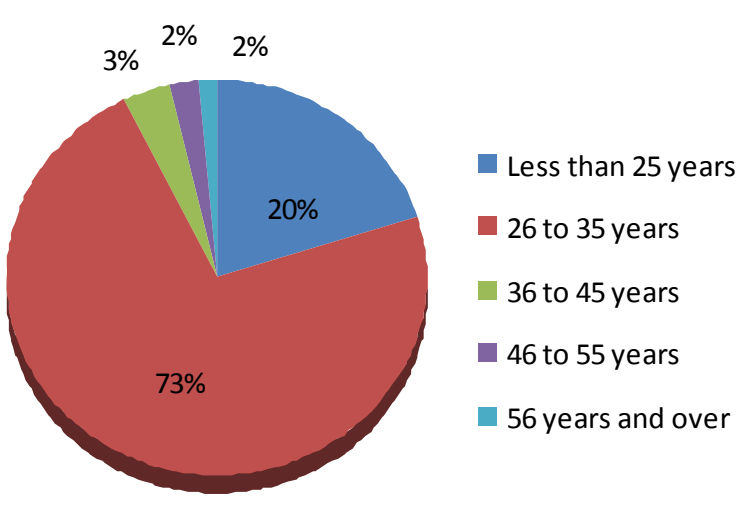

Fig 4.2 Participation by Age

In terms of the organizational backgrounds of the survey participants, majority of respondents were Individual Contributors, followed by Managers and Supervisors (fig 4.3). The term (years working for Wipro) for majority of the respondents who participated in this study, ranged between one and ten years (fig 4.4). In terms of the life-stage; $45 \%$ of the participants were single and another $25 \%$ were married with children (fig 4.5). Moreover, majority of the respondents were situated in an open-plan 
office setting as compared to respondents who had an enclosed workspace or personal offices (fig 4.6).

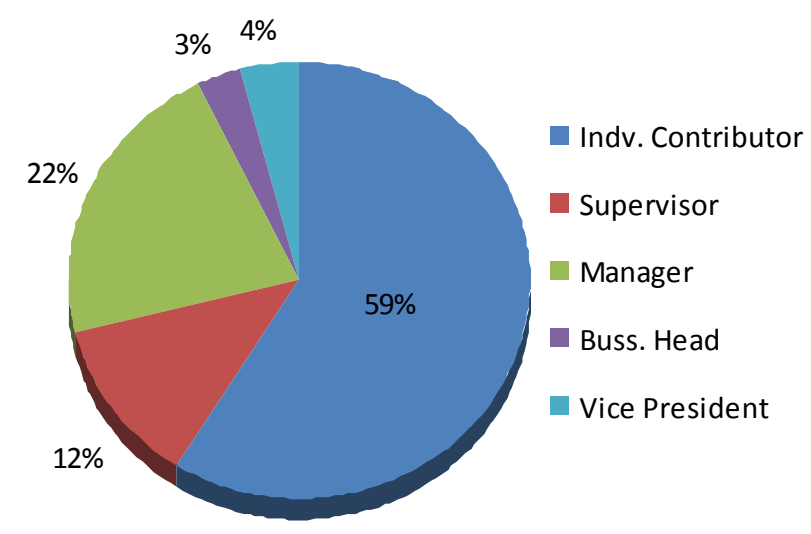

Fig 4.3 Participation by Job Level

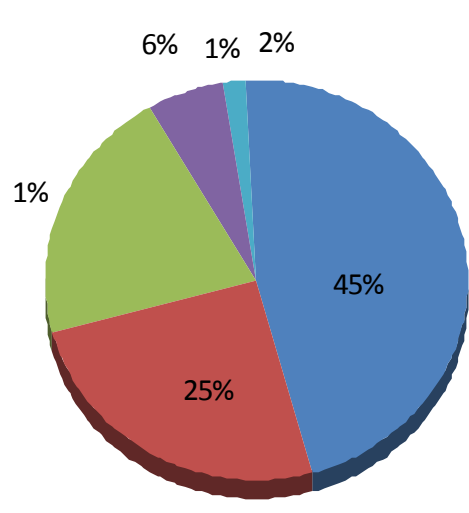

Fig 4.5 Participation by Life Stage

$$
\text { Single }
$$

M. w/o children 5 years in age years in age in age

Empty Nester

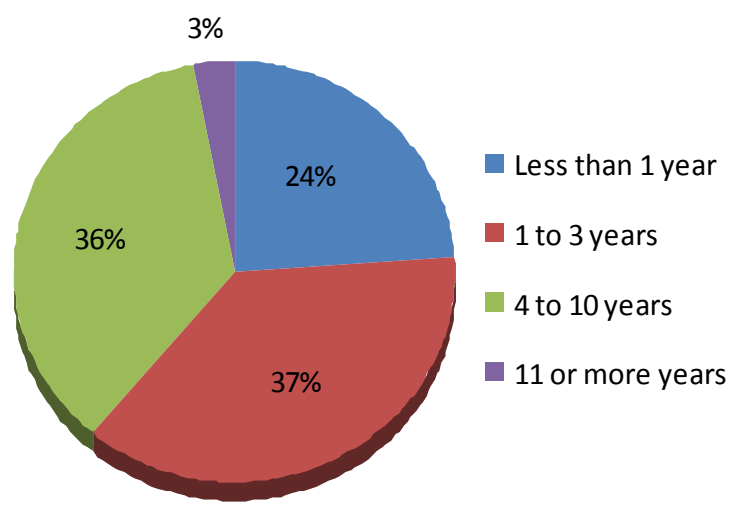

Fig 4.4 Participation by Term w/Wipro

Mor S w/ children und

Mor S w/ children 6 to:

- Married or Single w/ children 13 years or old

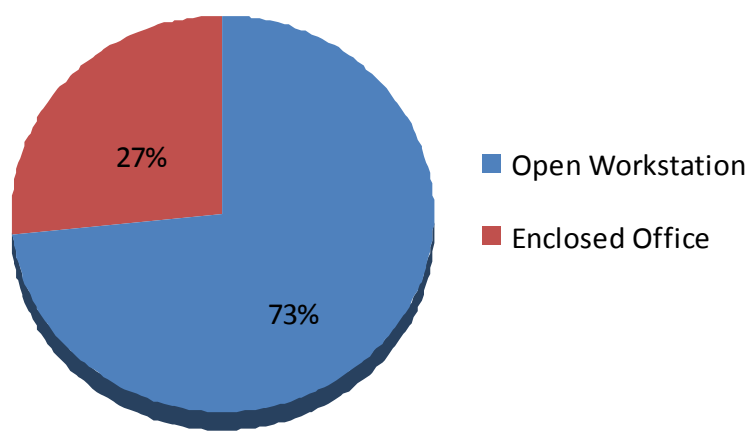

Fig 4.6 Participation by Workspace Type 


\subsubsection{Employees Sense of Belonging/ Organizational Identity:}

Descriptive findings of the data indicate that majority of the respondents in this study agreed that, 'working on a corporate campus' was important to them (mean=2.05, on a scale of $1-5 ; 1=$ 'Strongly Agree' and $5=$ 'Strongly Disagree') and that they felt a strong 'sense of belonging' with Wipro (mean=1.73), (fig 4.7).

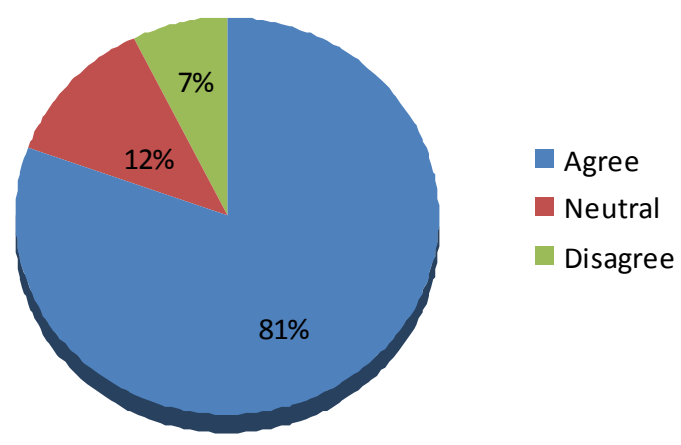

Fig 4.7 Employees' Response: I feel a Strong Sense of Belonging with Wipro

A cross tabulation between employees self-reported 'sense of belonging' and control variables of gender, job level and age (figures 4.8, 4.9 and 4.10); indicated that a slightly higher proportion of male than female respondents; Supervisors and Mangers as compared to Individual Contributors and Business Heads and respondents 25 years or less or 46 years and over, compared to respondent 26 to 35 years or less or 36 to 45 years in age, reported feeling a strong 'sense of belonging' with Wipro. 


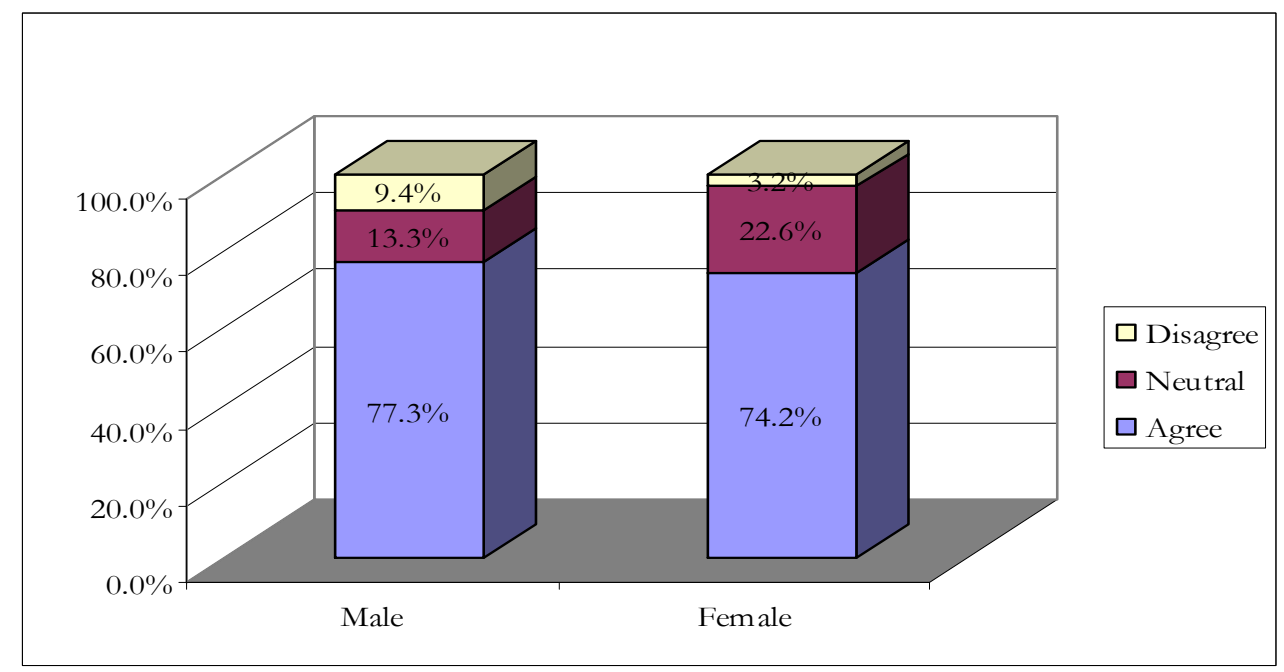

Fig. 4.8 Employees' Sense of Belonging by Gender

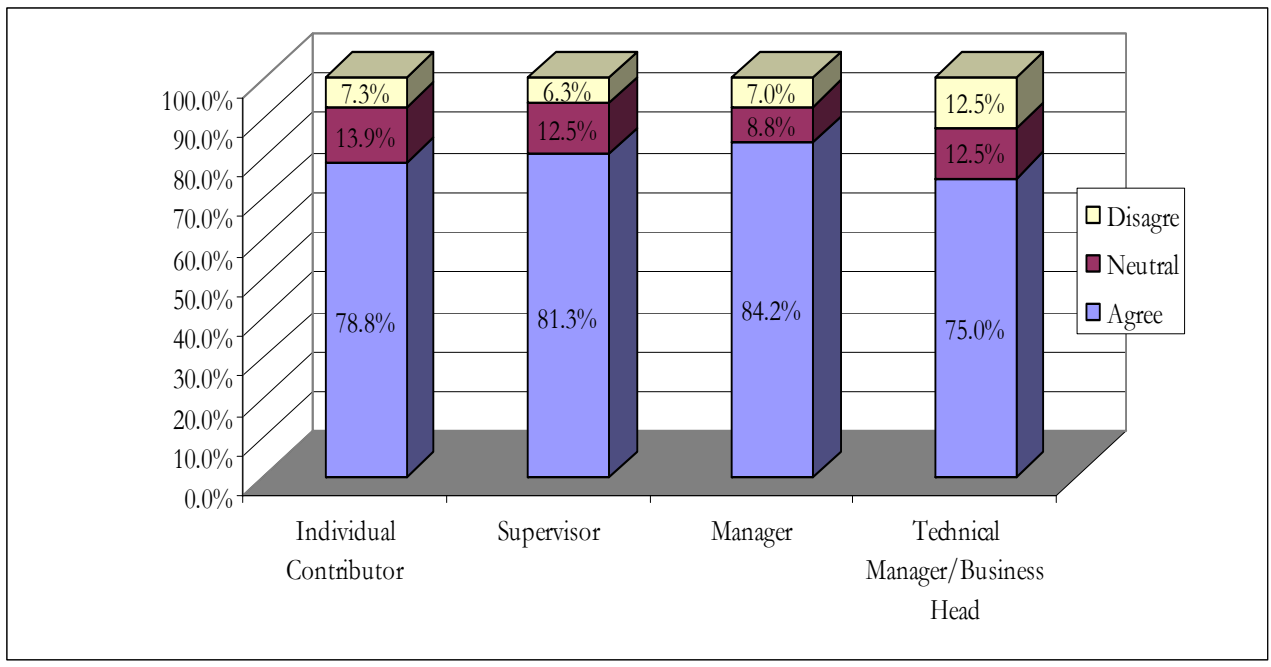

Fig. 4.9 Employees' Sense of Belonging by Job Level

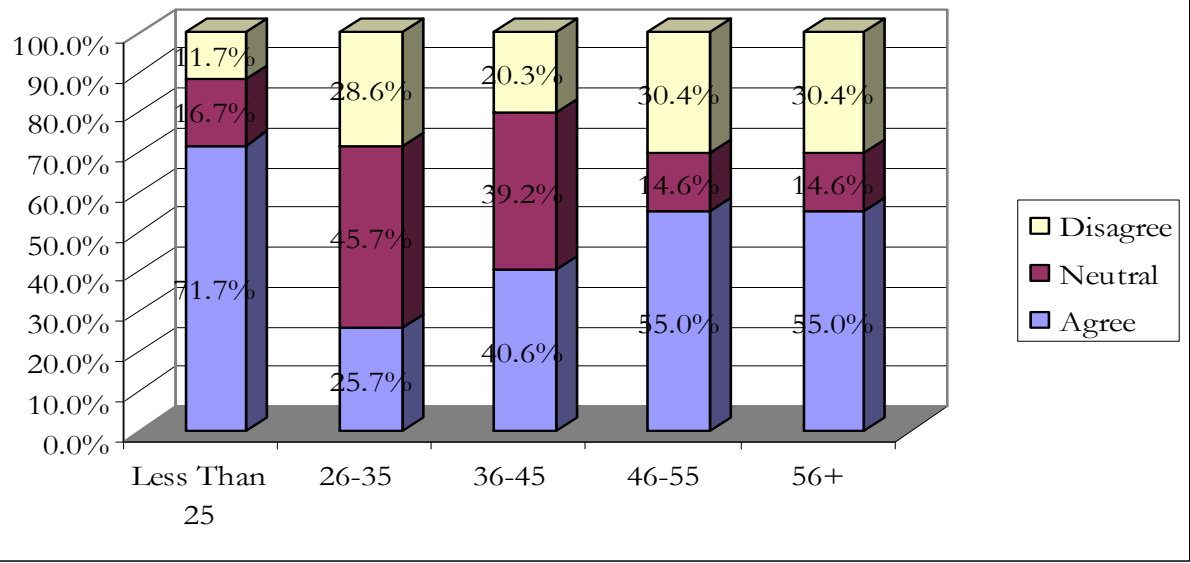

Fig. 4.10 Employees Sense of Belonging by Age 
In terms of corporate identity, when asked, majority of the participants 'agreed' that, 'the exterior and interior appearance of Wipro's campus buildings reflected its culture and values' (fig 4.11). Employees' opinion regarding the appearance Wipro's campus buildings was not found to have a significant relation with their 'sense of belonging', as a high level of 'sense of belonging' was reported by majority of survey participants, irrespective of their opinion regarding the exterior and interior appearance of Wipro's campus buildings reflected its culture and values (fig 4.12).

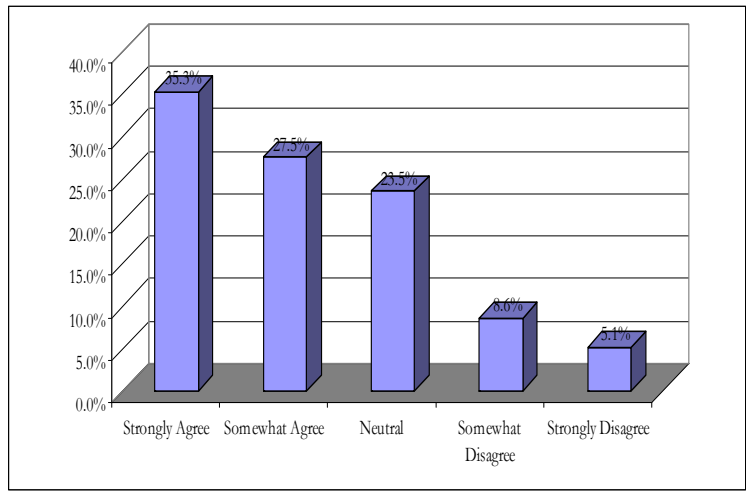

Fig 4.11 Employees' opinion on Appearance of Wipro' Buildings reflecting its Culture and Values

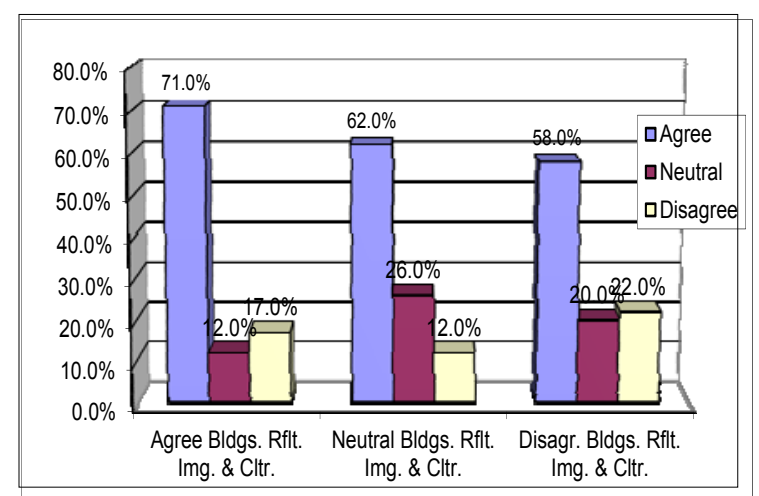

Fig 4.12 Cross-Tab: Employees' Sense of Belonging and Appearance Of Wipro' Buildings reflecting its Culture and Values

\subsubsection{Employee Interaction across Physical and Organizational Distances:}

In terms of face-to-face interaction among employees across physical distance(s) at Wipro's corporate campus; results indicated that majority of the face-to-face interaction among co-workers took place on 'one's own floor'. The trend was similar irrespective of employees' demographic background of age, gender or job level. The frequency of face-to-face communication between employees fell from an average of 4.5 times per week on one's own floor to an average of 2.2 times per week or approximately half as 
much, on a different floor and dropped further to an average of 1.1 times per week in a different building.

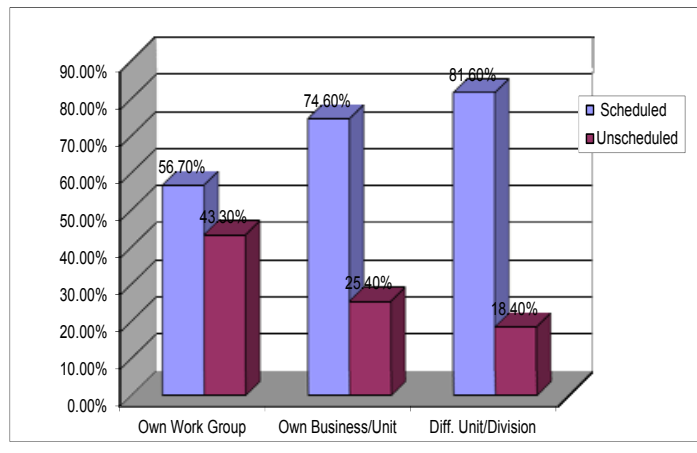

Fig 4.13 Meeting Type with One Person across Organizational Distance

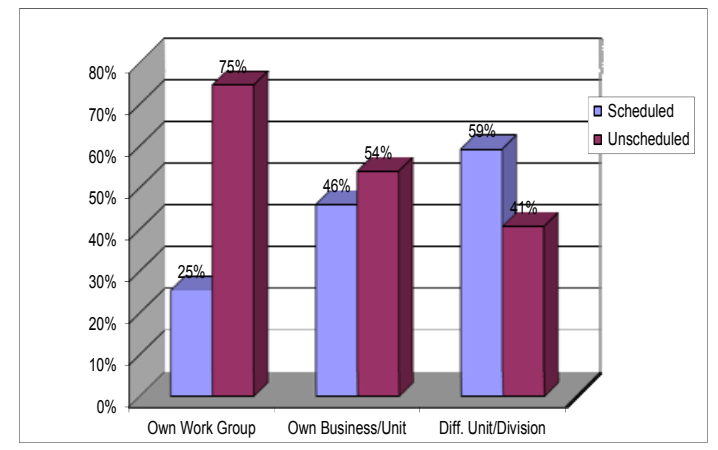

Fig 4.14 Meeting Type with 3+ Persons across Organizational Distance

Similarly, for face-to-face interaction among co-workers across organizational distances, at Wipro's corporate campus, results showed that face-to-face communication dropped from an average of 3.5 times per week with one's own work group to 2.7 times per week or approximately $25 \%$ less frequently with own business unit/division and fell further to an average of 1.02 times per week or approximately $71.6 \%$ less frequently with a different business unit/division. Figures 4.13 and 4.14 above, present the proportion of scheduled versus un-scheduled meetings across organizational distances, at Wipro's corporate campus.

Even in the case of face-to-face meetings involving a greater number of persons (three or more), meetings dropped by approximately $56 \%$ from 3.75 times per week with own work group to 1.65 times per week with own business unit/division. It dropped further by 
approximately $67.5 \%$ to an average of 1.2 times per week, with a different business unit/division.

Results of a cross tabulation between employee demographics of job level and frequency of interaction across organizational distances, illustrated that an increase in the organizational distance resulted in a decrease in the frequency of employee interaction across all job levels; from own work group to own business unit/division to different business unit/division.

Individual Contributors were found to have most frequent face-to-face interactions with three or more persons within their own work group in comparison to employees in other job levels. Technical Managers/ Business Heads were found to have most frequent face-to-face interaction with persons outside their own group; co-workers from own business unit/division and/or different unit/business division.

In terms of the pattern and nature of meetings among employees working across Wipro's campus, it was recorded that shorter meetings $(<15$ minutes $)$ were more common within one's own group as compared to less frequent but longer (16 to 90 minutes) meetings with persons from one's own business unit or another division/ business unit. Respondents reported that, on average, it took them approximately 15 minutes to travel to meetings within different parts of Wipro's corporate campus and that they were often accompanied by co-workers while travelling to and from meetings across Wipro' corporate campus. When asked, respondents expressed that they 
'sometimes' (as opposed to 'almost always' or 'almost never') discussed business related issues with co-workers during their accompanied travels to attend meeting across Wipro's corporate campus.

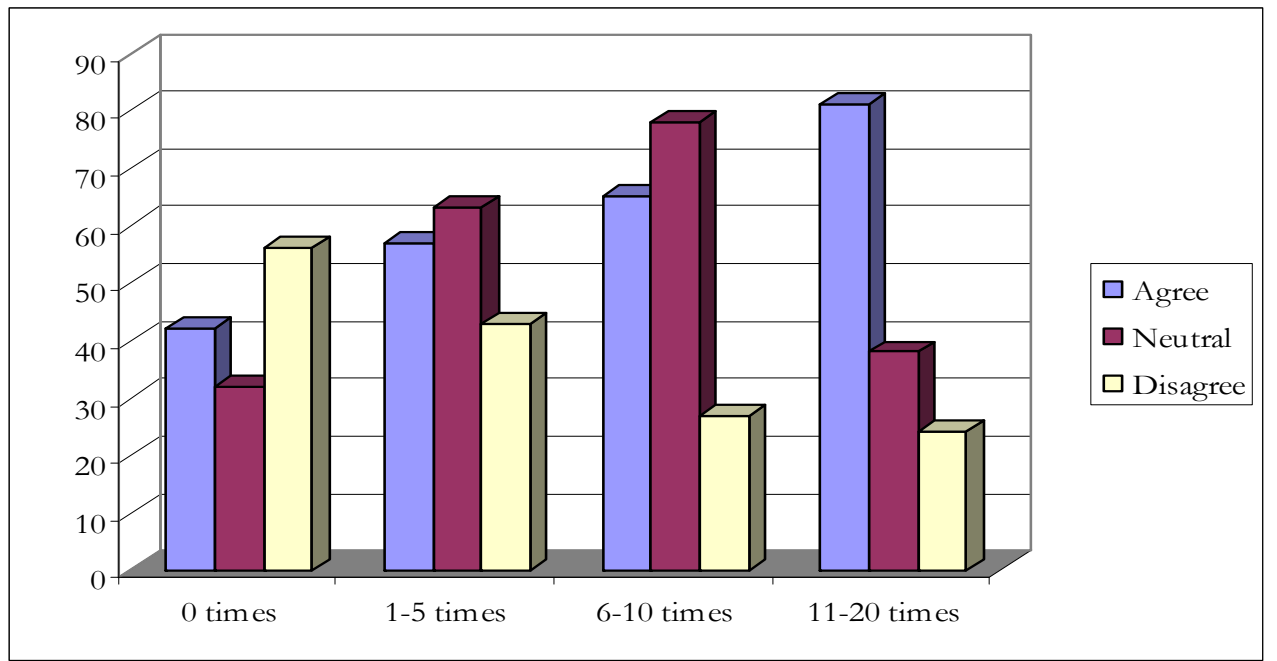

Fig 4.15 Cross-Tab: Sense of Belonging and Frequency of Interaction across Physical Distances

Fig. 4.15 above represents the results of a cross-tabulation between employees' selfreported 'sense of belonging' and the frequency of interaction between co-workers across physical distance(s) at Wipro's campus. The results indicated that employees' who interacted most frequently across the physical distances at Wipro's corporate campus; own floor, different floor, different building, reported feeling a greater 'sense of belonging' with Wipro. 


\subsubsection{Importance of Physical Collocation in the Workplace:}

Physical collocation with one's own group was highly desired by majority of the respondents, with relatively lesser importance placed on collocation with 'own division/business unit' or 'a different division/business unit'. Fig 4.16 presents the frequency of electronic communication (in contrast to face-to-face communication) between co-workers in a typical workday. Fig 4.17 presents employees' opinion regarding the importance of collocation considering the quality of present day computing and telecommunications technology, in general.

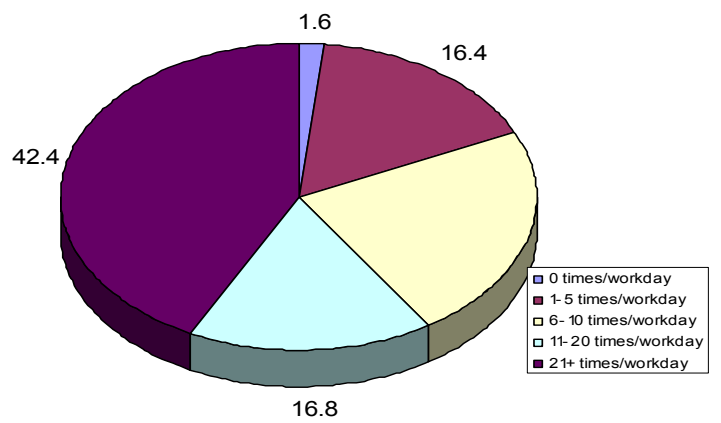

Fig 4.16 Question: In a typical workday, how often do you need to communicate with your co-workers electronically, (via e-mail, teleconference, intranet, voicemail etc)?

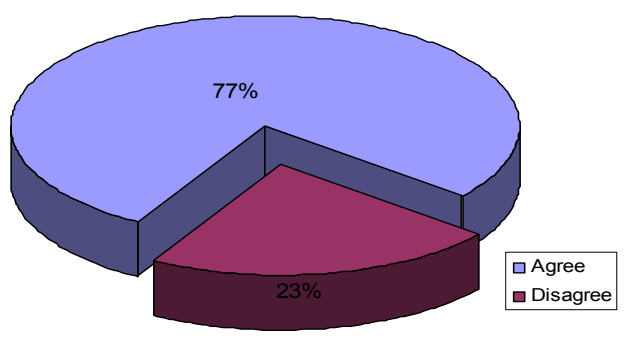

Fig 4.17 Question: Do you agree/disagree that 'with today's computers and telecommunication technology, collocation is much less important than it once was?'

It was noted that majority of the employees agreed that, based on the extent and quality of the computing and telecommunications technology services available at Wipro's (rated 'excellent' by nearly all of the respondents), collocation had become much less important than it once was. When asked, majority of the respondents in this study, highly desired the option to work from home/telecommute and believed that telecommuting would save time from their work-day and as a result, help them be more 
productive. A cross tabulation indicated that, irrespective of their opinion regarding 'collocation with own group'; employees reported feeling a strong 'sense of belonging' with Wipro (see fig 4.18).

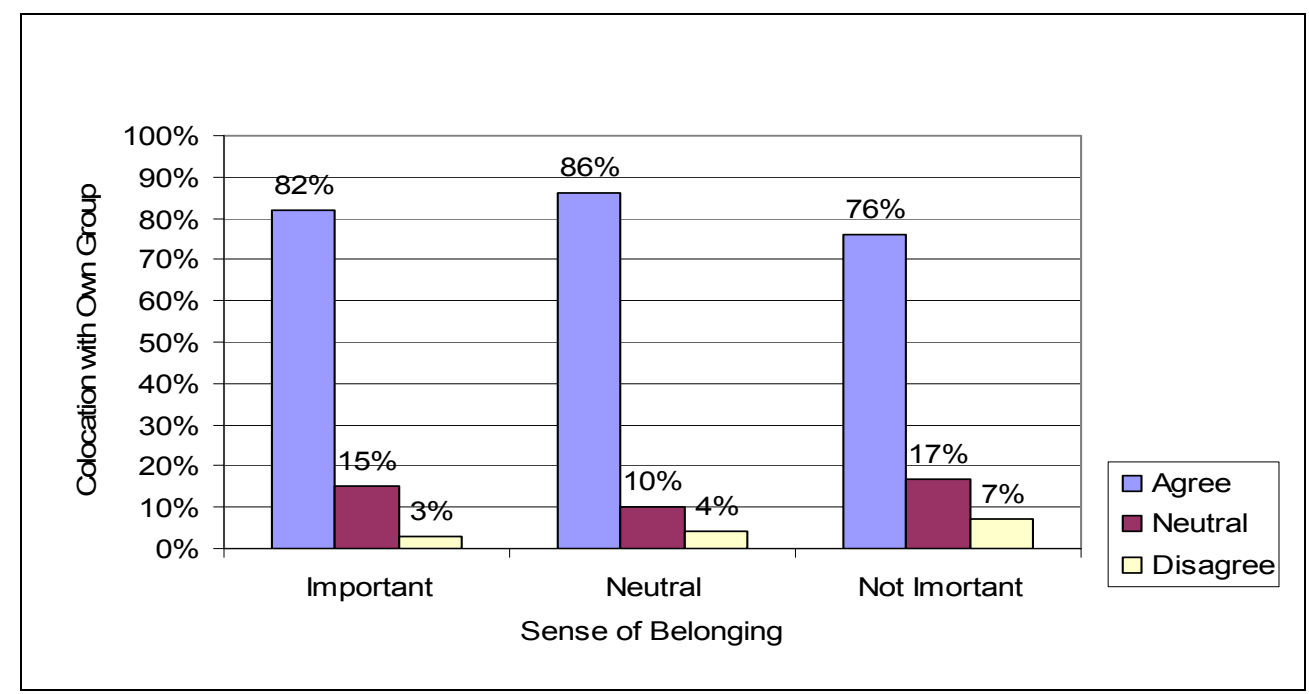

Fig 4.18 Cross-Tab: Sense of Belonging and Opinion regarding the Importance of Collocation with Own-Group

\subsubsection{Wipro's Corporate campus' Physical Factors:}

(A) Factors contributing to employees' satisfaction with the physical environment at Wipro's corporate campus: Employees selected- personal workspace, campus amenities, the location of the campus in Bangalore, having a corporate campus and flexible/mobile workplace, as the five factors that contributed most significantly towards their satisfaction with Wipro's corporate campus. Personal workspace and the interior design, layout and appearance of the building were regarded as relatively more 
significant; as compared to having a corporate campus and the look and feel of the exterior of the corporate campus (see fig. 4.19).

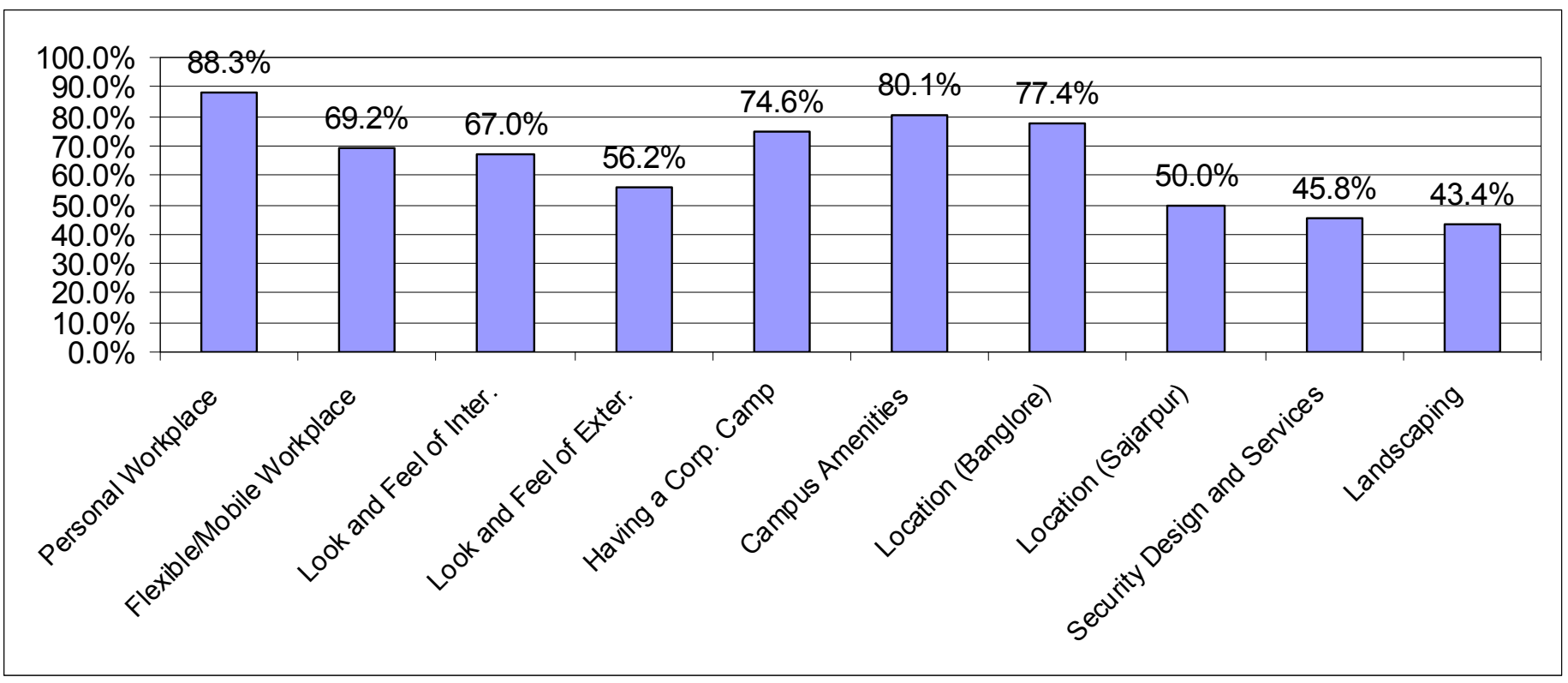

Fig 4.19 Physical Factors Contributing Most to Employees' Satisfaction with Wipros' Corporate campus

(B) Physical Factors of Wipro's corporate campus that are of significance to employees' attraction and retention with Wipro: In terms of attraction and retention, employees reported that for taking a job at Wipro, the factors that motivated them the most were; the pride of working for a major corporation, people with whom they worked, location of the campus in Bangalore, Wipro's corporate culture and values, and having a corporate campus. For continuing a job at Wipro, employees reported that; pride in working for a major corporation, corporate culture and values, people with whom you work, location of the campus in Bangalore, and campus amenities, were the five most influencing factors contributing to their decision to continue working at Wipro in Bangalore, India. 
(C ) Employees' report of most preferred amenities to have on the Corporate campus: In terms of campus amenities, the five amenities rated as most preferred to have on the corporate campus, were a Dining Center, Fitness Centers, ATM Banking, Fitness Center, Medical Services and Learning Centers. Employees' age had an effect on choice of preferred amenities, more than demographics variable like job level and gender (see fig 4.20).

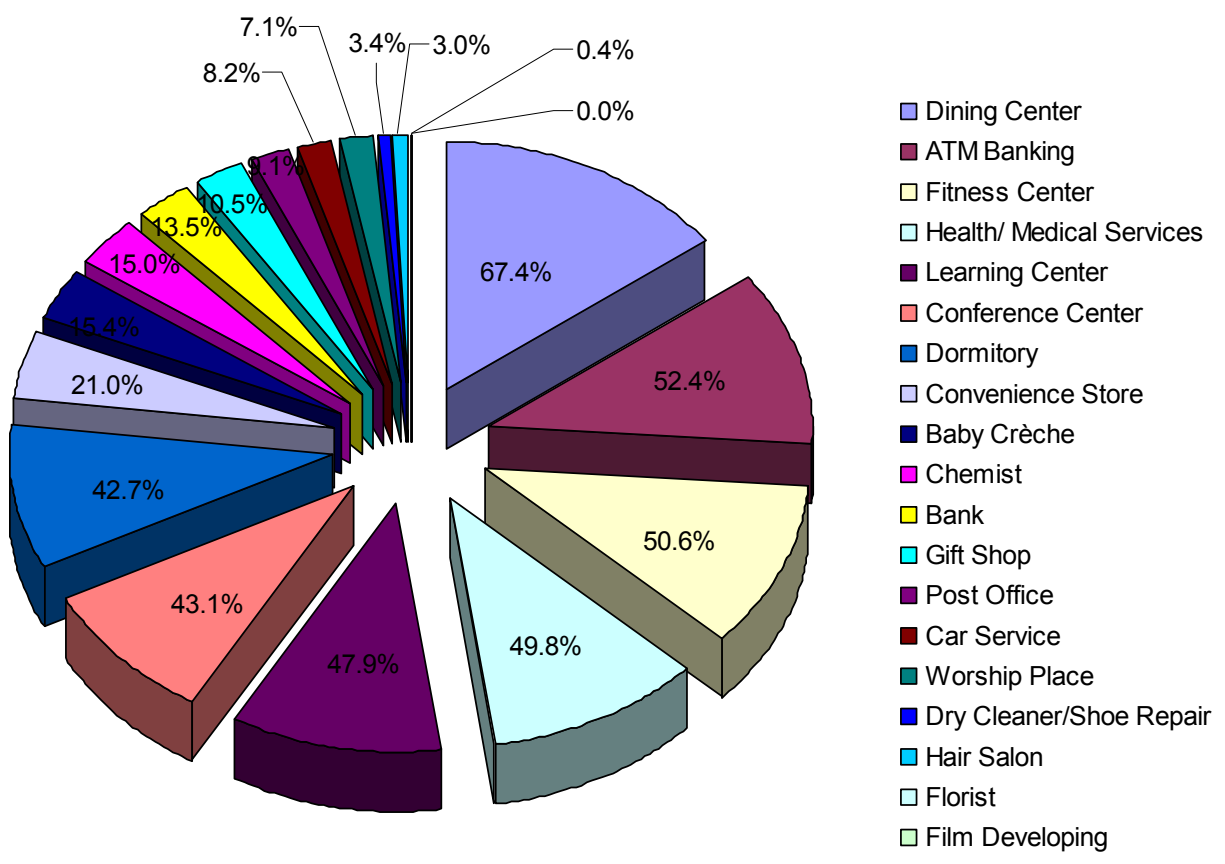

Fig 4.20 Amenities Most Preferred by Employees to have at Wipros' Corporate campus 


\subsection{Exploratory Factor Analysis}

An exploratory factor analysis was conducted as the first step in process to test the construct-validity of the IWSP Workplace Survey to predict 'sense-of-belonging'. Fifteen statements addressing employees' opinion regarding the physical and spatial aspects of Wipro's corporate campus were factor analyzed using principal component analysis with promax (orthogonal) rotation.

Exploratory factor analysis has traditionally been used to explore the possible underlying factor structure of a set of measured variables without imposing any preconceived structure on the outcome (Child, 1990). Factor analysis has two basic purposes; first, to explore variable areas in order to identify the factors presumably underlying the variables, and second, to test the hypotheses about the relations among variables. The analysis identifies clusters of variables or factors. Items within a factor are highly correlated with each other, and they are not correlated with items from other factors. Items are identified as belonging to a factor based on their correlation with that cluster of items. Factor loadings are the weights and correlations between each variable and the factor; the higher the load the more relevant the variable in defining the factor's dimensionality. A negative value indicates an inverse impact on the factor. Rotation allows the simplest solution among a variety of solutions that may be compatible with the data (Portney LG, Jette DU, 2003).

When using arbitrarily chosen variables for analysis, it should be first be determined if the correlation matrix is appropriate for factor analysis. Studies have shown that random 
variates may give rise to seemingly acceptable pattern and structure matrices (Dzuiban and Shirkey 1974). The SPSS software package used in this research includes Bartlett's test of sphericity (Bartlett 1950) and the Kaiser-Meyer-Olkin measure of sampling adequacy (Kaiser 1970) to assist users to assess the adequacy of their correlation matrices for factor analysis.

For a large sample Bartlett's test approximates a chi-square distribution where it is typically assumed that the sample correlation is based upon a multivariate normal population for which the variables being analyzed are independent. If they are not independent; then the data are appropriate for analysis using factor analysis. However, while the Bartlett test forms a sort of a bottom line test for large samples, it is less reliable for small samples. Very small values of significance $(p<0.05)$ indicate a high probability that there are significant relationships between the variables, whereas higher values $(p=$ or $>0.1)$ indicate the data is inappropriate for factor analysis.

The Kaiser-Meyer-Olkin (KMO) measure of sampling adequacy provides an index of the proportion of variance among the variables (between 0 and 1), that might be common variance (i.e., that might be indicative of underlying or latent common factors). The SPSS software package suggests that a KMO near 1.0 supports a factor analysis and that anything less than 0.5 is probably not amenable to useful factor analysis. Kaiser (1974) refined the index further and suggested that anything in the 0.90s was 'marvelous', in the $0.80 \mathrm{~s}$ 'meritorious', in the $0.70 \mathrm{~s}$ 'middling', in the $0.60 \mathrm{~s}$ 'mediocre', in the 0.50 s 'miserable' and below 0.50 'unacceptable'. 
Lastly, to demonstrate the internal consistency of items within each factor, the Cronbach alpha was computed. Cronbach's alpha or the coefficient of reliability also provides confirmation on how closely related a set of items are as a group and whether the items within a factor are measuring the same underlying construct.

Given the total sample size of 267 participants in this study, the Kaiser-Meyer-Olkin measure of sampling adequacy at $\mathrm{KMO}=0.678$, is considered 'mediocre' but factorable. The Bartlett's test of sphericity was significant $\left(\chi^{2}=748.54, d f=105, \quad p<.000\right)$, which provides additional support that the sample inter-correlations did not represent a set of variables that were entirely non-collinear (non-collinear variables have zero correlation, and are hence non-factorable) and were therefore factorable (Charles M. Friel Ph.D).

Table 4.1 presents a summary of the basic statistics for the fifteen survey items that were factors analyzed. Each statement was scored on a five-point likert scale where 1='Strongly Agree' and 5= 'Strongly Disagree'. 
Table 4.1 Basic statistics for fifteen survey items factor analyzed

\begin{tabular}{|c|c|c|c|c|c|c|c|}
\hline Statements & $\mathbf{N}$ & Mean & Median & Mode & Min & $\operatorname{Max}$ & SD \\
\hline $\begin{array}{l}\text { 1. Layout of the building enables me to work } \\
\text { productively }\end{array}$ & 239 & 2.19 & 2.00 & 2 & 1 & 5 & 1.098 \\
\hline $\begin{array}{l}\text { 2. Interior appearance of the building helps me to } \\
\text { work productively }\end{array}$ & 239 & 2.21 & 2.00 & 2 & 1 & 5 & 1.079 \\
\hline $\begin{array}{l}\text { 3. Overall layout of the building enable me to } \\
\text { work productively }\end{array}$ & 239 & 2.22 & 2.00 & 2 & 1 & 5 & 1.055 \\
\hline $\begin{array}{l}\text { 4. There are adequate places in the building } \\
\text { where I work, to get together informally with my } \\
\text { colleagues }\end{array}$ & 239 & 2.54 & 2.00 & 1 & 1 & 5 & 1.243 \\
\hline $\begin{array}{l}\text { 5. Number of buildings worked at Wipro's } \\
\text { Corporate campus }\end{array}$ & 239 & 2.20 & 2.00 & 2 & 1 & 5 & 1.281 \\
\hline $\begin{array}{l}\text { 6. Times relocated on Wipro's corporate campus } \\
\text { site }\end{array}$ & 239 & 2.05 & 2.00 & 2 & 1 & 5 & 1.042 \\
\hline 7. Length of time working for WIPRO (yrs) & 239 & 1.72 & 2.00 & 3 & 1 & 5 & 0.996 \\
\hline $\begin{array}{l}\text { 8. Design of my individual workspace is more } \\
\text { important to me than the design and layout of the } \\
\text { campus as a whole }\end{array}$ & 239 & 2.22 & 2.00 & 1 & 1 & 5 & 1.154 \\
\hline $\begin{array}{l}\text { 9. Care more about the interior design and layout } \\
\text { of the buildings than the design and layout of the } \\
\text { campus as a whole }\end{array}$ & 239 & 2.36 & 2.00 & 1 & 1 & 5 & 1.321 \\
\hline $\begin{array}{l}\text { 10. With today's computers and } \\
\text { telecommunications technology, collocation is } \\
\text { much less important than it once was. }\end{array}$ & 239 & 2.18 & 5.00 & 5 & 4 & 5 & 1.019 \\
\hline $\begin{array}{l}\text { 11. Working on a corporate campus is important } \\
\text { to me } \\
\text { 12. Exterior and interior layout of WIPRO'S }\end{array}$ & 239 & 1.83 & 2.00 & 1 & 1 & 5 & 0.823 \\
\hline $\begin{array}{l}\text { Campus buildings reflects WIPRO's culture and } \\
\text { values } \\
\text { 13. Exterior and interior appearance of WIPRO'S }\end{array}$ & 239 & 1.47 & 1.00 & 1 & 1 & 5 & 0.697 \\
\hline $\begin{array}{l}\text { Campus buildings reflects WIPRO's culture and } \\
\text { values. }\end{array}$ & 239 & 1.85 & 2.00 & 1 & 1 & 5 & 1.722 \\
\hline $\begin{array}{l}\text { 14. Frequently run into colleagues and have } \\
\text { short conversations when I move around my } \\
\text { building }\end{array}$ & 239 & 2.30 & 2.00 & 2 & 1 & 5 & 1.332 \\
\hline $\begin{array}{l}\text { 15. It is important to be collocated in the same } \\
\text { building with own group }\end{array}$ & 239 & 2.20 & 1.00 & 1 & 1 & 5 & 0.850 \\
\hline
\end{tabular}


An initial factor analysis of the data identified five workplace physical factors underlying the IWSP Workplace Survey questionnaire. Only the factors with Eigenvalue greater than 1.0 were retained, yielding the five factor solution that explained a total of $59.18 \%$ of the variance in the data. The minimum primary factor loading criteria was set at 0.40 . No items fell off and there were no cross loadings recorded at the minimum 0.40 primary loading cut-off. There was little difference between the promax and varimax solutions, thus only the solutions from the initial promax rotation were examined for the final solution.

Table 4.2 presents the summary of the outcome of the factor analysis of the fifteen survey items. All cases with missing data were excluded from the factor analysis. The final factor solution included 239 complete cases. 
Table 4.2 Descriptive Statistics, Factor Loadings and Communalities based on a principle components analysis with promax rotation for 15 items from the Workplace Survey $(\mathrm{N}=239)$

\begin{tabular}{|c|c|c|c|c|c|c|}
\hline Statements & $1^{*}$ & 2* & $3^{*}$ & 4* & 5* & $h^{2 * *}$ \\
\hline $\begin{array}{l}\text { 1. Layout of the building enables me to work } \\
\text { productively }\end{array}$ & .933 & & & & & .803 \\
\hline $\begin{array}{l}\text { 2. Interior appearance of the building helps me } \\
\text { to work productively }\end{array}$ & .864 & & & & & .732 \\
\hline $\begin{array}{l}\text { 3. Overall layout of the building enable me to } \\
\text { work productively }\end{array}$ & .814 & & & & & .638 \\
\hline $\begin{array}{l}\text { 4. There are adequate places in the building } \\
\text { where I work, to get together informally with } \\
\text { my colleagues }\end{array}$ & .513 & & & & & .754 \\
\hline $\begin{array}{l}\text { 5. Number of buildings worked at Wipro's } \\
\text { Corporate campus }\end{array}$ & & .764 & & & & .768 \\
\hline $\begin{array}{l}\text { 6. Times relocated on Wipro's corporate } \\
\text { campus site }\end{array}$ & & .754 & & & & .507 \\
\hline 7. Length of time working for WIPRO (yrs) & & .706 & & & & .513 \\
\hline $\begin{array}{l}\text { 8. Design of my individual workspace is more } \\
\text { important to me than the design and layout of } \\
\text { the campus as a whole }\end{array}$ & & & .873 & & & .548 \\
\hline $\begin{array}{l}\text { 9. Care more about the interior design and } \\
\text { layout of the buildings than the design and } \\
\text { layout of the campus as a whole }\end{array}$ & & & .848 & & & .322 \\
\hline $\begin{array}{l}\text { 10. With today's computers and } \\
\text { telecommunications technology, collocation is } \\
\text { much less important than it once was }{ }^{* * * *}\end{array}$ & & & & .764 & & .696 \\
\hline $\begin{array}{l}\text { 11. Working on a corporate campus is } \\
\text { important to me } \\
\text { 12. Exterior and interior lavout of WIPRO'S }\end{array}$ & & & & .607 & & .567 \\
\hline $\begin{array}{l}\text { Campus buildings reflects WIPRO's culture } \\
\text { and values } \\
\text { 13. Exterior and interior appearance of }\end{array}$ & & & & .426 & & .592 \\
\hline $\begin{array}{l}\text { WIPRO'S Campus buildings reflects WIPRO's } \\
\text { culture and values. }\end{array}$ & & & & .411 & & .503 \\
\hline $\begin{array}{l}\text { 14. Frequently run into colleagues and have } \\
\text { short conversations when I move around my } \\
\text { building }\end{array}$ & & & & & .826 & .376 \\
\hline $\begin{array}{l}\text { 15. It is important to be collocated in the same } \\
\text { building with own group }\end{array}$ & & & & & .531 & .556 \\
\hline
\end{tabular}

Extraction Method: Principal Component Analysis. Rotation Method: Promax with Kaiser Normalization.

*Factor Characteristics:

Factor 1: Employees' perception of the Support for Productivity provided by the physical factors of the workplace

Factor 2: Employees' Familiarity with Wipro's organizational and the facilities /physical factors of Wipro's corporate campus

Factor 3: Relative importance placed by employees' on their Immediate Vs. Overall Physical Environment Factor 4: Relevance of a corporate campus

Factor 5: Face-to-Face Interaction among employees as a result of the physical layout

${ }^{* *} h^{2}=$ Item Communality or the total variance explained by the individual item

***: Due to the negative connotation of the statement, the raw scores were re-coded prior to factor analysis as follows; '1' to '5', '2' to '4', '3' to '3', '4' to '2', and '5' to '1' 
Table 4.3 presents a summary of the Eigenvalues and the total variance explained by each of the five individual workplace physical factors with Eigenvalue greater than 1.0.

Table 4.3: Un-rotated Initial Factor Solution; Total Variance Explained by each Individual Factor with Eigenvalue Greater than 1.0

\begin{tabular}{ccccccc}
\hline & \multicolumn{3}{c}{ Initial Eigenvalues } & \multicolumn{3}{c}{ Extraction Sums of Squared } \\
\cline { 3 - 6 } Factor & Total & $\begin{array}{c}\text { \% of } \\
\text { Variance }\end{array}$ & $\begin{array}{c}\text { Cumulative } \\
\%\end{array}$ & Total & $\begin{array}{c}\text { \% of } \\
\text { Variance }\end{array}$ & $\begin{array}{c}\text { Cumulative } \\
\%\end{array}$ \\
\hline 1 & 3.101 & 20.677 & 20.677 & 3.101 & 20.677 & 20.677 \\
2 & 1.901 & 12.673 & 33.349 & 1.901 & 12.673 & 33.349 \\
3 & 1.443 & 9.618 & 42.967 & 1.443 & 9.618 & 42.967 \\
4 & 1.252 & 8.344 & 51.311 & 1.252 & 8.344 & 51.311 \\
5 & 1.180 & 7.866 & 59.177 & 1.180 & 7.866 & 59.177 \\
\hline
\end{tabular}

\subsection{Factor Development}

Factor 1 had an Eigenvalue of 3.101 and accounted for $20.70 \%$ of the total variance in the data set. Four items loaded highly on factor 1, with the communalities of the items ranging from 0.638 to 0.803 . The reliability test for internal consistency of the items was good (Cronbach's $\alpha=0.773$ ). Majority of the items that loaded high on factor 1 were statements that asked the respondents to evaluate whether the spatial characteristics, particularly the design, appearance and layout of their workspace, contributed towards their 'perceived productivity' at work. The four statements that loaded highly on factor 1 were; (i) layout of the building enables me to work productively, (ii) interior appearance of the building helps me to work productively, (iii) overall layout of the building enable me to work productively and, (iv) there are adequate places in the building where I work, to get together informally with my colleagues. Therefore, factor 1 was labeled 'support 
for productivity'; to represent employees' perception of the support provided by workplace physical and spatial characteristics towards their productivity.

Factor 2 had an Eigenvalue of 1.901 and accounted for $12.70 \%$ of the total variance in the data set. Three items loaded highly on factor 2 , with the communalities of the items ranging from 0.507 to 0.768 . The reliability test for internal consistency of the items was moderate (Cronbach's $\alpha=0.557$ ). The three items that loaded on to factor 2 were statements that addressed a respondent's extent of experience and their consequent familiarity with their organization and its physical framework. The statements that comprised this factor were; (i) number of buildings worked at Wipro's corporate campus, (ii) times relocated on Wipro's corporate campus site, and (iii) length of time (years) working for Wipro. Consequently, factor 2 was labeled as 'familiarity', to represent employee's familiarity with Wipro's facilities as a result of their tenure and knowledge of the physical infrastructure on Wipro's corporate campus.

Factor 3 had an Eigenvalue of 1.443 and accounted for $9.60 \%$ of the total variance in the data set. Two items loaded highly on factor 3 , with the communalities of the items ranging from 0.322 to 0.548 . The reliability test for internal consistency of the items was good (Cronbach's $\alpha=0.675)$. The items that loaded on to factor 3 were statements that asked the respondents to consider the relative importance of their personal/immediate surroundings vs. the corporate campus at large. The two statements that loaded highly on factor 3 were; (i) design of my individual workspace is more important to me than the design and layout of the corporate campus as a whole, and (ii) I care more about the 
interior design and layout of the buildings than the design and layout of the campus as a whole. Consequently, factor 3 was labeled 'immediate vs. overall physical environment' to represent the relative importance placed by employees on their immediate versus overall physical environment.

Factor 4 had an Eigenvalue of 1.252 and accounted for $8.30 \%$ of the total variance in the data set. Four items loaded highly on factor 4 , with the communalities of the items ranging from 0.503 to 0.696 . The reliability test for internal consistency of the items was low (Cronbach's $\alpha=0.414)$. The items that loaded on to factor 4 were all statements addressing collocation and corporate identity. The four statements that loaded highly on factor 4 were; (i) with today's computers and telecommunications technology, collocation is much less important than it once was, (ii) working on a corporate campus is important to me, (iii) Exterior and interior layout of WIPRO'S Campus buildings reflects WIPRO's culture and values, (iv) Exterior and interior appearance of WIPRO'S Campus buildings reflects WIPRO's culture and values. Collocation and corporate identity are among the most commonly cited attributes of a corporate campus. Consequently, factor 4 was labeled 'corporate campus' to represent employees' opinion regarding the relevance of a corporate campus.

Factor 5 had an Eigenvalue of 1.180 and accounted for $7.80 \%$ of the total variance in the data set. Two items loaded on to factor 5 , with the communalities of the items ranging from 0.376 to 0.556 . The reliability test for internal consistency of the items was moderate (Cronbach's $\alpha=0.551$ ). The items that loaded on to factor 5 were all 
statements that conceptually addressed the significance of physical proximity (which is expected to support greater face-to-face interaction) among co-workers who are a part of the same workgroup. The two statements that loaded on factor 5 were; (i) I frequently run into colleagues and have short conversations when I move around my building, and (ii) it is important to be collocated in the same building with own group. Factor 5 was labeled 'face-to-face interaction' among to represent the occurrence of interaction among employees as a result of the physical layout of their workspace.

The composite scores for the five physical or spatial factors derived through factor analysis were computed and retained in SPSS, to form five new workplace physical factors. Each of the five workplace physical factor or variable was used as an independent predictor variable for further statistical analyses to predict 'sense of belonging'.

In addition to the physical factors discussed above, employees' level of satisfaction with their current personal office/workstation and their level of satisfaction with Wipro's overall campus were measured with a single statement for each. In order to assess the level of satisfaction, employees were asked to report their level of satisfaction with their current workstation/office and with Wipro's corporate campus, as, 'satisfied', 'neutral' or dissatisfied'. Henceforth, Employees' self-reported level of 'satisfaction' with their own office/workspace and Wipro's corporate campus, were included as independent variables to predict 'sense of belonging'. 
In aggregate, seven independent workplace physical factors or variables were developed for further analysis. The final correlation matrix included three control variables and seven workplace physical variables to predict employees' 'sense of belonging'. The three control variables were employees' demographics of (i) age, (ii) gender, (iii) job level. The seven workplace physical variables were; (i) employees' satisfaction with own office/workstation, (ii) employees' satisfaction with Wipro's Corporate campus, (iii) factor 1: employees' perception of the support provided by the workplace physical factors towards their productivity, (iv) factor 2: employees' familiarity with Wipro and the facilities at their corporate campus, (v) factor 3: the relative importance placed by employees' on their immediate vs. overall physical environment, (vi) factor 4: employees' opinion regarding the relevance of the corporate campus, and (viii) factor 5: face-to-face interaction among employees as a result of the physical layout of their workspace.

\subsection{Correlations}

In order to test the hypothesis for this study, that assumes that 'there is no association among workplace physical factors and employees' 'sense of belonging'; correlations among employees' self-reported 'sense of belonging' and the workplace physical variables or factors were computed. The null hypothesis is rejected based on the results of the correlations that indicated a statistically significant relation between employees' 'sense of belonging' and the physical factors of the workplace. A summary of the correlations are presented in Table 4.4. 
Table 4.4- Correlation among employees' 'sense of belonging', control variables and workplace physical factors

\begin{tabular}{|c|c|c|c|c|c|c|c|c|c|c|c|}
\hline & 0 & 1 & 2 & 3 & 4 & 5 & 6 & 7 & 8 & 9 & 10 \\
\hline 00. Sense-of-Belonging & - & & & & & & & & & & \\
\hline 01. Age & .007 & & & & & & & & & & \\
\hline 02. Gender & .062 & $-.142^{*}$ & & & & & & & & & \\
\hline 03. Job Level & -.002 & $.427^{* \star}$ & -.046 & & & & & & & & \\
\hline $\begin{array}{l}\text { 04. Satisfaction; With } \\
\text { Own Office }\end{array}$ & $.205^{\star *}$ & .047 & -.080 & .004 & & & & & & & \\
\hline $\begin{array}{l}\text { 05. Satisfaction; With } \\
\text { Corporate campus }\end{array}$ & $.411^{* *}$ & -.006 & -.004 & -.041 & $.438^{* *}$ & & & & & & \\
\hline $\begin{array}{l}\text { 06. Support for } \\
\text { Productivity' }\end{array}$ & $.531^{* *}$ & -.026 & .059 & .071 & $.449^{* *}$ & $.544^{* *}$ & & & & & \\
\hline 07. Familiarity & $.203^{* *}$ & $.310^{* *}$ & .065 & $.261^{* *}$ & .020 & -.001 & $.131^{*}$ & & & & \\
\hline $\begin{array}{l}\text { 08. Immediate. Vs. } \\
\text { Overall Physical } \\
\text { Environment }\end{array}$ & $-.253^{* *}$ & .059 & .065 & $.164^{*}$ & $-.215^{* *}$ & -.101 & -.120 & .059 & & & \\
\hline $\begin{array}{l}\text { 09. The Corporate } \\
\text { campus }\end{array}$ & $.562^{\star *}$ & -.082 & .051 & .052 & .103 & $.293^{* *}$ & $.308^{* *}$ & .026 & -.090 & & \\
\hline $\begin{array}{l}\text { 10. Face-to-face } \\
\text { Interaction }\end{array}$ & $.163^{*}$ & -.001 & .112 & .100 & .019 & .038 & .093 & $.163^{*}$ & .020 & .111 & - \\
\hline
\end{tabular}

Results of the correlations indicated that employees' demographics of age, gender and job level were not significantly associated with their 'sense of belonging' $(p>0.05)$. On the other hand, the correlation data confirmed a statistically significant $(p<0.05)$ association among all of the workplace physical factors and employees' 'sense of belonging. Each of the seven workplace physical factors, namely; (i) employees' satisfaction with their office/workstation, (ii) employees' satisfaction with Wipro's corporate campus, (iii) employees' perception of the support provided by the workplace physical factors towards their productivity, (iv) employees' familiarity with the facilities on 
their corporate campus, (v) the relative importance placed by employees' on their immediate versus overall physical environment, (vi) the relevance of a corporate campus and (vii) face-to-face interaction among co-workers as a result of the physical layout of their workspace, indicated a statistically significant association with employees' self-reported 'sense of belonging' $(p<0.05)$.

Overall, a higher level of 'sense of belonging' was found to be significantly associated with; (i) the relevance of a corporate campus $(r=0.562, p<0.01)$, (ii) with employees' perception of the support provided for employees perceived productivity, by the spatial features of their workspace $(r=0.531, p<0.01)$ and (iii) with employees' overall level of satisfaction with own workstation/office and Wipro's corporate campus ( $r=0.411$, $\mathrm{p}<0.01)$

Results also indicated a significant negative association between 'sense of belonging' and the relative importance placed by employees on their immediate versus overall physical environment at Wipro's corporate campus $(r=-0.253, p<0.01)$, which, suggests that the more the respondents focused on their personal office/workspace and the less they focused on the overall corporate campus; the lower the 'sense of belonging' they would be expected to reported. A relatively weaker but statistically significant association was also recorded among 'sense of belonging' and; employees' satisfaction with their current office/workstation $(r=0.205, p<0.01)$, employees' familiarity/orientation $(r=0.203, p<0.01)$ with their organization and its facilities, and face-to-face interaction $(r=0.163, p<0.05)$ among employees. 
Among other variables, employees' level of satisfaction with Wipro's corporate campus was significantly associated with their level of satisfaction with their current office/workstation $(r=0.438, p<0.01)$. Statistically significant associations were also recorded between employees' opinion of the support provided by the workplace spatial features towards their perceived productivity and their satisfaction with their current office/workstation $(r=0.449, p<0.01)$ as well as their satisfaction with Wipro's overall corporate campus $(r=0.544, p<0.01)$.

Albeit weak, but statistically significant associations were observed between the relevance of Wipro's corporate campus and; employees' overall satisfaction with Wipro's corporate campus $(r=0.293, p<0.01)$ and their opinion of the support provided by the workplace physical or spatial features towards their perceived productivity $(r=0.308, p<0.01)$. Also statistically significant, was an association between the employees' familiarity with their organization/facilities and their perception of the support provided by the workplace spatial features $(r=0.131, p<0.05)$, which suggests that the more familiarity that employees' develop with their organization and the physical framework of their corporate campus, the more likely they are to perceive the physical features of their workplace as contributors towards their productivity.

Results of the correlations also indicated a positive association between; employees' familiarity with their organization and the facilities at their corporate campus and face-toface interaction among employees working on Wipro's corporate campus ( $r=0.163$, $\mathrm{p}<0.05)$. Further, a statistically significant association was indicated between 
employees' familiarity with their organization and its facilities at their corporate campus with both; the respondents age $(r=0.310, p<0.01)$ and with the level of their satisfaction with their current office/workstation $(r=0.215, p<0.01)$.

\subsection{Multiple Regression Assessing Goodness-of-Fit}

Following the confirmation of the association between workplace physical factors or variables and employees; self-reported 'sense of belonging', multiple regression analyses were undertaken to assess the goodness-of-fit or the predictive value of the independent variables as predictors of employees' 'sense of belonging'. A significant model $\left(F_{7,239}=24.412, \mathrm{df}=10 p<0.000\right)$ emerged, explaining $52.5 \% \quad\left(R^{\wedge} 2=0.525\right.$, $\mathrm{R}=0.724$ ) of the total variance in the data for employees' self-reported 'sense of belonging'. It was observed that three workplace physical factors or predictors, namely; (i) employees' level of 'satisfaction' with own office/workstation and Wipro's corporate campus, (ii) the relevance of the 'corporate campus' and (iii) employees' 'familiarity' with the facilities at Wipro's corporate campus, accounted for approximately $45.0 \%$ of the variation in the data (or approximately $86.0 \%$ of the total explained variance) for selfreported 'sense of belonging'. All prediction models, with the exception of model 1 which, included only the control variables, of employees' demographics, were statistically significant at predicting employees' sense of belonging.

In aggregate, seven prediction models were developed using the ENTER method offered in the linear regression function in SPSS. The hierarchical multiple regression techniques was selected for this study to allow the examiner to control the order in 
which each predictor or independent variable is entered into the model and therefore, to monitor the consequential change in the predictive value of the model that results with the entry of each subsequent independent variable. Employees' self-reported 'sense of belonging' was entered as the outcome (dependent) variable in each of the seven models. Following model 1, each subsequent hierarchical regression model added one additional predictor variable, to the set of predictor variable(s) included in the preceding model. Table 4.5 below, summarizes the pertinent statistical results for the seven regression models that were developed to predict employees' 'sense of belonging'.

Table 4.5 Pertinent Statistics; Model(s) Summary and ANOVA for seven hierarchical multiple regression models to predict employees' 'sense of belonging' $(\mathrm{N}=239)$

\begin{tabular}{|c|c|c|c|c|c|c|c|}
\hline \multirow[b]{2}{*}{ Model } & \multicolumn{5}{|c|}{ Model Summary } & \multicolumn{2}{|c|}{ ANOVA } \\
\hline & $\mathbf{R}$ & $R^{\wedge} \mathbf{2}$ & Adj. $R^{\wedge} 2$ & Std. Err. of Est. & $\begin{array}{c}R^{\wedge} 2 \\
\text { Change } \\
\end{array}$ & $\mathbf{F}$ & Sig \\
\hline 1 & .073 & .005 & -.008 & 1.006 & .005 & 0.405 & $.749 a$ \\
\hline 2 & .414 & .172 & .153 & .922 & .166 & 9.360 & .000 \\
\hline 3 & .552 & .305 & .287 & .846 & .134 & 16.463 & .000 \\
\hline 4 & .575 & .330 & .309 & .833 & .025 & 15.772 & .000 \\
\hline 5 & .610 & .372 & .349 & .808 & .042 & 16.501 & .000 \\
\hline 6 & .722 & .521 & .502 & .707 & .149 & 26.862 & .000 \\
\hline 7 & .724 & .525 & .503 & .706 & .004 & 24.412 & .000 \\
\hline
\end{tabular}

Model 1 included the employees' demographics of age, gender and job level, to analyze the variance in the data for employees' 'sense of belonging' explained by employees' demographic backgrounds. The result of the regression Model 1 indicated that employee demographics of age, gender and job level, accounted for $5.0 \%\left(R^{\wedge} 2=0.005\right.$, $\mathrm{R}=0.073$ ) of the variation in the data for employees' self-reported 'sense of belonging'. 
However, with $p>0.05$, Model 1 was not significant $\left(F_{4,239}=0.405, d f=3,228\right.$, sig. $\left.=0.749\right)$ for predicting employees' sense of belonging.

Model 2 added the 'Satisfaction' variables; employee' level of satisfaction with own workstation/office and level of satisfaction with Wipro's Corporate campus, to the set of independent variables included in Model 1 . The combination of the predictor variables in Model 2, explained a total of $17.2 \%\left(R^{\wedge} 2=0.172, R=0.414\right)$ of the variation in the data for employees' self-reported 'sense of belonging'. It was noted that employees' level of satisfaction; with their office/workstation and with Wipro's overall corporate campus, by itself, accounted for an additional $16.6 \%$ of the variation in the data for employees' selfreported 'sense of belonging'. Model 2 was significant $(F=9.360, \mathrm{df}=5,226$, sig. $=0.000)$.

Model 3 added workplace physical factor; 'employees' perception of the 'support provided by the physical attributes of their workplace towards their productivity', to the set of independent variables included in Model 2. The combination of the predictor variables in Model 3, explained a total of $30.5 \%\left(R^{\wedge} 2=0.305, R=0.552\right)$ of the variation in the data for employees' self-reported 'sense of belonging', whereas employees' perception of the support provided by the physical attributed of their workplace towards their productivity, alone, accounted for an additional $13.4 \%$ of the variation in the data for employees' self-reported 'sense of belonging'. Model 3 was significant ( $F=16.463$, df $=6,225$, sig. $=0.000$ ). 
Model 4 added workplace physical factor; employees' 'familiarity' with Wipro and the facilities at Wipro's corporate campus, to the set of independent variables included in Model 3. The combination of the predictor variables in Model 4, explained a total of $33.0 \%\left(R^{\wedge} 2=0.330, R=0.575\right)$ of the variation in the data for employees' self-reported 'sense of belonging'. At the same time, employees' 'familiarity', alone, accounted for an additional $2.5 \%$ of the variation in the data for employees' self-reported 'sense of belonging'. Model 4 was significant $(F=15.772, \mathrm{df}=7,224$, sig. $=0.000)$.

Model 5 added workplace physical factor; the relative importance placed by employees' on their 'immediate versus overall physical environment', to the set of independent variables included in Model 4. The combination of the predictor variables in Model 5, explained a total of $37.2 \%\left(R^{\wedge} 2=0.372, R=0.610\right)$ of the variation in the data for employees' self-reported 'sense of belonging'. Employees' 'familiarity', by it self, accounted for an additional $4.2 \%$ of the variation in the data for self-reported 'sense of belonging'. Model 5 was significant $(F=16.501, \mathrm{df}=8,223$, sig. $=0.000)$.

Model 6 added workplace physical factor; the relevance of the corporate campus, to the set of independent variables included in Model 5. The combination of the predictor variables in Model 5 , explained a total of $52.1 \%\left(R^{\wedge} 2=0.521, R=0.722\right)$ of the variation in the data for employees' self-reported 'sense of belonging'. Employees' opinion regarding the relevance of a corporate campus', alone, accounted for an additional $14.9 \%$ of the variation in the data for employees' self-reported 'sense of belonging' for employees. Model 6 was significant $(F=26.862, \mathrm{df}=9,222$, sig. $=0.000)$. 
Finally, Model 7 added workplace physical factor; the occurrence of 'face-to-face interaction' among employees' on a corporate campus as a result of the layout of the physical workspace, to the set of independent variables included in Model 6. The combination of the predictor variables in Model 7 , explained a total of $52.5 \%\left(R^{\wedge} 2=\right.$ $0.525, \mathrm{R}=0.724$ ) of the variation in the data for employees' self-reported 'sense of belonging'. 'Face-to-face interaction' among employees, on it self, accounted for an additional $4.0 \%$ of the variation in the data for employees' self-reported 'sense of belonging'. Model 7 was significant $(F=24.412, \mathrm{df}=10,221$, sig. $=0.000)$.

\subsection{Model Parameters}

Next, the parameters for the prediction models above were assessed to identify the predictor(s) or the workplace physical factors that made the most significant contribution to the model to predict 'sense of belonging'. In particular, the value of the standardized coefficient $(\beta)$ and specifically the t-test score associated with each of the $\beta$ and the associated value in the "sig." column for each of the workplace physical factor or predictor variable was examined.

While all of the Models that included the workplace physical factors as predictors of 'sense of belonging', were found to be statistically significant $(p<0.001)$, particular emphasis was placed on testing the parameters for model 7 because it included all of workplace physical factors that, in combination, explained the maximum amount of variation in the data for self-reported 'sense of belonging'. A summary of coefficients for model 7 is presented in Table 4.6. 
Table 4.6 Summary of Model 7, Beta Coefficients and T-Test scores to assess Model Parameters

\begin{tabular}{|c|c|c|c|c|c|}
\hline Model 7 & \multicolumn{2}{|c|}{ Un-Standardized } & Standardized & $\mathbf{t}$ & Sig. \\
\hline \multicolumn{6}{|l|}{ 'Sense of Belonging' (DV) } \\
\hline Age & .095 & .118 & .044 & .801 & .424 \\
\hline Gender & .065 & .148 & .021 & .436 & .663 \\
\hline Job Level & -.103 & .058 & -.095 & -1.782 & .076 \\
\hline $\begin{array}{l}\text { Satisfaction w/t own } \\
\text { office/workstation }\end{array}$ & -.078 & .067 & -.064 & -1.166 & .245 \\
\hline Satisfaction w/t corporate campus & .161 & .083 & .113 & 1.923 & .056 \\
\hline Support for Productivity & .328 & .060 & .329 & 5.453 & .000 \\
\hline Familiarity & .164 & .051 & .164 & 3.222 & .001 \\
\hline Immediate vs. Overall Environment & -.179 & .049 & -.179 & -3.690 & .000 \\
\hline The corporate campus & .412 & .050 & .412 & 8.222 & .000 \\
\hline Face-to-Face Interaction & .061 & .048 & .061 & 1.284 & .200 \\
\hline
\end{tabular}

Results indicated that demographic variables of age, gender and job level did not make a significant contribution $(p>0.05)$ to Model 7 . Moreover, workplace physical factors; (i) employees' level of satisfaction with own office/workstation, (ii) employees' level of satisfaction with Wipro's corporate campus and (iii) face-to-face interaction among employees as a result of the physical layout of the workspace, did not make a significant contribution to the model to predict 'sense of belonging'.

Results indicated that four workplace physical factors; (i) the relevance of a corporate campus, (ii) employees' perception of the support provided by the physical attributes of their workplace towards their productivity, (iii) the relative importance placed by employees' on their immediate versus overall physical environment, and (iv) employees' familiarity with Wipro and the facilities at their corporate campus, made a significant contribution $(p<0.001)$ to the model to predict 'sense of belonging' among employees' working on a corporate campus. 
To further refine Model 7, a reduced regression model was tested using only the four significant workplace spatial predictors of 'sense of belonging'. The combination of the four significant predictors accounted for $51.0 \%\left(R^{\wedge} 2=0.509, R=0.714\right)$ of the variation in the data. The results of the ANOVA for the reduced model indicated that it was statistically significant $\left(F_{4,239}=59.964, \mathrm{df}=4.000\right.$, sig. $\left.=0.00\right)$. The coefficient matrix for the reduced model further confirmed that all of the four predictors continued to be significant contributors to the overall model. Table 3.7 below, summarizes the key statistics for the reduced model with only the four significant predictors; (i) support for productivity, (ii) Familiarity, (iii) immediate versus overall physical environment, and (iv) the corporate campus.

Table 4.7 Reduced Model; four significant workplace physical factors as predictors of 'Sense of Belonging'

\begin{tabular}{|c|c|c|c|c|c|}
\hline & \multicolumn{2}{|c|}{ Un-standardized } & \multirow{2}{*}{$\frac{\text { Standardized }}{\text { Beta }}$} & \multirow{2}{*}{$\mathbf{t}$} & \multirow{2}{*}{ Sig. } \\
\hline & B & Std. Error & & & \\
\hline Sense of Belonging (DV) & 1.733 & .046 & & 37.433 & .000 \\
\hline Support for Productivity & .358 & .049 & .356 & 7.244 & .000 \\
\hline Familiarity & .157 & .047 & .156 & 3.355 & .001 \\
\hline $\begin{array}{l}\text { Immediate vs. Overall } \\
\text { Environment }\end{array}$ & -.182 & .047 & -.181 & -3.883 & .000 \\
\hline Corporate campus & .435 & .049 & .432 & 8.904 & .000 \\
\hline
\end{tabular}

It was noted that each of the four workplace physical factors, included in the reduced regression model, contributed significantly to predict 'sense of belonging' among employees working at a corporate campus. Of the four workplace physical factors; the relevance of a 'corporate campus' made the most significant contribution to the model $(t=8.904, p<0.000)$, followed by employees' perception of the support provided by their 
workplace physical environment towards their productivity $(t=7.244, p<0.000)$, followed by the relative importance placed by employees on their immediate versus overall physical environment at Wipro's corporate campus $(t=-3.883, p<0.000)$ and finally by employees' familiarity with Wipro and the facilities at Wipro's corporate campus $(t=3.355, p<0.001)$.

\subsection{The Regression Equation}

Based on the coefficient values $(\beta)$ for each significant predictor or independent variables; the following regression equation was formed to predict employees' 'sense of belonging':

$$
\hat{y}=1.7333+0.358 \times 1+0.157 \times 2-0.182 \times 3+0.435 \times 4
$$

Where,

$. \hat{y}=$ 'Employees' 'sense of belonging' (the dependent variable);

$\mathrm{X}_{1}=$ 'Support for productivity'; provided by the workplace physical environment;

$\mathrm{X} 2=$ 'Familiarity'; employees' familiarity with Wipro's organizational aspects and its physical framework;

$\mathrm{X} 3=$ 'Immediate versus overall physical environment'; as their importance to employees, and;

$\mathrm{X}_{4}=$ 'Corporate campus'.

In order to estimate an employees' 'sense of belonging', the above regression equation assumes that, "with all other independent variables held constant, a one unit change in employees' opinion regarding the support provided by their physical environment towards their perceived productivity $\left(x_{1}\right)$, should result in a 0.358 unit change in their 'sense of belonging'". Since the $\beta$ value is positive, the 'sense of belonging' should be expected to increase by 0.358 units with a 1.0 unit increase in the employees' opinion 
regarding the support provided by their physical environment towards their perceived productivity.

Likewise, a one unit increase in predictor variables; employees' familiarity with Wipro and the facilities at its corporate campus $\left(\mathrm{x}_{2}\right)$ and relevance of a corporate campus $\left(\mathrm{x}_{4}\right)$, employees' 'sense of belonging' should be increased by 0.157 and 0.435 units, respectively. However, a negative $\beta$ value for predictor variable; the relative value placed by employees on their immediate versus overall physical environment $\left(\mathrm{x}_{3}\right)$, suggests an inverse relationship with 'sense of belonging'. As mentioned in earlier sections, these results suggest that 'the more that the employees' focus on aspects of their immediate physical environment versus the physical aspects of the overall physical environment of their corporate campus, the less 'sense of belonging', they are likely to report." Based on the $\beta$ value for this predictor variable, a one unit change in the importance placed by employees' on their immediate versus overall physical environment, should result in a 0.182 units decrease in their 'sense of belonging'. 


\section{CHAPTER 5-DISCUSSION}

This study examined and confirmed a statistically significant association between the workplace physical factors and employees' 'sense of belonging'. In addition to classifying the key workplace physical factors that underlay the IWSP Workplace Survey questionnaire, this study identified the set of workplace physical factors that will likely be significant predictors of employees' 'sense of belonging'.

This research commenced with the null hypothesis that, "there is no association among workplace physical factors and employees' 'sense of belonging'.' The null hypothesis is rejected as the results of the correlation provide empirical evidence for a statistically significant relationship among workplace physical factors and employees' self-reported 'sense of belonging'. A statistically significant prediction model comprised of four workplace physical factors was developed to predict 'sense of belonging'; explaining $51.0 \%$ of the variance in the data for employees' 'sense of belonging'.

Factor analysis of survey items identified five independent factors that underlay the IWSP Workplace Survey questionnaire. They were labeled; (i) support for employees' productivity by workplace physical factors, (ii) employees' familiarity with Wipro and the facilities at its corporate campus, (iii) the relative importance of immediate vs. overall physical environment, (iv) the relevance of a corporate campus, and (v) face-to-face interaction among co-workers, as a result of the physical layout of the workplace. All 
workplace physical factors identified in this study were significantly correlated with employees' self-reported 'sense of belonging'.

The workplace physical factors that were found most significantly correlated with employees' sense of belonging were; (i) the relevance of a corporate campus, followed by (ii) employees' perception of the support provided by the workplace physical features towards their productivity, followed by (iii) employees' overall level of satisfaction (with own workstation/office and Wipro's corporate campus), followed by (iv) the relative importance placed by employees on their immediate versus overall workplace physical environment, followed by (v) employees' familiarity with Wipro and the facilities at Wipro's corporate campus and finally with (vi) face-to face interaction among employees as a result of the physical layout of the workplace.

While the majority $(51.0 \%)$ of the variance in the data on employees 'sense of belonging' is explained, a significant proportion (49.0\%) of the variance remains unexplained. It is reasonable to assume at this point, that 'sense of belonging' may be influenced by other organizational factors, which are beyond the scope of this study. Nevertheless, the primary strength and contribution that this study makes is to serve as an empirical foundation for the continued exploration, refinement and examination of the associations between the physical factors of a workplace and employees' 'sense of belonging'. The results of this study can serve as groundwork to develop more sensitive and versatile instruments to predict 'sense of belonging' across a variety of workplace physical settings. Each of the significant workplace physical factors identified in this 
study is discussed below in the descending order of its association with employees' 'sense of belonging'.

\subsection{The Relevance of a 'Corporate Campus'}

Results indicated that the corporate campus was the physical factor that was most significantly associated with employees' 'sense of belonging'. A corporate campus is a prototype of a physical workplace which best integrates many of the attributes that are considered requisites for employees' 'sense of belonging.' These attributes include, but are not limited to, strong identification through corporate branding, enhanced communication and collaboration among co-workers from across an organization as a result of their mass physical collocation on one site, the provision of on-site amenities that potentially improve the quality employees' experience working for an organization and otherwise foster a sense of community that employees can feel a part of.

When asked, majority of the participants in this study 'agreed' that 'it was important for them to work on a corporate campus' (mean=1.83). Furthermore, majority of the participants also agreed to the statements that, "the layout of the interior and exterior of Wipro's campus buildings' (mean=1.47), and 'the appearance of the interior and exterior of Wipro's campus buildings' (mean=1.85), reflect its corporate culture and values. The positive nature of employees' opinion regarding physical characteristics of Wipro's corporate campus is relatable to the suggestion made by Smidts et. al (2001) regarding the 'perceived external prestige' of an organization. Smidts et. al. suggest that perceived external prestige represents how an employee thinks outsiders view his or 
her organization. Architectural aesthetics or the external physical form of an organization can serve as a reflection of its internal stereotype, central beliefs and missions of the organization. Likewise, in this study- a strong positive correlation between employees' 'sense of belonging' and the relevance of a corporate campus indicate that the external physical form of Wipro, that is, its buildings, architectural style and a strongly branded corporate campus contribute significantly towards enhancing its external image. Moreover, this visual distinction allows its employees to feel a sense of pride and identity with the culture and values of their organization and therefore has a positive affect on their 'sense of belonging'.

At a more detailed look at the items that loaded onto the factor labeled 'significance of a corporate campus' (or 'corporate campus'); positive factor loadings of statements addressing the importance of working on a corporate campus and the external and internal image of the facilities, not only confirm that Wipro's corporate campus is strongly acknowledged by the employees who work their but also that its architecture is a endearing representation of its corporate culture and values.

Interestingly, the factor 'corporate campus' also included the statement that asked the participants if, 'with today's computers and telecommunications technology, collocation is much less important than it once was". This item had the greatest loading value $(r=0.764)$ on to the factor. The frequency analysis of this individual statement indicated that majority of the participants agreed that collocation (in general) was much less important than it once was as a result of the advancements in computers and 
telecommunication technology (mean=2.18). At the same time, when asked, majority of the participants in this study also 'agreed' to the statement that, 'it was important to be collocated in the same building with own group" (mean=2.20).

These results lead to a few inferences. First, they indicate that 'physical collocation' in itself, specifically with members of one's own group is considered to be important by employees. Second, they indicate that while working at a corporate campus is of great significance to employees'; 'physical collocation' is not one of the attributes that contributes towards employees' opinion regarding the importance of working at a corporate campus.

Lastly, based on the negative connotation of the statement and the strength of the items' loading on to the factor 'corporate campus', a third plausible inference can be drawn which suggests that, 'the more that the employees consider collocation as 'unimportant', the less they will value the corporate campus".

\subsection{The perceived support from the physical workplace towards employees' productivity}

The second strongest and statistically significant association was found among employees' 'sense of belonging' and the workplace physical factor 'support for productivity'. This factor captured employees' opinion regarding the support provided by specific characteristics of their physical workspace, towards their productivity (perceived)'. A statistically significant and positive correlation among employees' 'sense

of belonging' and their perception of 'support for productivity' by the physical attributes 
of the workplace, suggests that, "the greater the perception of support by the physical attributes of a workplace, the higher the 'sense of belonging', that can be expected".

Majority of the participants in this study Survey agreed with the statements; (i) 'the layout of the building (where they worked) enables me to work productively' (mean=2.19), (ii) 'the interior appearance of the building helps me to work productively' (mean=2.21) and (iii) 'the overall layout of the buildings (at Wipro's Campus) enable me to work productively' (mean=2.22). The preceding three statements loaded positively on to the factor labeled 'support for productivity (by spatial features)' with high loading scores $(r>0.80)$. These results indicate that employees place significant weight age on the physical characteristics of a workplace while they perceive their personal productivity.

A fourth item that loaded on to the factor 'support for productivity' was the statement asking participants if, 'there were adequate places in the building, where they worked to get together informally with their co-workers'. Frequency analysis of this individual item indicated that majority of the participant agreed that the building, where they worked at Wipro's campus, incorporated adequate spaces where they could get together informally with their colleagues (mean=2.54). The clustering of this item with the statements addressing employees' productivity as a result of the physical characteristics 
of the workplace, suggests that employees' associate informal interaction with their coworkers to be a component of their self productivity in the workplace.

While a variety of workspace features such as lighting levels, ergonomic furniture and equipment, and finishes can have a direct effect on employees' productivity; the plan and layout of workspace influences employee productivity, indirectly. For instance, open-plan work settings promote the notion of equality across job levels, greater visibility and transparency across hierarchies, acknowledgment of another's contribution, an open atmosphere for formal and in-formal communication and knowledge sharing. At the same time, informal and common spaces like the coffee station, copy rooms etc., serve as major circulation points that employees frequent each day. These common spaces support behavioral outcomes like increased interaction among co-workers, particularly at an informal level- as people can stand and talk, often catching up on each other's work. Such an experience provides a refreshing break in the workday, increasing employee satisfaction and, in turn, their productivity.

Further more, referring back to the idea of 'value congruence' (Box \& Chattam, 1991); where value congruence is defined as, 'the fit between professed organizational values and the values deemed appropriate by employees'; a company that wants to promote a culture that eliminates barriers between work groups and encourages the free exchange of ideas to enhance innovation, creativity and productivity, can utilize the physical 
workspaces to support such organizational outcomes. Considering that everyone wants to be part of a large group effort, the design of a workspace can directly addressed a firm's goals of building a strong sense of community among its employees, and make it possible for them to see where they fit in. In such a set-up and with this knowledge, people can increase their potential.

\subsection{Employees' level of satisfaction with the physical attributes of their workplace}

The next strongest and statistically significant association was found between employees' 'sense of belonging' and their level of satisfaction with their own workspace/office and their level of satisfaction with Wipro's overall corporate campus. Edwards and Peccei (2001) suggest that perceived organizational support or "the extent to which individuals believe that their employing organization values their contribution and cares for their well-being" is one of the antecedents to organizational identity. They argued that when organizations show concern for their employees' well being, there will be a tendency for these individuals to develop an attachment and identify with the organization. The relationship between organizational identity and perceived organizational support further develops as organizational identity mediates the relationship between perceived organizational support and organizational involvement.

Past workplace studies conducted by IWSP (Becker, Sims, and Schoss, 2002, Wang 2003, Baik 2003) emphasize the relevance of personal workspace/office and having a corporate campus, as factors that are crucial to employees' satisfaction with their 
workplace. Likewise, respondents in this study ranked personal workstation/office and corporate campus, among the top five factors that contributed to their satisfaction with their workplace. Frequency analysis of the statements addressing employees' satisfaction indicated that employees at Wipro's corporate campus were more satisfied with their corporate campus (mean=1.47) compared to their level of satisfaction with their own office/workstation (mean=1.83).

These two survey items comprised the factor that was labeled 'satisfaction', to represent employees' satisfaction with the workplace physical factors; personal workspace and Wipro's corporate campus. A statistically significant and positive correlation among employees' 'sense of belonging' and their level of 'satisfaction' with spatial features of their workplace suggests that, the more 'satisfied' the employees feel with their own personal workspace and with the overall corporate campus, the greater the 'sense of belonging' that would likely be reported.

Employees satisfaction with their personal workspace and corporate campus, may also be affected by physical factors such as the actual size of an employee's workspace (or office), privacy levels, chair/desk design and ergonomics, quality and characteristics and quality of campus amenities etc. These variables were not addressed in the IWSP Workplace Survey. The inclusion of these factors, among others, is crucial for more indepth understanding of the components that comprise an employees' satisfaction with spatial features of their workspace. 


\subsection{The relative importance placed by employees' on their immediate versus overall workplace physical environment}

The factor labeled 'Immediate versus Overall Environment', comprised of statements that recorded the relative emphasis placed by employees' on aspects of their immediate physical surroundings versus the emphasis placed on the overall physical setting of a corporate campus. Employees' sense of belonging' was found to have a statistically significant and negative correlation with the workplace physical factor; 'the relative importance placed by employees on the physical characteristics of their immediate environment versus the overall workplace physical environment of their corporate campus'.

Majority of the respondents in this study agreed that the design of individual workspace and the interior design and layout of their building was more important to them than the design and layout of the overall corporate campus. Specifically, slightly greater emphasis was placed on the importance of the design of the individual workspace (mean=2.22) as compared to the importance of the interior design and layout of a respondents' own building (mean=2.36).

The negative correlation among employees' 'sense of belonging' and the workplace physical factor; 'the relative importance placed by employees on their 'immediate versus overall physical environment'; suggests that the more importance that employees place on the physical features of their immediate environment in relation to the importance placed on the physical features of the overall corporate campus, the lower the 'sense of 
belonging' they would likely report. The above results also indicate that, in general, employees' are highly sensitive to the quality of their immediate environment; more so than to the qualities of the overall corporate campus.

\subsection{Employees' familiarity with Wipro and the facilities at Wipro's corporate campus}

Results indicated that there is a statistically significant and positive association between employees' 'sense of belonging' and their 'familiarity' with Wipro and the facilities at its corporate campus. The factor labeled, employees' 'familiarity' comprised of three variables; employees' tenure (in years) with Wipro, times relocated on Wipro's corporate campus and the number of buildings worked at on Wipro's corporate campus.

Dutton et. al (1994) and Jong et. al (2009) suggest that the attractiveness of the organizational identity varies with a member's length of tenure (years in the organization) and that employees who work in the organization for a longer time will perceive the organizational identity as stronger. March and Simon (1958) propose that the longer an individual remains in an organization, the more his interactions occur within the organization, the more his needs are satisfied within the organization, and, therefore, the more he identifies with the organization.

Employees' familiarity with the physical framework of their workplace, to an extent, relates to their experience, knowledge, or awareness of the facilities and amenities that exist on their corporate campus. For example, an employee who frequently utilizes onsite amenities such as an on-site gymnasium, the corporate cafeteria or the conference 
room or a R\&D facility, etc., will be more aware of its organizations' initiatives to provide a workplace that enhances its employees' overall experience of working there compared to someone who is unaware that such amenities exist and has never leveraged such perks.

However, contradictory to the notion discussed above, descriptive analysis of individual items that comprised this factor indicated that neither employees tenure (number of years working for Wipro) nor their awareness/acquaintance with the facilities at their corporate campus (measured as- times relocated on Wipro's campus and number of buildings worked at on Wipro's campus) had a consequential affect on their 'sense of belonging'.

Based on the correlation data, a relatively small, however statistically significant positive correlation was recorded between employee 'familiarity' and 'sense of belonging'; suggesting that the higher an employee's score on familiarity variables, the greater the 'sense of belonging' they would likely report. Nevertheless and notwithstanding the above positive direction of the correlation; employees' 'familiarity' was found to have a positive affect on their 'sense of belonging' but only up to a point. Results of a crosstabulation between the number of times an employee had been relocated on Wipro's campus and their 'sense of belonging', indicated slightly lower 'sense of belonging' among employees who had been relocated more frequently (6-10 times) on Wipro's campus, as compared to the employees who had been relocated less frequently (0-5 times). 


\subsection{Face-to-Face Interaction among employees as a result of the physical layout of a workspace}

In this study, the physical factor labeled; 'face-to-face Interaction' as a result of the layout of the workplace, was found to have a significant positive correlation with employees' 'sense of belonging'. This result suggests that the more that the employees' perceive the physical layout of their workplace to incorporate features that support faceto-face interaction, the higher the 'sense of belonging' they would likely report. When asked, majority of the respondents in this study agreed that they frequently ran into colleagues and had short conversations, when they moved around their building' (mean=2.30). Majority of the employees also 'agreed' that it was important for them to be collocated in the same building with their own group (mean=2.20); stressing the importance of having face-to-face time with the people they work with closely.

Face-to-face interaction among employees is an essential feature of any workplace. Spatial layouts are known to affect the probability of chance encounters and therefore make people 'available' for interaction that, otherwise no one would have imagined, needed to interact. Face-to-face communication; either scheduled/planned or random ad hoc chance encounters, subsequently results in a number of benefits including tacit knowledge sharing, and higher productivity. Penn et. al. suggests; the perceived "usefulness" of a person is to a measurable extent, derived from the frequency of contacts with others and not just from the individual's personal qualities, status, or job description. 


\subsection{Implications for design and management of the physical workplace to enhance employees' sense of belonging}

Prior to proceeding to the design and management implications of this research, it should be noted that the data for this study was collected in 2003 and the results were analyzed in 2011. For that reason, it is important to highlight that while this gap in time has no relevance to the association established between 'sense of belonging' and workplace physical factors, it does signify the evolution of the physical workplace itself.

For instance, corporate campuses were a common concept in developed countries like North America long before 2003. On the other hand, 'a corporate campus'; at the time, was a concept that was in its nascent stages in developing nations like India and is still slowly making its way to popularity as organizations grasp and evaluate the attributes and benefits (or drawbacks) associated with them. Moreover, workplace concepts like telecommuting and hotel ling (which have had a significant impact on the traditional physical workplace) have been tested and implemented in organizations across developed countries like North America. Whereas, even in current times of tremendous expansion, economic growth and a pressure to compete at a global level, many developing countries have been slow to adapt or fully implement these concepts, To some extent, these variations exist due to the categorical differences in the underlying national and work cultures across different nations and partly due to the lack of infrastructure that can effectively support concepts like telecommuting. 
Nevertheless it is now common to find examples in North America whereby organizations' (irrespective of the nature of their business or size) are shifting their resources away from investing in expensive office space or large corporate campuses to less concentrated decentralized physical set-ups. By so doing, companies not only control the cost of their operations during unfavorable economic cycles but are also increasingly opting for more environmentally sustainable alternatives.

To conclude the discussion above- It is understood that every organization has unique physical requirements and a large scale corporate campus which is expensive to develop and maintain, may not be the desirable or appropriate option for every type of company. Keeping that in mind, this study has design and management implications that do not hold-up specifically in the context of corporate campuses; instead they can also be applied to a variety of physical workplaces irrespective of their location, scale or industry sector.

Firstly, the results of this study imply that the corporate campus is instrumental for enhancing a sense of belonging among employees. For instance, participants in this study strongly acknowledged that the interior and exterior image of Wipro's campus buildings' reflected its corporate culture and values. This in turn, had a significant affect on their sense of belonging with Wipro. However, this type of distinction and branding of facilities and specifically designing the interior of an office building in a way that its inhabitants can identify with it and relate to it with the ideology of their company can be accomplished at a corporate campus or a single building. 
Secondly, in this study participants 'sense of belonging' was significantly affected by their perception of the support provided by the physical factors of their workplace towards their individual-productivity. The important point to note here is that employees consider their physical environment as a component of their productivity. Results suggested that; the better the perception of support by the workplace environment, the greater the sense of belonging that the employees are expected to report. Therefore, decision makers at any organization must be mindful to incorporate the physical features of a workplace that are perceived as productivity enhancers. For instance, if physical features like open-plan layout promote equality, enhance visibility and communication among co-workers and as a result improve employees' productivity then that should be incorporated in the company's goals while planning their physical set-up.

Thirdly, employees' satisfaction with the physical characteristics of their workplace appeared as a crucial component of their sense of belonging. In other words, results indicate that a higher level of satisfaction with the physical environment leads to a greater 'sense of belonging'. As results indicate, employees place more importance on the quality of their immediate surrounding; their own workspace and the quality and appeal of the interior of the building where they work, in comparison to the exterior or overall layout of their workspace. Considering that an employee spends majority of the working hours indoors at their desk, this outcome is easily relatable. At the same time, broader features on the corporate campus, that is, the image, branding, amenities etc, are also found to be significantly associated with employees' 'sense of belonging'. 
In order to enhance employees' satisfaction with their own workspace, organizations who strive to enhance a sense of belonging among its employees must consider the user perspective. One way to achieve this is to make the design process more interactive to increase employee input on which elements of their personal workspace are most satisfying for them. Additionally, doing so will not only make an impact in terms of a greater sense of satisfaction among employees; it will additionally result in the best use of a firms limited resources and promote a sense of responsibility on the employers part to care for their employees. However, the ideal solution for an organization would be to balance their resources between the enhancements to the interiors as well as the overall appeal of the exterior spaces.

Next, employees' familiarity with their organization and its facilities affects their sense of belonging. While employees' sense of belonging is known to increase as a function of their tenure; an organization can take active measures to improve its employees' familiarity to the physical features of the workplace. One such measure can be to situate amenities like cafeterias, gymnasiums, conference rooms, resource centers, medical facilities, R\&D labs etc in a way that they are easily visible and accessible by employees. By so doing, the organization can increase awareness among its employees regarding the existence of these facilities. The more an employee utilizes these supportive facilities, the more they appreciate them in comparison to someone who is unaware of its existence and greater the sense of belonging they can be expected to feel. 
Organizations that employ significant effort and resources to designing unique spaces for its employees must compliment their effort by communicating with their employees regarding the unique features of a space and the thought process that resulted in a specific selection. If employees have greater knowledge of the process that was followed and get a chance to experience the outcome, they have more information to relate to. Communication of this nature can help employees identify better with the culture and values of their organization. 


\section{CHAPTER 6: LIMITATIONS AND FUTURE REASERCH}

\subsection{Study Limitations}

Self-Reported Data: This study relied on self-reported data by employees to a websurvey. For instance, data such as meeting frequency and average travel time to meetings are self-reported by participants and difficult to verify. While they are direct responses from each participant, additional measures such as on-site observations and in-person interviews can compliment the information gathered through the web survey. Direct observations allow a researcher to capture a respondent's verbal and facial expressions when reporting an individual opinion and provide a better sense of whether the reported preferences translate into actual behaviors. Corroborating data from other supplemental sources can provide greater confidence to a researcher with generalizing the results.

Mono-Method: Due to limited resources, this research relied on only one method to collect data; the Wipro Workplace web-survey. The use of a single method makes it difficult to reveal deeper and valid data. The web-survey generated self-reported quantitative data by human subjects. There were no personal interviews or on-site observations conducted in this study. Qualitative data may compliment the qualitative data by providing better insight and understanding of the statistical relationship among variables. Although there was an open ended response section provided in the websurvey, this section was not designed to encourage employees to express their views on 
attributes like identity, attraction and retention, satisfaction and productivity, which are difficult to measure in quantitative terms.

Quantitative Data on Site Characteristics: Limited data regarding the physical characteristics of the subject site was available in this study. Detailed data on physical attributes of the subject site, such as floor layouts; workstation/common area locations, workstation size/density/privacy levels, the quality, condition and extent of the existing buildings and amenities, actual vertical/horizontal distance between two physical points, etc. were not collected. Quantitative data of this nature, in combination with the quantitative and qualitative data collected from employee responses and site observations, is imperative to form and authenticate applicable strategies.

\subsection{Considerations for Future Research}

Future research should consider additional methods to the web-survey, for collecting data. The use of a single method makes it difficult to infer the qualitative aspect of the quantitative responses provided by the survey respondents. The method used to measure productivity should be designed to reveal the relationship between productivity and the physical design of a workplace, for instance, experiments can be conducted in work settings specifically designed to study certain employee behaviors.

Similarly, the self report of travel times to and from meetings or to workplace can be supplemented with measuring the actual physical distance between two points and recording the travel time through observation of employees on site. The study of the 
actual physical layout and architectural plans of a corporate campus can aid the researcher in understanding the factors that impact travel times such as number of staircases between two points, the average wait time for an elevator, the movement pattern of employees in getting from one point to another, and other similar travel patterns. The study of physical features at this level of detail can provide meaningful data to supplement what has been self reported by employees.

More detailed understanding of factors affecting employees; sense of belonging can be developed through further categorization of the participants. For instance, future research can further classify participant data by their building locations or frequency of use of amenities and then assess it for statistical distinctions among their reported sense of belonging.

This is the first study that has examined the construct validity of the IWSP Workplace Survey as an instrument to predict employees' 'sense of belonging'. Therefore, many of the ideas explored in this study are based upon theories suggested in the past. Likewise, this study employs the Exploratory Factor Analysis (EFA) technique whereby the researcher has no priori assumption regarding how the survey items will correlate to each other and on the nature of the factors that will ultimately be revealed. For that reason, as a follow up to the factors derives and loading patterns observed in this study; it is imperative to conduct a Confirmatory Factor Analysis (CFA). A CFA can be useful to determine if the number of factors and the loadings of measured variables on them conform to what is expected on the basis of pre-established results of the EFA. 
A CFA will allow for indicator variables to be selected on the basis of prior results (that of this study) and factor analysis can be used to examine if they load as predicted on the expected number of factors. In future endeavors, the researcher's priori assumption can be that each factor is associated with a specified subset of indicator variables. A minimum requirement of confirmatory factor analysis is that the investigators hypothesize beforehand, the number of factors in the model, but usually also that the researcher presets expectations about which variables will load on which factors. The researcher should seek to determine, for instance, if measures created to represent a latent factors or variable in this study really belong together. 


\section{APPENDIX A \\ IWSP Workplace Survey- Non-HTML Version}

IVP

Cornell University

\section{International Workplace Studies Program Workplace Survey}

Cornell University International Workplace Studies Program (IWSP) is conducting a survey of major corporations, including WIPRO Technologies to better understand the nature of collocation and corporate campuses.

All participation is voluntary. Your replies to the web-based survey are sent to an independent Cornell server and your responses will be kept anonymous and confidential. The survey should take approximately fifteen minutes to complete. We request you to complete the entire survey in one go, before submission, since it is not possible for us to retrieve all the responses if the survey is filled in parts at multiple times. Thank you for participating.

General Note: All meetings referred to in this survey may be defined as ranging from scheduled meetings with many people to short unscheduled conversations with one person. Please note that exchanging pleasantries (e.g., "Hi! How are you doing?) would not qualify as a meeting for this survey.

\begin{tabular}{|c|c|c|c|c|c|}
\hline OWN Building & $\begin{array}{c}0 \\
\text { times/wk. }\end{array}$ & $\begin{array}{c}1-5 \\
\text { times/wk. }\end{array}$ & $\begin{array}{c}6-10 \mathrm{t} \\
\text { times/wk. }\end{array}$ & $\begin{array}{c}11-20 \\
\text { times/wk. }\end{array}$ & $\begin{array}{c}20+ \\
\text { times/wk. }\end{array}$ \\
\hline \multicolumn{6}{|c|}{ A. On my own floor (please check one answer) } \\
\hline \multicolumn{6}{|c|}{ B. On different floors within my own building (please check one answer) } \\
\hline DIFFERENT BUILDING & $\begin{array}{c}0 \\
0 \\
\text { times/wk. }\end{array}$ & $\begin{array}{c}1-5 \\
\text { times/wk. }\end{array}$ & $\begin{array}{c}6-10 \\
\text { times/wk. }\end{array}$ & $\begin{array}{c}11-20 \\
\text { times/wk. }\end{array}$ & $\begin{array}{c}20+ \\
\text { times/wk. }\end{array}$ \\
\hline \multicolumn{6}{|c|}{ C. In a different building (please check all that apply and leave your own building blank): } \\
\hline -Corporate/ A Block & -All Buttons- & & & & \\
\hline \multicolumn{6}{|l|}{-Learning Centre/ B Block } \\
\hline \multicolumn{6}{|l|}{$\begin{array}{l}\text {-Consumer Care and Lighting/ C } \\
\text { Block }\end{array}$} \\
\hline \multicolumn{6}{|l|}{-Hardware and Infotech/ D Block } \\
\hline \multicolumn{6}{|l|}{-Software/ E Block } \\
\hline \multicolumn{6}{|l|}{$\begin{array}{l}\text {-EC1 Software Block 1/Tower } \\
\text { 1/TB } 1\end{array}$} \\
\hline \multicolumn{6}{|l|}{$\begin{array}{l}\text {-EC1 Software Block 2/Tower } \\
\text { 2/TB } 2\end{array}$} \\
\hline \multicolumn{6}{|l|}{$\begin{array}{l}\text {-EC1 Software Block 3/Tower } \\
\text { 3/TB } 3\end{array}$} \\
\hline \multicolumn{6}{|l|}{$\begin{array}{l}\text {-EC1 Software Block 4/Tower } \\
\text { 4/TB } 4\end{array}$} \\
\hline \multicolumn{6}{|l|}{$\begin{array}{l}\text {-EC2 Software Block 1/Tower } \\
\text { 5/TB } 5\end{array}$} \\
\hline \multicolumn{6}{|l|}{$\begin{array}{l}\text {-EC2 Software Block 2/ Tower 6/ } \\
\text { TB } 6\end{array}$} \\
\hline \multicolumn{6}{|l|}{$\begin{array}{l}\text {-EC } 2 \text { Software Block 3/ Tower 7/ } \\
\text { TB } 7\end{array}$} \\
\hline \multicolumn{6}{|l|}{-Dining/Cafeteria } \\
\hline -Guest Block & & & & & \\
\hline
\end{tabular}




\begin{tabular}{|l|l|}
\hline $\begin{array}{l}\text { 2. Please select appropriate } \\
\text { answers for the following: }\end{array}$ & \\
\hline -My Building & List all NAME OF COMPANY Buildings \\
\hline -My Floor & $\begin{array}{l}\text { List all floors up to the maximum floors on } \\
\text { NAME OF COMPANY Buildings }\end{array}$ \\
\hline -My Division / Business Unit & List all NOC Divisions \\
\hline -My Job Level & $\begin{array}{l}\text { List all possible NOC job levels related to } \\
\text { selected Dept. above (refresh) }\end{array}$ \\
\hline
\end{tabular}

\begin{tabular}{|c|c|c|c|}
\hline \multicolumn{4}{|c|}{$\begin{array}{l}\text { 3. Please select the typical FREQUENCY, MEETING TYPE \& AVERAGE TIME for face-to-face meetings of"3 or } \\
\text { more people" (including yourself) with the following groups: }\end{array}$} \\
\hline & & & \\
\hline & Frequency & Meeting Type & $\begin{array}{l}\text { Average Time Spent } \\
\text { on Each Meeting }\end{array}$ \\
\hline A. My Work Group & $\begin{array}{c}\text {-Select From Here- } \\
0 \text { times/week } \\
1-5 \text { times/week } \\
6-10 \text { times/week } \\
11-20 \text { times/week } \\
21+\text { times/week }\end{array}$ & $\begin{array}{l}\text {-Select From } \\
\text { Here- } \\
\text { Majority } \\
\text { Scheduled } \\
\text { Majority } \\
\text { Unscheduled }\end{array}$ & $\begin{array}{l}\text {-Select From Here- } \\
\text { Less than } 15 \mathrm{~min} . \\
16-30 \mathrm{~min} . \\
31-60 \mathrm{~min} . \\
61-90 \mathrm{~min} \\
91-120 \mathrm{~min} . \\
120+\mathrm{min} .\end{array}$ \\
\hline B. My Division / Business Unit & -Repeat- & -Repeat- & -Repeat- \\
\hline C. Different Division / Business Unit & -Repeat- & -Repeat- & -Repeat- \\
\hline
\end{tabular}

4. Please select the typical FREQUENCY, MEETING TYPE and AVERAGE TIME for face-to face meetings with "one other person" with the following groups:

\begin{tabular}{|c|c|c|c|}
\hline 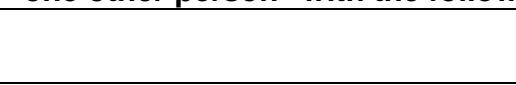 & Frequency & Meeting Type & $\begin{array}{c}\text { Average Time Spent on } \\
\text { Each Meeting }\end{array}$ \\
\hline A. My Work Group & $\begin{array}{c}\text {-Select From Here- } \\
0 \text { times/week } \\
1-5 \text { times/week } \\
6-10 \text { times/week } \\
11-20 \text { times/week } \\
21+\text { times/week }\end{array}$ & $\begin{array}{l}\text {-Select From } \\
\text { Here- } \\
\text { Majority } \\
\text { Scheduled } \\
\text { Majority } \\
\text { Unscheduled } \\
\end{array}$ & $\begin{array}{l}\text {-Select From Here- } \\
\text { Less than } 15 \mathrm{~min} . \\
16-30 \mathrm{~min} . \\
31-60 \mathrm{~min} . \\
61-90 \mathrm{~min} \\
91-120 \mathrm{~min} . \\
120+\mathrm{min} .\end{array}$ \\
\hline B. My Division / Business Unit & -Repeat- & -Repeat- & -Repeat- \\
\hline C. Different Division / Business Unit & -Repeat- & -Repeat- & -Repeat- \\
\hline
\end{tabular}

\section{How far in advance are most "scheduled" meetings planned?}

\begin{tabular}{|c|c|c|c|c|c|}
\hline$<2$ Hour & Half Day & 1 Day & 2-3 Days & $3-5$ Days & $>1$ Week \\
\hline -All Buttons- & & & & & \\
\hline
\end{tabular}

6. How important is it to be collocated in the same building with the following groups:

\begin{tabular}{|l|c|}
\hline \multicolumn{2}{|l|}{ 6. How important is it to be collocated in the same building with the following groups: } \\
\hline & Level of Importance \\
\hline A. My Work Group & $\begin{array}{c}\text { Select From Here- } \\
\text { Important } \\
\text { Neutral } \\
\text { Not Important }\end{array}$ \\
\hline B. My Division/Business Unit & -Repeat- \\
\hline C. Different Diffusion/Business Unit & -Repeat- \\
\hline
\end{tabular}




\begin{tabular}{|c|c|}
\hline $\begin{array}{l}\text { 7. In a typical week, } \\
\text { WIPRO's sites (WITH } \\
\text { "other than your owr }\end{array}$ & $\begin{array}{l}\text { m meetings } \\
\text { ampus and } E\end{array}$ \\
\hline Less than 15 minutes & -All Buttons- \\
\hline $15-30$ minutes & \\
\hline $31-60$ minutes & \\
\hline $61-90$ minutes & \\
\hline $91-120$ minutes & \\
\hline $120+$ minutes & \\
\hline
\end{tabular}

\begin{tabular}{|l|c|}
\hline $\begin{array}{l}\text { 8. Please scroll down and select appropriate responses to the } \\
\text { questions below: }\end{array}$ \\
\hline \\
$\begin{array}{l}\text { A. How many times in a week do you WALK to meetings in other } \\
\text { buildings with someone else from (versus walking alone)? }\end{array}$ \\
\hline & - Select From Here- \\
& 0 times/week \\
B. On the way, do you usually talk about business-related issues? & $6-10$ times/week \\
& $11-20$ times/week \\
& $21+$ times/week \\
\hline & - Select From Here- \\
C. In a typical work day, how often do you need to communicate & Almost always \\
with your co-workers electronically (e-mail, teleconference, intranet, & Almost never \\
etc)? & - Select From Here- \\
& 0 times/week \\
\hline
\end{tabular}

\begin{tabular}{|l|c|}
\hline 9. Please indicate the extent to which you agree with each statement: & \\
\hline $\begin{array}{l}\text { 1. I feel that the layout of the interior of the buildings where I work at WIPRO's Campus } \\
\text { enables me to work productively. }\end{array}$ & $\begin{array}{c}\text {-Select From Here- } \\
\text { - Strongly Agree } \\
\text { 2- Agree } \\
3 \text { - Neutral } \\
\text { - Disagree } \\
\text { - Strongly Disagree }\end{array}$ \\
\hline $\begin{array}{l}\text { 2. I feel that the interior appearance of the buildings where I work at WIPRO'S Campus } \\
\text { enables me to work productively. }\end{array}$ & -Repeat- \\
\hline $\begin{array}{l}\text { 3. I feel that the overall layout of the buildings on WIPRO'S Campus enables me to work } \\
\text { productively. }\end{array}$ & -Repeat- \\
\hline $\begin{array}{l}\text { 4. I care more about the interior design and layout of the buildings than the design and } \\
\text { layout of the campus as a whole. }\end{array}$ & -Repeat- \\
\hline $\begin{array}{l}\text { 5. The design of my individual workspace is more important to me than the design and } \\
\text { layout of the campus as a whole. }\end{array}$ & -Repeat- \\
\hline $\begin{array}{l}\text { 6. Working on a corporate campus (e.g., multiple buildings within walking distance of each } \\
\text { other) is important to me. }\end{array}$ & -Repeat- \\
\hline 7. I feel a strong sense of belonging and identity with WIPRO. & -Repeat- \\
\hline $\begin{array}{l}\text { 8. I feel that the exterior and interior layout of WIPRO'S Campus buildings reflects } \\
\text { WIPRO's culture and values. }\end{array}$ & -Repeat- \\
\hline $\begin{array}{l}\text { 9. I feel that the exterior and interior appearance of WIPRO'S Campus buildings reflects } \\
\text { WIPRO's culture and values. }\end{array}$ & -Repeat- \\
\hline $\begin{array}{l}\text { 10. I feel that there are adequate places in the building where I work, to get together } \\
\text { informally with my colleagues. }\end{array}$ & -Repeat- \\
\hline $\begin{array}{l}\text { 11. I feel that I frequently run into colleagues and have short conversations when I move } \\
\text { around my building. }\end{array}$ & -Repeat- \\
\hline
\end{tabular}




\section{Please select the appropriate numeric figures for the two questions below}

A. How many times have you been relocated on WIPRO's Sajarpur or Electronic City sites?

B. How many buildings have you worked in on WIPRO's Campus?
-Select From Here1-Never-

2-At least Once3-Two to Three Times4-Three to Four Times5-More than Five Times-

-Select From Here1-1 Building Only-

2-Different Buildings-

3-Three Different Buildings-

4-Four Different Buildings-

5-Five Different Buildings-

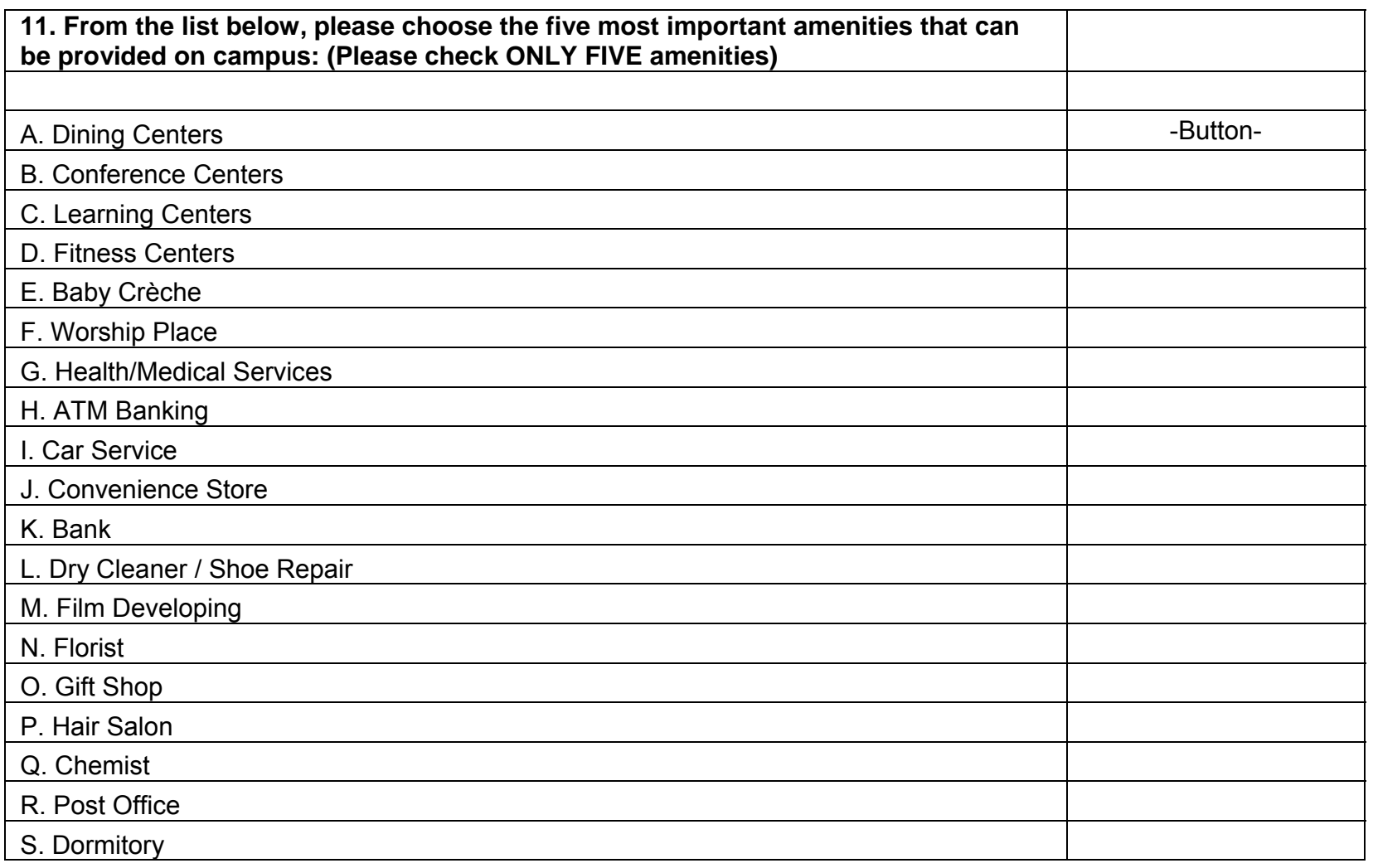

\section{Please indicate your level of agreement for the following questions:}

A. With today's computers and telecommunications technology, collocation is much less important than it once was.

B. The extent and quality of Web-based internal information services (i.e. Intranet) at WIPRO are outstanding.

C. The extent and quality of WIPRO's telecommunications systems and services (mobile computing and telephony, email, etc.) are outstanding.

-Select From Here-

1- Strongly Agree

2- Agree

3- Neutral

4- Disagree

5- Strongly Disagree

-Repeat-

-Repeat- 


\begin{tabular}{|l|c|}
\hline 13. Please indicate the appropriate answer to the following questions: & \\
A. Do you have an enclosed office or an open workspace? & $\begin{array}{c}\text { Select From Here- } \\
\text { Enclosed Office } \\
\text { Open Workspace }\end{array}$ \\
$\begin{array}{lc}\text { Welect From Here- } \\
\text { Satisfied } \\
\text { B. How satisfied are you with the enclosed office or the open workspace you use? } & \text { Neutral } \\
\text { Dissatisfied }\end{array}$ \\
\hline C. How satisfied are you with the WIPRO's Campus, where you work? & -Repeat- \\
\hline
\end{tabular}

\begin{tabular}{|c|c|}
\hline 14. Please indicate the appropriate answer to the following questions: & \\
\hline A. How much time do you spend in a day to commute to and from work? & $\begin{array}{l}\text {-Select From Here- } \\
\text { Less than } 30 \text { minutes } \\
\text { About } 60 \text { minutes } \\
\text { About } 90 \text { minutes } \\
\text { About } 120 \text { minutes } \\
\text { Greater than } 150 \\
\text { minutes }\end{array}$ \\
\hline B. Depending on the nature of your work, would you rather work from home/ telecommute? & $\begin{array}{c}\text {-Select From Here- } \\
\text { Yes } \\
\text { Neutral } \\
\text { No }\end{array}$ \\
\hline $\begin{array}{l}\text { C. Do you feel that telecommuting would help you save time from your work day, thus help } \\
\text { you be more productive? }\end{array}$ & -Repeat- \\
\hline
\end{tabular}

\begin{tabular}{|c|c|c|}
\hline $\begin{array}{l}\text { 15. Indicate the extent to which each of the following factors contributed } \\
\text { positively to your decision to "take a job" and then "to continue working" } \\
\text { with Wipro: }\end{array}$ & $\begin{array}{l}\text { "take a job" } \\
\text { with Wipro }\end{array}$ & $\begin{array}{l}\text { " continue } \\
\text { working" } \\
\text { with Wipro }\end{array}$ \\
\hline A. Own personal office or workstation & $\begin{array}{c}\text {-Rate From } \\
\text { Here- } \\
1 \\
2 \\
3 \\
4 \\
5 \\
\text { NA }\end{array}$ & \\
\hline \multicolumn{3}{|l|}{ B. Look and feel of interiors of buildings } \\
\hline \multicolumn{3}{|l|}{ C. Look and feel of exteriors of buildings } \\
\hline \multicolumn{3}{|l|}{ D. Having a corporate campus } \\
\hline \multicolumn{3}{|l|}{ E. Campus amenities (e.g., dining, fitness, etc.) } \\
\hline \multicolumn{3}{|l|}{ F. Location of the campus (within the Bangalore City area) } \\
\hline \multicolumn{3}{|l|}{ G. Location of the campus (this part of the country) } \\
\hline \multicolumn{3}{|l|}{ H. Security design and services. } \\
\hline \multicolumn{3}{|l|}{ J. People with whom you work. } \\
\hline \multicolumn{3}{|l|}{ K. Opportunities for face-to-face communication with people. } \\
\hline \multicolumn{3}{|l|}{$\begin{array}{l}\text { L. Opportunities for face-to-face communication with people outside your own } \\
\text { group and/or department. }\end{array}$} \\
\hline \multicolumn{3}{|l|}{ M. Pride in working for a major corporate company. } \\
\hline N. corporate culture \& values. & & \\
\hline
\end{tabular}




\section{Select the FIVE most important physical factors contributing to your satisfaction working at Headquarters Campus, and rank them in order of their importance to you:}

\begin{tabular}{|l|c|}
\hline & -Rank From Here- \\
A. Own personal office or workstation & 2 \\
& 3 \\
\hline B. Flexible / Mobile workspace & 4 \\
\hline C. Look and feel of interiors of buildings & - Repeat- \\
\hline D. Look and feel of exteriors of buildings & - Repeat- \\
\hline E. Having a corporate campus & - Repeat- \\
\hline F. Campus amenities (e.g., dining, fitness, etc.) & - Repeat- \\
\hline G. Location of the campus (in this part of Bangalore) & -Repeat- \\
\hline H. Location of the campus (this part of the country) & - Repeat- \\
\hline J. Security design and services & - Repeat- \\
\hline K. Landscaping on campus & - Repeat- \\
\hline
\end{tabular}

\begin{tabular}{|c|c|c|c|c|c|}
\hline \multicolumn{6}{|l|}{ BACKGROUND INFORMATION } \\
\hline \multicolumn{6}{|c|}{ (All information collected is kept confidential and the data is used exclusively in the aggregate, not individually) } \\
\hline \multirow[t]{2}{*}{ a. Gender } & Male & Female & & & \\
\hline & -Button- & -Button- & & & \\
\hline \multirow[t]{2}{*}{ b. My Age } & Less than 25 & $26-35$ & $36-45$ & $46-55$ & $56+$ \\
\hline & -Button- & -Button- & -Button- & -Button- & -Button- \\
\hline \multirow[t]{2}{*}{$\begin{array}{l}\text { c. Manager or Individual } \\
\text { Contributor }\end{array}$} & Manager & $\begin{array}{l}\text { Individual } \\
\text { Contributor }\end{array}$ & & & \\
\hline & -Button- & -Button- & & & \\
\hline \multirow[t]{2}{*}{ d. Job Level. } & $\begin{array}{l}\text { Individual } \\
\text { Contributor }\end{array}$ & Supervisor & Manager & $\begin{array}{c}\text { Tech. } \\
\text { Manager/ } \\
\text { Bus. Head }\end{array}$ & $\begin{array}{c}\text { Vice } \\
\text { President }\end{array}$ \\
\hline & -Button- & -Button- & -Button- & -Button- & -Button- \\
\hline \multirow[t]{2}{*}{ e. Length of time working for } & $\begin{array}{c}\text { Less than } 1 \\
\text { year }\end{array}$ & $1-3$ years & $4-10$ years & $11+$ years & \\
\hline & -Button- & -Button- & -Button- & -Button- & \\
\hline \multirow[t]{2}{*}{$\begin{array}{l}\text { f. Life Stage (please mark all } \\
\text { that apply): }\end{array}$} & Single & $\begin{array}{l}\text { Married w/o } \\
\text { Children }\end{array}$ & $\begin{array}{c}\text { Married or } \\
\text { Single w/ } \\
\text { Children } \\
\text { under } 5 \\
\text { years }\end{array}$ & $\begin{array}{c}\text { Married or } \\
\text { Single w/ } \\
\text { Children 6- } \\
12 \text { years }\end{array}$ & $\begin{array}{c}\text { Married } \\
\text { or Single } \\
\text { w/ } \\
\text { Children } \\
13+ \\
\text { years }\end{array}$ \\
\hline & -Button- & -Button- & -Button- & -Button- & -Button- \\
\hline $\begin{array}{l}\text { Please share any additional } \\
\text { comments you might have: }\end{array}$ & & & & & \\
\hline
\end{tabular}

\section{Thank You.}

\section{APPENDIX B}


SPSS SYNTAX

Factor Analysis

Notes

\begin{tabular}{|c|c|c|}
\hline \multirow[t]{6}{*}{ Input } & Data & C:IUsers|ruchilDesktopISecond.sav \\
\hline & Active Dataset & DataSet1 \\
\hline & Filter & <none> \\
\hline & Weight & <none> \\
\hline & Split File & <none> \\
\hline & $\begin{array}{l}\text { N of Rows in } \\
\text { Working Data File }\end{array}$ & 267 \\
\hline \multirow{3}{*}{$\begin{array}{l}\text { Missing } \\
\text { Value } \\
\text { Handling }\end{array}$} & $\begin{array}{l}\text { Definition of } \\
\text { Missing }\end{array}$ & $\begin{array}{l}\text { MISSING=EXCLUDE: User-defined missing values are treated as } \\
\text { missing. }\end{array}$ \\
\hline & Cases Used & $\begin{array}{l}\text { LISTWISE: Statistics are based on cases with no missing values for any } \\
\text { variable used. }\end{array}$ \\
\hline & Syntax & $\begin{array}{l}\text { FACTOR } \\
\text { NARIABLES q09a q09I q09b q09d q09m q09e q09c q09x q09y q10a } \\
\text { q10b q17e q13a q09i q06a } \\
\text { /MISSING LISTWISE } \\
\text { /ANALYSIS q09a q09I q09b q09d q09m q09e q09c q09x q09y q10a } \\
\text { q10b q17e q13a q09i q06a } \\
\text { /PRINT INITIAL CORRELATION KMO EXTRACTION ROTATION } \\
\text { FSCORE } \\
\text { /FORMAT SORT BLANK(.40) } \\
\text { /CRITERIA MINEIGEN(1) ITERATE(25) } \\
\text { /EXTRACTION PC } \\
\text { /CRITERIA ITERATE(25) } \\
\text { /ROTATION PROMAX(4) } \\
\text { /SAVE REG(ALL) } \\
\text { /METHOD=CORRELATION. }\end{array}$ \\
\hline \multirow{5}{*}{$\begin{array}{l}\text { Variables } \\
\text { Created }\end{array}$} & FAC1_1 & Component score 1 \\
\hline & FAC2_1 & Component score 2 \\
\hline & FAC3_1 & Component score 3 \\
\hline & FAC4_1 & Component score 4 \\
\hline & FAC5_1 & Component score 5 \\
\hline
\end{tabular}


Total Variance Explained

\begin{tabular}{|c|c|c|c|c|c|}
\hline \multirow[b]{2}{*}{ Component } & \multicolumn{3}{|c|}{ Initial Eigenvalues } & \multicolumn{2}{|c|}{$\begin{array}{l}\text { Extraction Sums of } \\
\text { Squared Loadings }\end{array}$} \\
\hline & Total & $\begin{array}{c}\% \text { of } \\
\text { Variance }\end{array}$ & Cumulative \% & Total & $\%$ of Variance \\
\hline 1 & 3.101 & 20.677 & 20.677 & 3.101 & 20.677 \\
\hline 2 & 1.901 & 12.673 & 33.349 & 1.901 & 12.673 \\
\hline 3 & 1.443 & 9.618 & 42.967 & 1.443 & 9.618 \\
\hline 4 & 1.252 & 8.344 & 51.311 & 1.252 & 8.344 \\
\hline 5 & 1.180 & 7.866 & 59.177 & 1.180 & 7.866 \\
\hline 6 & .958 & 6.389 & 65.566 & & \\
\hline 7 & .913 & 6.085 & 71.651 & & \\
\hline 8 & .776 & 5.170 & 76.821 & & \\
\hline 9 & .728 & 4.855 & 81.677 & & \\
\hline 10 & .639 & 4.258 & 85.935 & & \\
\hline 11 & .574 & 3.825 & 89.760 & & \\
\hline 12 & .536 & 3.572 & 93.333 & & \\
\hline 13 & .440 & 2.933 & 96.266 & & \\
\hline 14 & .366 & 2.437 & 98.703 & & \\
\hline 15 & .195 & 1.297 & 100.000 & & \\
\hline
\end{tabular}

Extraction Method: Principal Component Analysis. 


\section{Correlations}

Notes

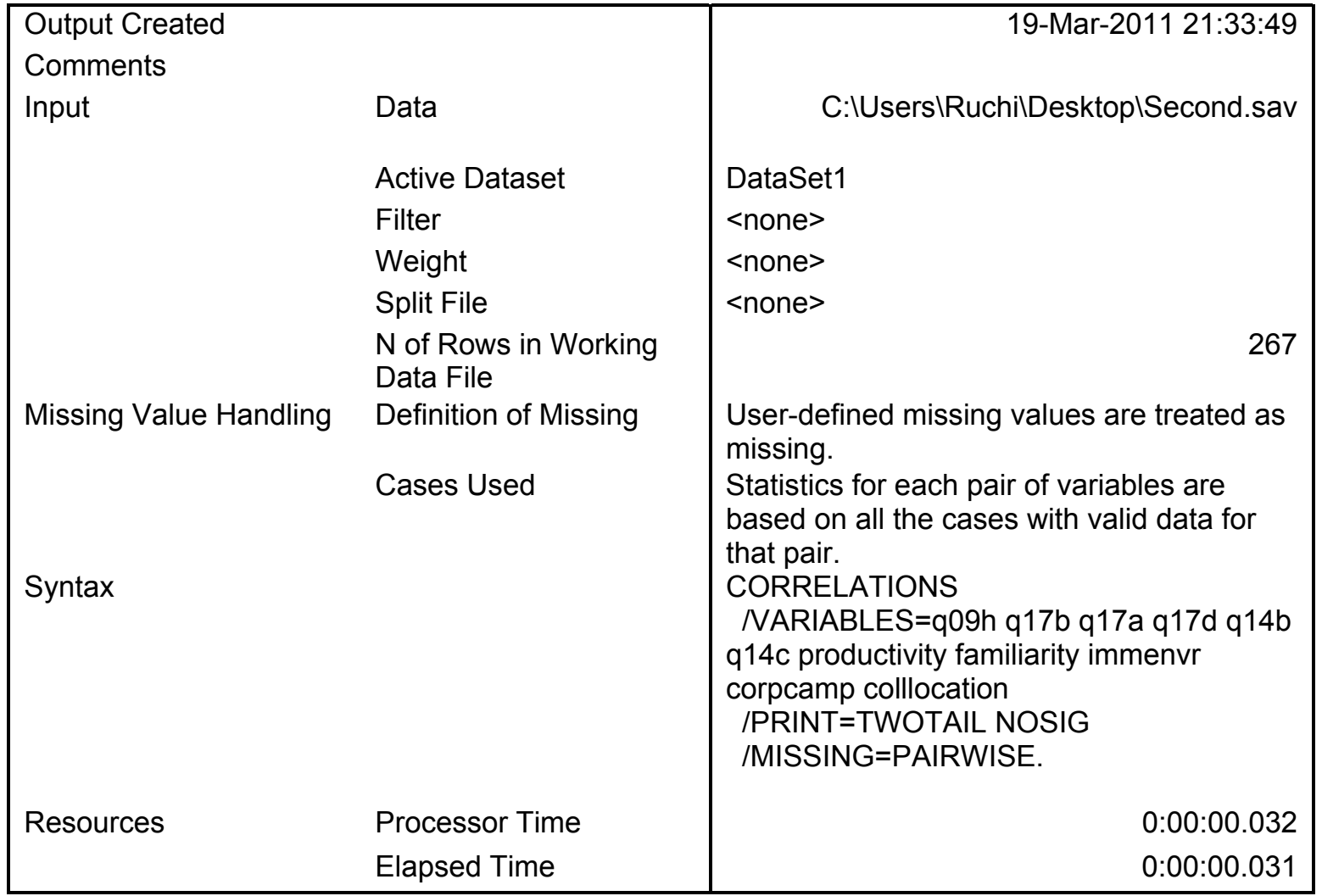




\section{Regression}

Notes

\begin{tabular}{|c|c|c|}
\hline \multicolumn{2}{|c|}{$\begin{array}{l}\text { Output Created } \\
\text { Comments }\end{array}$} & $\begin{array}{l}\text { 02-Apr-2011 11:18:55 } \\
\text { C.U Users\RuchilDesktonlSecond sav }\end{array}$ \\
\hline & $\begin{array}{l}\text { Data } \\
\text { Active Dataset } \\
\text { Filter } \\
\text { Weight } \\
\text { Split File } \\
\text { N of Rows in } \\
\text { Working Data File }\end{array}$ & $\begin{array}{l}\text { C:IUsers|RuchilDesktoplSecond.sav } \\
\text { DataSet1 } \\
\text { <none> } \\
\text { <none> } \\
\text { <none> } \\
\end{array}$ \\
\hline $\begin{array}{l}\text { Missing } \\
\text { Value } \\
\text { Handling }\end{array}$ & $\begin{array}{l}\text { Definition of } \\
\text { Missing } \\
\text { Cases Used }\end{array}$ & $\begin{array}{l}\text { User-defined missing values are treated as } \\
\text { missing. } \\
\text { Statistics are based on cases with no } \\
\text { missing values for any variable used. }\end{array}$ \\
\hline Syntax & & $\begin{array}{l}\text { REGRESSION } \\
\text { /DESCRIPTIVES MEAN STDDEV CORR } \\
\text { SIG N } \\
\text { /MISSING LISTWISE } \\
\text { /STATISTICS COEFF OUTS R ANOVA } \\
\text { CHANGE } \\
\text { /CRITERIA=PIN(.05) POUT(.10) } \\
\text { /NOORIGIN } \\
\text { /DEPENDENT q09h } \\
\text { /METHOD=ENTER productivity familiarity } \\
\text { immenvr corpcamp } \\
\text { /RESIDUALS DURBIN. }\end{array}$ \\
\hline Resources & $\begin{array}{l}\text { Processor Time } \\
\text { Elapsed Time } \\
\text { Memory Required } \\
\text { Additional Memory } \\
\text { Required for } \\
\text { Residual Plots }\end{array}$ & $\begin{array}{l}9504 \text { bytes } \\
0 \text { bytes }\end{array}$ \\
\hline
\end{tabular}




\section{Descriptive Statistics}

\begin{tabular}{|l|r|r|r|}
\hline & \multicolumn{1}{|c|}{ Mean } & Std. Deviation & $\mathrm{N}$ \\
\hline feel strng sns of blngng & 1.73 & 1.002 & 232 \\
w/WIPRO & & & 232 \\
age & 1.84 & .464 & 232 \\
gender & 1.12 & .321 & 232 \\
job lever & 1.68 & .931 & 232 \\
how stsfd w/office or & 1.84 & .825 & 232 \\
workspace & 1.48 & .702 & 232 \\
how stsfd w/WIPRO & & & 232 \\
cmps whr you wrk & -.0017283 & 1.00513382 & 232 \\
REGR factor score 1 & & & 232 \\
for analysis 1 & .0088651 & 1.00242906 & 232 \\
REGR factor score 2 & .0012661 & .99875197 & \\
for analysis 1 & & & \\
REGR factor score 3 & .0015452 & 1.00213493 & \\
for analysis 1 & & & \\
REGR factor score 4 & -.0028069 & 1.00174008 & \\
for analysis 1 & & & \\
REGR factor score 5 & & & \\
for analysis 1 & & & \\
\hline
\end{tabular}

\section{Regression Models}

Variables Entered/Removed $^{\mathbf{b}}$

\begin{tabular}{|c|c|c|c|}
\hline Model & Variables Entered & $\begin{array}{l}\text { Variables } \\
\text { Removed }\end{array}$ & Method \\
\hline 1 & job lever, gender, age ${ }^{a}$ & & Enter \\
\hline 2 & $\begin{array}{l}\text { how stsfd w/WIPRO cmps whr you } \\
\text { wrk, how stsfd w/office or } \\
\text { workspace }^{\text {a }}\end{array}$ & & Enter \\
\hline 3 & REGR factor score 1 for analysis $1^{a}$ & & Enter \\
\hline 4 & REGR factor score 2 for analysis $1^{a}$ & & Enter \\
\hline 5 & REGR factor score 3 for analysis $1^{a}$ & & Enter \\
\hline 6 & REGR factor score 4 for analysis $1^{a}$ & & Enter \\
\hline 7 & REGR factor score 5 for analysis $1^{a}$ & & Enter \\
\hline
\end{tabular}

a. All requested variables entered.

b. Dependent Variable: feel strng sns of blngng w/WIPRO 


\section{Regression: Reduced Model with Significant Predictors Only}

\begin{tabular}{|l|l|l|l|}
\hline \multicolumn{5}{|c|}{ Variables Entered/Removed $^{\text {b }}$} \\
\hline Model & Variables Entered & $\begin{array}{l}\text { Variables } \\
\text { Removed }\end{array}$ & Method \\
\hline 1 & REGR factor score & & Enter \\
& 4 for analysis 1, & & \\
& REGR factor score & & \\
& 2 for analysis 1, \\
& REGR factor score & & \\
& 3 for analysis 1, & & \\
& REGR factor score & & \\
& 1 for analysis 1 & & \\
& & & \\
& & & \\
& & & \\
\end{tabular}

a. All requested variables entered.

b. Dependent Variable: feel strng sns of blngng w/WIPRO 


\section{APPENDIX C}

\section{Campus Typology defined by IWSP}

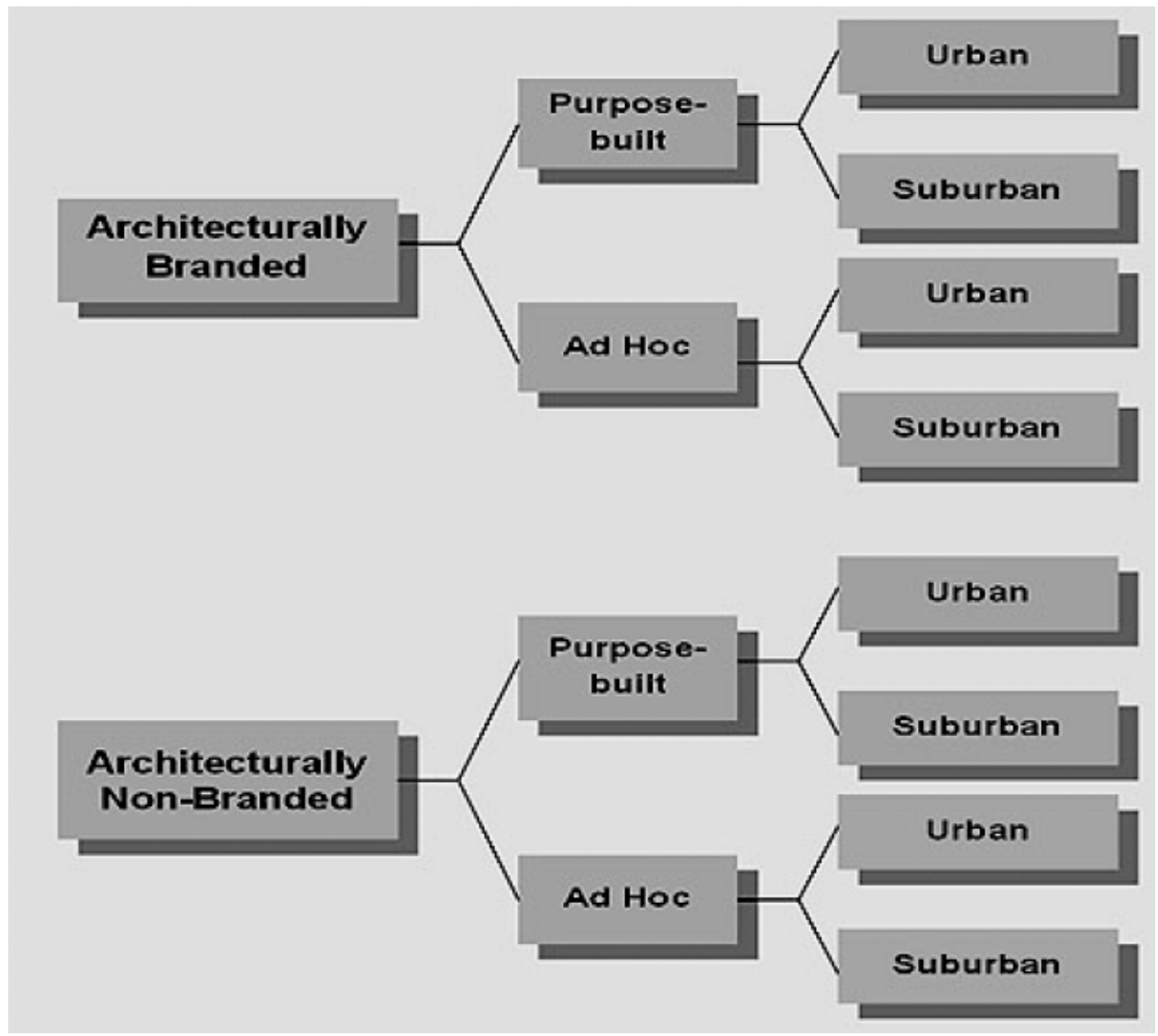

The IWSP corporate campus typology breaks the corporate campus into two major categories: Architecturally Branded and Non-Architecturally Branded. An Architecturally Branded corporate campus can be defined as a group of buildings that are collocated and are consistent in terms of architectural look and feel. Whereas, a Non-Architecturally Branded corporate campus is defined as a group of buildings that may be collocated but do not necessarily share a common architectural theme or style.

Corporate campuses can be further categorized into two sub groups: Purpose Built and Ad-hoc corporate campuses. The purpose built campus is deliberately designed as a corporate campus from the beginning, and typically for a specific company (at least initially). The Ad hoc campus acquires buildings within walking distance of each other one by one, as they become available, without regard for their architectural style or form.

The above sub groups can also be separated by the geographical locations: Urban and Suburban campuses. The Urban Campus is one located in the central business district (CBD) or in the city as compared to the Suburban Campus which is located in a suburban setting, outside a downtown or the urban areas of a city. 


\section{APPENDIX D}

\section{Copy of E-mail Correspondence regarding Workplace study sent to all Employees working at Wipro's Sarjapur and Electronic City Campus}

From: Group Announcement

Sent: Tuesday, July 01, 2003 2:26 PM

To: all-ec; all-sp

Subject: Cornell International Workplace Studies Survey

Dear Wiproites:

Wipro Technologies has the opportunity to participate in a study of corporate campus environments being conducted by the Cornell University International Workplace Studies Program (IWSP), New York.

We ask that you support our participation by completing a 15-minute, online workplace survey. In exchange, Wipro will benefit by receiving the Program's study results which in turn could be used to benefit employees and the company.

This benchmark information, in addition to the summary of Wipro's specific responses, will provide valuable input in our efforts to improve the efficiency of the Wipro's Bangalore Campus and the productivity of the associates who work here.

Responses will be anonymous and confidential and will be sent directly to an= independent Cornell server. To get started, click

http://www.sri.cornell.edu/wiprotech/survey.cfm

Thank you for your consideration and participation.

Cornell IWSP Team 


\section{REFERENCES}

"Wipro". Hoovers. http://www.hoovers.com/company/Wipro_Limited/jrhtif-1-1njea5.html.

Albert, S. and Whetten, D.A. (1985), "Organizational identity”, Research in organizational behavior, Vol. 7, pp. 263-295.

Albert, S. Ashforth, B.E. and Dutton, J.E. (2000) "Organizational identity and identification: Charting new waters and building new bridges", The Academy of Management Review, Vol. 25 Iss. 1, pp. 13-18.

Allen, N.J., \& Meyer, J.P. (1990). The measurement and antecedents of affective, continuance, and normative commitment to the organization. Journal of Occupational Psychology, 53, 337-348.

Allen, T. J. (1977) Managing the flow of technology. Cambridge, MA: MIT Press.

Annette van den Bosch - Corporate visual identity management: Practices, impact and assessment (Diss. Universiteit Twente, 28 oktober 2005). In samenwerking met dr. W.J.L. Elving (UvA), prof.dr. P.J.M.C. Schellens (UT) en prof.dr. E.R. Seydel (UT).

Ashforth, B. E., \& Mael, F. (1989). Social identity and the organization. Academy of Management Review, 14, 20-39.

Ashforth, B.E. and Mael, F.A. (1996) "Organizational identity and strategy as a context for the individual", Advances in Strategic Management, Vol 13, pp. 17-62.

Ashforth, B.E., and F.A. Mael (1996). Organizational identity and strategy as a context for the individual. Advances in Strategic Management, 13, 19-64.

Bartels, J., Douwes, R., de Jong, M., \& Pruyn, A. (2006). Organizational identification during a merger: Determinants of employees' expected identification with the new organization. British Journal of Management, 17, 49-67.

Bartels, J., Peters, O., de Jong, M., Pruyn, A., \& van der Molen, M. (2010). Horizontal and vertical communication as determinants of professional and organizational identification. Personnel Review, 39, 210-226.

Bartlett, M. S. (1950). British Journal of Statistical Psychology. Volume 3 Issue 2 pp 77-85. June 1950.

Becker, F., Sims, W., and Schoss, J. (2003) Interaction, Identity and Collocation: What Value Is a corporate campus?

Bergami, M., and R.P. Bagozzi (2000). Self-categorization, affective commitment and group self-esteem as distinct aspects of social identity in the organization. British Journal of Social Psychology, 39, 555-577.

Box, W.R., Odom, R.Y. \& Dunn, M.G. (1991). Organizational values and value congruency and their impact on satisfaction, commitment, and cohesion: An empirical examination within the public sector. Public' Personnel Management, 20: 195-205.

Child, D. (1990). The essentials of factor analysis, second edition. London: Cassel Educational Limited.

Downey, D. Hellriegel, and J. Slocum, "Congruence Between Individual Needs, Organizational Climate, Job Satisfaction and Performance," Academy of Management Journal, 1975, 18, 149-155.

Dutton, J.E., Dukerich, J.M. and Harquail, C.V. (1994) Organizational images and member identification. Administrative Science Quarterly, 39, 239-263. 
Dziuban, Charles D.; Shirkey, Edwin C. (1974). When is a correlation matrix appropriate for factor analysis? Some decision rules. Psychological Bulletin, Vol 81(6), Jun 1974, 358-361.

Hall, D.T., and B. Schneider (1972). Correlates of Organizational Identification as a function of career pattern an organizational type. Administrative ScienceQuarterly, 17, 340-350.

Hall, D.T., B. Schneider, and H.T. Nygren (1970). Personal Factors in Organizational Identification. Administrative Science Quarterly, 15, 176-190.

Haresign, D. T. (1999) Is a corporate campus Right for Your Business? Site Selection, 1118-1119.

http://www.rediff.com/business/slide-show/slide-show-1-tech-indias-it-based-services-providersboom/20110512.htm

J.S. Brown and P. Duguid, "Organizational Learning and Communities-of-Practice: Toward a Unified View of Working, Learning, and Innovation," Organization Science, Vol. 2, No. 1, 1991, pp. 40-57.

Jette DU, Portney LG (2003). Construct validation of a model for professional behavior in physical therapist students. Physical Therapy: Journal of American Physical Therapy Association. May 2003:83: 432-443.

Kaiser, H.F. (1970). A second generation little jiffy. Psychometrika, 35, 401-416.

Kaiser, H.F. (1974). An index of factorial simplicity. Psychometrika, 39, 31-36.

Kraut, R. E., Egido, C., and Galegher, J. (1990) Patterns of contact and communication in scientific research collaboration. In Galegher, J., Kraut R. E., and Egido, C. Intellectual teamwork: Social foundations of cooperative work. Lawrence Erlbaum Associates: Hillsdale, New Jersey, 149-171.

Kraut, R. E., Fish, R., Root, R., \& Chalfonte, B. (1990). Informal communication in organizations: Form, function, and technology. In S. Oskamp \& S. Spacapan (Eds.), Human reactions to technology: Claremont symposium on applied social psychology (pp. 145-199). Beverly Hills, CA: Sage Publications.

Kraut, R.E., S.R. Fussell, S.E.Brennan, J. Seigel. 2002. Understanding Effects of Proximity on Collaboration: Implications for Technologies to support remote collaborative work. P.J.Hinds, S. Kiesler, eds. Distributed Work. MIT Press, Cambridge, MA, 137-162.

Mael, F.A. and B.E. Ashforth (1992). Alumni and their alma mater: A partial test of the reformulated model of organizational identification. Journal of Organizational Behavior, 13, 103-123.

March, J.G., and H.A. Simon (1958). Organizations. New York: Wiley.

Mark Seiley September 18, 2005 The Sunday Times:

http://www.timesonline.co.uk/tol/news/uk/scotland/article567258.ece

Monge, P.R., Rothman, L.W., Eisenberg, E.M., Miller, K.I., \& Kirste, K.K. (1985). The dynamics of organizational proximity. Management Science, 31, 9, 1129-1141.

Mowday, R.T., Porter, L.W., \& Steers, R.M. (1982). Organizational Linkages: The Psychology of Commitment, Absenteeism, and Turnover. San Diego, CA: Academic Press.

O'Reilly, C., \& Chatman, J. (1986). Organizational commitment and psychological attachment: The effects of compliance, identification, and internalization on prosocial behavior. Journal of Applied Psychology, 71, 492-499.

O'Reilly, C., J. Chatman, and D. Caldwell (1991) People and organizational culture: A profile comparison approach to assessing person-organization fit. Academy of Management Journal, 34, 487-516. 
Penn A, Desyllas J, Vaughan L, 1999, "The space of innovation: interaction and communication in the work environment" Environment and Planning B: Planning and Design 26(2) 193 - 218.

Peponis, J., Zimring, C., \& Choi, Y. K. (1990). "Finding the building in wayfinding," Environment \& Behavior, 22(5), 555-590.

Pietkiewicz T., Chin, M. "Technology, Teamwork and. Collaboration: Now and the Future." Illuminations, a Journal of Organizational Psychology (APS) September 2008.

Qrtr_Results,Dec2010."WIPRO_Qtr_result_dec_2010".www.wipro.com.

http://www.wipro.com/corporate/investors/q4_1011_pdf/IFRS_GAAP_Press_Release_Q4_FY10-11.pdf. Retrieved 21 January 2011.

Rogers, E. M., \& Agarwala-Rogers, R. (1976). Communication in organizations, pp.102.

Smidts, A., A.T.H. Pruyn, and C.B.M. van Riel (2001). The impact of employee communication and perceived external prestige on organizational identification. Academy of Management journal, 44, 10511062.

Thea Turner, Pernilla Qvarfordt, Jacob T. Biehl, Gene Golovchinsky, Maribeth Back: Exploring the workplace communication ecology. 2009. Maribeth Back FX Palo Alto Laboratory.

Van den Bosch, A.L.M., De Jong, M.D.T., \& Elving, W.J.L., (2005). How corporate visual identity supports reputation. Corporate Communications: An International Journal, 10 (2), pp. 108-116.

Whetten, D.A (2006) "Albert and Whetten Revised. Strengthening the Concept of Organizational Identity", Journal of Management Inquiry, Vol. 15 No.3, pp. 219-234.

Wiesenfeld, B. M., Raghuram, S., \& Garud, R. (1999). Communication patterns as determinants of organizational identification in a virtual organization. Organization Science, 10, 777-790.

Wiesenfeld, B.M., Raghuram, S. and Garud, R (1999) Communication patterns as determinants of organizational identification in a virtual organization. Organization Science, 10(8), 1-18. 